\title{
X. Der Akteur im Überlebenskampf der Dritten Republik
}

\section{Das Vorspiel: Paul Reynaud und die Wirtschaftspolitik der Volksfront 1936/37}

Reynauds Verhältnis zu jener Koalition aus Sozialisten, Kommunisten und Radikalsozialisten, die unter dem Namen der "Volksfront" ab Juni 1936 den ersten sozialistischen Ministerpräsidenten in der Geschichte Frankreichs stellte1, war komplex. Weit davon entfernt, in seinen Äußerungen so "volksfrontfreundlich“ zu sein, wie man es seitens der deutschen Botschaft recht undifferenziert an das Auswärtige Amt gemeldet hatte ${ }^{2}$, nahm er gegenüber dem wirtschafts- und gesellschaftspolitischen Werk, das Léon Blum unter großen Erwartungen ab Sommer 1936 zu realisieren begann, eine durchaus kritische Stellung ein. Was ihn indes von den meisten oppositionellen Kritikern unterschied, war das Verhältnis gegenseitiger freundschaftlicher Achtung, das er zu dem neuen Regierungschef unterhielt. Noch im Rückblick Jahrzehnte später formulierte Reynaud seine Hochachtung vor der intellektuellen Kapazität und der moralischen Integrität Blums: „[... je n'ai jamais fait mystère de mon admiration pour son talent et de l'attrait que j'éprouve pour son caractère, incapable d'une petitesse et totalement exempt de la méfiance qui empoisonne la vie publique et qui émane le plus souvent d'un complexe d'infériorité. "3 Den kontinuierlichen sachlichen Schlagabtausch in der Kammer und in der Presse verhinderte diese Disposition nicht, wohl aber begründete sie eine für Reynauds Verhältnisse ungewöhnlich milde Form des Diskurses. Spürbar bemüht, das Gedankensystem seines Gegenübers zunächst einmal mit Sympathie zu betrachten, gewährte er Blum ein Maß an Vertrauensvorschuß, das er für gewöhnlich ebensowenig pflegte wie die Bereitschaft, eine Schwäche des Gegners nicht rhetorisch zum eigenen Vorteil umzumünzen. So verzichtete er in der parlamentarischen Diskussion um die Franc-Abwertung von 1936 bewußt darauf, den offensichtlichen Wortbruch der Regierung Blum anzuprangern, die bei ihrem Antritt den Verzicht auf den Währungseingriff zum publikumswirksamen Programm erhoben hatte. ${ }^{4}$

1 Aus der Überfülle der Literatur zur Volksfront in Frankreich seien stellvertretend hervorgehoben: Julian Jackson, The Popular Front in France defending democracy, 1934-38, Cambridge 1988; Serge Wolikow, Le Front populaire en France, Paris 1996; Jacques Delperrié de Bayac, Histoire du Front populaire, Paris 1972.

2 Botschaftsrat Bräuer an AA, 11. 4. 1938 (PA-AA, R 102862).

Reynaud, France I, S. 366.

4 Die Kritik Reynauds blieb in der fraglichen Debatte ohne ironische Schärfe: „Le conflit n'est pas entre vous et moi. Il n'y a pas une dévaluation de gauche et une dévaluation de droite, il y a la dévaluation qui réussit et il y a celle que l'on recommence. [...] Le reproche que je pourrais vous faire, ce 
Auch konnte er sich nicht ganz dem reformerischen Schwung, der Atmosphäre des Aufbruchs und der verbreiteten Hoffnung auf gerechtere Gestaltung der Lebensbedingungen entziehen, die den Regierungsantritt Blums begleiteten. Damit stand er in der politischen Landschaft keineswegs isoliert, zeigte sich doch die neue Minderheit im Parlament bis mindestens Ende 1937 wenig geschlossen. Durchschnittlich in einem von zwei Fällen stimmten Abgeordnete aus Gruppierungen rechts der Radikalsozialisten für Regierungsprojekte, und die inaugurierten Sozialreformen - insbesondere die Einführung des zweiwöchigen bezahlten Urlaubs - fanden sogar nahezu durchgehend die Unterstützung auch der Opposition. ${ }^{5}$ Paul Reynaud gab sich in seinen ersten öffentlichen Äußerungen wie eine Reihe von führenden Abgeordneten aus dem liberalen Milieu der rechten Mitte bereit zu fairer Oppositionsarbeit, nicht ohne allerdings energisch auf Inkohärenzen in den geplanten wirtschaftspolitischen Maßnahmen hinzuweisen. ${ }^{6}$

In der Sache war der Dissens nahezu vollständig, insbesondere was das zentrale Problem der Sanierung der Staatsfinanzen und die Strategien zur Überwindung der immer noch nicht behobenen Folgen der Weltwirtschaftskrise anging. Zwar stimmte Reynaud im Gegensatz zur Mehrheit der konservativen Ökonomen mit den Sozialisten überein, die Ursache der Krise in einer weltweiten Phase des Unterkonsums zu lokalisieren. Wo er allerdings eine Fehlregulation der Weltmarktpreise zugrundelegte, die durch technische Mittel wie die Währungsabwertung zu beheben war, hob man in der SFIO entsprechend der dominierenden orthodox marxistischen Deutung auf die inneren Widersprüche des kapitalistischen Systems schlechthin ab. Durch „technische“ Palliative waren solche Grundgegebenheiten demgemäß lediglich zu mildern, auf Dauer jedoch nur durch den Übergang zum Sozialismus zu beheben. Als Interimslösung, die die ideologische Prinzipientreue mit den Erfordernissen des koalitionspolitischen Kompromisses zu vereinen hatte, setzte die Regierung Blum auf eine „politique du pouvoir d'achat“, die von Maßnahmen zur Kaufkraftsteigerung der Massen neben sozialpolitischen Effekten vor allem stimulierende Wirkung auf Konsum und Gesamtwirtschaft erhoffte. Davon sollte dann auch heilsame Wirkung auf das anhaltend überaus prekäre Problem der Budgetdefizite ausgehen, dem man im Grunde aber ohne ausgearbeitete finanzpolitische Konzepte entgegentrat.7 Die Maßnahmen, die Blum ab Juni 1936

ne serait pas d'avoir échoué hier. Vous avez fait une tentative de bonne foi. Oh! mon Dieu! c'est déjà arrivé à des hommes et à des partis politiques de faire loyalement une politique et d'échouer. Mais ce que je vous reprocherais, ce serait de ne pas avoir compris qu'il faut changer de politique. [...] J'ai apporté à cette tribune, avec modération je crois, un avertissement qui est une collaboration." (JO, Chambre des Députés, Débats parlementaires, Session extraordinaire du 28 septembre 1936, S. 2773-2777, hier: S. 2776f.); Reynaud, France I, S. 371-375.

5 Lediglich ein Votum wurde in der entscheidenden Abstimmung gegen die Einführung der „congés payés" abgegeben. Zu Zusammensetzung und Verhalten der Opposition gegen die Volksfront immer noch grundlegend: René Rémond/Janine Bourdin, Les forces adverses, in: Léon Blum, Chef de gouvernement 1936-1937 (Cahiers de la Fondation Nationale des Sciences Politiques 155), Paris 1967, S. 137-159, hier: S. 140f.; Margairaz, L'Etat, les finances et l'économie, S. 232 f.; Irvine, French Conservatism, S. 89; Jackson, Popular Front, S. 249-268.

6 Rémond/Bourdin, Forces adverses, S. 141.

$7 \mathrm{Zu}$ den wirtschafts- und finanzpolitischen Plänen der Sozialisten, die als größte Fraktion der Kammer und der Volksfrontmehrheit in dieser Hinsicht tonangebend waren: Jackson, Popular Front, S. 159-167; Ders., Politics of depression, S. 202-208; Jean-Marcel Jeanneney, La politique économi- 
mit Unterstützung seiner Parlamentsmehrheit einleitete, umfaßten im wesentlichen ein Programm von Lohnerhöhungen, forcierten öffentlichen Arbeiten und verschiedenen arbeitsrechtlichen Neuerungen. Als Kern fungierte die Einführung der 40-Stunden-Woche, die, obwohl nur eine Disposition innerhalb eines ganzen Bündels von Maßnahmen, für Gegner und Anhänger der Volksfront bald zum Symbol der neuen Politik avancierte. Mehr noch als in der erreichten Urlaubsregelung traf sich hier am augenfälligsten der sozialpolitische Impetus der außerparlamentarischen Volksfrontbewegung mit der eingeschlagenen wirtschaftspolitischen Neuorientierung der Regierung: Stand doch die Hoffnung auf Zugewinn an allgemeiner Lebensqualität für die Arbeiterschaft neben dem Kalkül, daß die reduzierte Beschäftigungszeit zur forcierten Neueinstellung von Arbeitslosen führen würde, die, in Arbeit und Brot gesetzt, ihrerseits in den Konsumkreislauf eintreten könnten. Die Nationalisierung von Rüstungsbetrieben, die Neuorganisation der Bank von Frankreich und die staatliche Regelung des Getreidehandels ergänzten die Umstrukturierung der Wirtschaftsverfassung des Landes unter der Zielsetzung, Schlüsselbereiche der Wirtschaft dem Zugriff des Kapitals und dem freien Spiel der Marktkräfte zu entziehen. ${ }^{8}$

Bekanntlich scheiterte der Versuch zur Wiederbelebung der Wirtschaft. Die im September 1936 endlich vorgenommene Abwertung des Franc brachte zwar eine kurzzeitige Erleichterung und regte insbesondere die Produktion an. Sie war während der ersten Monate der Amtszeit Blums rapide zurückgegangen und erreichte bis März 1937 einen seit Juni 1931 nicht mehr eingenommenen Höchststand. Die Arbeitslosenzahl fiel auf den tiefsten Stand seit 1933, und im Gefolge des Währungseingriffs gelang es zudem, die seit Einbruch der Krise vorherrschende Tendenz zur Abwanderung französischen Kapitals ins Ausland kurzzeitig umzukehren. Der wirtschaftliche Aufschwung des Herbstes 1936 kam jedoch schon im darauffolgenden Frühjahr ins Stocken. Bereits im Juli 1937 fiel die Industrieproduktion wieder auf den niedrigsten Stand seit Ende 1935. Obwohl Blum im Februar 1937 eine "Pause" in der Verwirklichung des Volksfrontprogramms angekündigt hatte, bestimmt zur Ermunterung konservativer Investoren und begleitet von deflationistischen Maßnahmen, bekam man die voranschreitende Inflation nicht in den Griff. Der positive Effekt des kurzzeitigen Kapitalrückflusses vom Oktober 1936 war bald erschöpft, und schon gegen Jahresende konnte das Funktionieren des Staatshaushalts - und das Überleben der Regierung - nurmehr durch den Rückgriff auf die überkommene Praxis von Anleihen bei der Bank von Frankreich garantiert werden. Diese Fehlentwicklung verhinderte nicht nur die angestrebte Beruhigung in Anlegerkreisen, sondern machte überdies die seit Sommer 1936 erreichten Einkommenssteigerungen zunichte: Im Mai 1938 waren die Löhne inflationär bedingt in etwa wieder auf ihr Niveau vom Mai 1936 gefallen. ${ }^{9}$

que de Léon Blum, in: Léon Blum, Chef de gouvernement 1936-1937, S. 207-232. Zur Erarbeitung des Volksfrontprogramms nun am ausführlichsten: Margairaz, L'Etat, les finances et l'économie, S. 163-228.

$8 \mathrm{Zu}$ den Programmpunkten im einzelnen: Margairaz, L'Etat, les finances et l'économie, S. $212 \mathrm{f}$. und 229-240.

9 Zu diesen Ergebnissen der Wirtschaftspolitik Blums: Jackson, Popular Front, S. 168-170; Ders., Politics of depression, S. $203 \mathrm{f}$. 
In der neueren wirtschaftshistorischen Forschung wurden für das wirtschaftsund finanzpolitische Scheitern des Volksfrontexperiments eine Vielzahl von Ursachen herausgearbeitet, wobei das zeitgenössische Argument vom unüberwindlichen "mur d'argent" und vom volksfrontfeindlichen Verhalten der Kapitalseigner und Großbanken eine gewisse Untermauerung erfuhr. ${ }^{10} \mathrm{Z}$ wei Schwachpunkte im Vorgehen Blums rückten daneben aber besonders in den Mittelpunkt: die verzögerte Inangriffnahme der unausweichlichen - und intern auch als unvermeidbar betrachteten - Franc-Abwertung einerseits ${ }^{11}$; die begrenzende Wirkung, die die Einführung der 40-Stunden-Woche auf den durch die Abwertung in Gang gesetzten Wirtschaftsaufschwung ausübte, andererseits. Als weitgehend gesichert kann dabei bezüglich des letztgenannten Aspekts gelten, daß man in der Volksfrontführung die Auswirkungen der gestiegenen Produktionskosten unterschätzte, die aufgrund der Einführung des bezahlten Urlaubs und der effektiven Arbeitszeitverkürzung zu erwarten waren. Die Hoffnung darauf, daß der wirtschaftliche Wiederaufschwung in Form eines Produktionsanstiegs greifen würde, bevor die erhöhten Kosten sich in Preissteigerungen und vermehrter Inflation niederschlagen würden, erfüllte sich nicht. Statt dessen stagnierte die Industrieproduktion nach anfänglich hoffnungsvoller Entwicklung bald aufgrund der zu geringen Zahl qualifizierter Kräfte, aufgrund veralteter Produktionsmittel sowie der Neigung vieler Industrieller zur Kostenminimierung anstelle von Produktionssteigerungen. Die dogmatische Anwendung der 40-Stunden-Woche trug daneben aber ganz wesentlich dazu bei, die Produktionskapazität und damit auch den Aufschwung zu begrenzen.12

In der Debatte um die Regierungserklärung des Kabinetts Blum am 6. Juni 1936 skizzierte Reynaud bereits ein wirtschaftspolitisches Alternativprogramm. Abgesehen von einigen verbindlichen Gemeinplätzen stand es den tatsächlichen und vermeintlichen Plänen der neuen Regierungskoalition diametral entgegen. Die

10 Die nach wie vor ausführlichste Studie zur Finanzpolitik der Regierung Blum bietet Belege dafür, daß es wohl auch zu politisch motivierter Spekulation und Kooperationsunwilligkeit von Banken kam (Frankenstein, Prix du réarmement, S. 100, 142f. und 155f.). Zur Bewertung auch Jackson, Popular Front, S. $180 \mathrm{f}$.

11 Aus Rücksicht auf die Reaktionen in der französischen Öffentlichkeit zögerte die Regierung Blum die Maßnahme so lange hinaus, bis sie auf der Basis eines internationalen Abkommens mit den USA und Großbritannien innenpolitisch leichter präsentierbar erschien (Jackson, Popular Front, S. 170-174). Zu den finanztechnischen Implikationen der „dévaluation“, den Gegnern und ihren Motiven vgl. oben Kapitel IX.2 dieser Arbeit.

12 Die bereits unter Zeitgenossen geführte Debatte um die Auswirkungen der 40-Stunden-Woche im Gesamtzusammenhang der französischen Wirtschaftskrise kann nach wie vor nicht als eindeutig entschieden betrachtet werden. Entgegen älteren Interpretationen, wonach ihre Einführung kaum negative Folgen für die gesamtwirtschaftliche Entwicklung zeitigte (vgl. etwa Henry Ehrmann, The Blum Experiment and the Fall of France, in: Foreign Affairs 10 (1941), S. 152-164) neigt die neuere Forschung unter Differenzierung des Verdikts von Alfred Sauvy (Sauvy, Histoire Economique II, S. 191-201 und 297-305) mehr und mehr dazu, den genannten Widerspruch hervorzuheben: Vgl. insbesondere Jean-Claude Asselain, Une erreur de politique économique: la loi des quarante heures de 1936, in: Revue économique 25/4 (1974), S. 672-705; Margairaz, L'Etat, les finances et l'économie, S. $398 \mathrm{ff}$.

Eine zusammenfassende Darstellung des Problems bietet unter ähnlichem Vorzeichen: Jackson, Popular Front, S. 173-177. Zum Aspekt der praktischen Anwendung des Gesetzes: Elisabeth du Réau, L'aménagement de la loi instituant la semaine de quarante heures, in: René Rémond/Janine Bourdin (Hg.), Edouard Daladier, Chef de Gouvernement. Avril 1938-septembre 1939, Paris 1977, S. 129-149. 
Abwertung des Franc statt der fortgesetzten Belastung der Wirtschaft durch eine überbewertete Währung, die Aufrechterhaltung des Budgetgleichgewichts anstelle der billigenden Inkaufnahme des Defizits waren zentrale Elemente, ebenso wie eine investorenfreundliche Niedrigzinspolitik, die Steigerung der Produktion und die Absage an jede Kontrolle des Außenhandels und des freien Devisenverkehrs. ${ }^{13}$ Diese Aspekte machten auch in der Folge die Hauptachse der volksfrontkritischen Stellungnahmen Reynauds aus, der sich bewußt weitgehend auf die wirtschaftstechnischen, also auf die vermeintlich weniger ideologieanfälligen Teile des Programms konzentrierte. ${ }^{14}$ Anders als er selbst im Rückblick suggerierte, war der „technische“ Diskurs, in den er mit mehreren Volksfrontregierungen eintrat, jedoch auch auf seiner Seite mitnichten frei von gesellschafts- und allgemeinpolitischen Grundannahmen, die im Hintergrund standen. Diese wurden im Gegenteil gerade durch die gouvernementale Umsetzung eines konkurrierenden, linken Politikmodells verstärkt aktiviert. ${ }^{15}$

In erster Linie richtete Reynaud zweifellos sein Augenmerk auf Theorie und voraussichtliche Praxis der "Loi de 40 heures“. Anders als die überwiegende Mehrheit der durchaus zahlreichen zeitgenössischen Kritiker des Gesetzes beschränkte er seine fachlichen Einwendungen nicht auf den zu erwartenden Kostensteigerungseffekt, sondern gab sich von Juli 1936 an bereits skeptisch hinsichtlich der resultierenden Produktionsrate. ${ }^{16}$ Und als im Frühjahr 1937 nach der mittlerweile erfolgten allgemeinen Umsetzung der 40-Stunden-Woche die Industrieproduktion tatsächlich jene Obergrenzen erreicht hatte, die ihr durch die Arbeitszeitverkürzung gesetzt waren, konnte er nüchtern die Bestätigung seiner frühen Warnungen konstatieren: „L'échec de l'expérience Léon Blum provient de la diminution du rendement des machines. " 17

$\mathrm{Da} ß$ dieser zugespitzt formulierten Einsicht ein Anteil an der komplexeren Wahrheit nicht abzusprechen war, geht aus dem bisher Gesagten hervor. Klarer noch tritt Reynauds Einschätzung in einer Notiz hervor, die er wenige Tage nach der Abwertung des Franc im September 1936 in bezug auf Blums Reformwerk anlegte: „Socialiste et frileusement prisonnier de son schéma doctrinal, il avait préféré se livrer à des spéculations désintéressées sur les contradictions du capitalisme jusqu'à ce que, parvenu au pouvoir, il ait appliqué les yeux bandés l'hygiène socialiste à l'économie libérale bien malade dont il avait cependant analysé correctement la crise... Sa doctrine s'écrase contre les faits et son seul résultat fut de faire fonctionner le capitalisme à perte..." 18

Reynaud wandte sich nicht allein gegen den Wirtschaftspolitiker Blum, sondern auch und vor allem gegen den sozialistischen Programmatiker, dessen Neuord-

13 JO, Chambre des Députés, Débats parlementaires, Séance du 6 juin 1936, S. 1320 f.; Le Temps, 8. 6. 1936.

14 So im Rückblick anhand der "Loi de 40 heures": Reynaud, France I, S. 368.

15 Vgl. dazu die Darstellung der Volksfrontzeit in seinen Memoiren: Reynaud, France I, S. 360-436; speziell zur Wirtschaftspolitik: S. 360-380. Reynaud, Mémoires II, S. 65-111 und 168-179.

16 Zum Tenor der zeitgenössischen Kritik: Asselain, Erreur de politique économique, S. 678; Jackson, Popular Front, S. 174. Paul Reynaud, „Ouvrier français, veux-tu partager l'abondance ou la misère?", in: Paris-Soir, 17. 7. 1936.

17 Paul Reynaud, "Comprenons que nous nous sommes trompés“, in: Paris-Soir, 6. 7. 1937.

18 Handschriftliche Aufzeichnung Reynauds, 30.9.1936 (AN, 74 AP 17); abgedruckt auch bei Du Réau, L'aménagement, S. 131. 
nungspläne langfristig eine grundlegende Umstrukturierung der Sozial- und Wirtschaftsverfassung des Landes nach sich gezogen hätten. Die Inhalte der neuen Politik erregten den Widerspruch des Wirtschaftsexperten Reynaud; der neue politische Stil, die Erweiterung der Trägerschaft politischen Handelns über die traditionellen Kreise parlamentarischer und publizistischer Öffentlichkeit hinaus stießen dagegen auf den Widerstand des bürgerlichen Liberalen. Anders als manche Sprecher des bürgerlichen Lagers, anders als die Presse der Rechten und der extremen Rechten vermied es Reynaud in seinen öffentlichen Äußerungen, der Atmosphäre „kollektiver Furcht" ${ }^{19}$ nachzugeben, die die Mobilisierung der Bevölkerung durch die Volksfrontparteien, die Präsenz von Großveranstaltungen und Umzügen im Pariser Stadtbild sowie eine bisher nicht dagewesene Welle von Streiks hervorgerufen hatte. Keineswegs beschwor er ein simples Schreckensszenario von Chaos, Bürgerkrieg und Revolution. Wenn er dennoch den zunehmenden Einfluß der „Massen“ auf die politische Willensbildung zu erkennen glaubte und darauf mit Bestürzung reagierte, dann stand dahinter nicht vorrangig die Furcht vor einem gewaltsamen Umsturz von links; mehr noch sah Reynaud sein traditionalistisches Verständnis des französischen Repräsentativsystems und der daraus hervorgegangenen Staatsorgane in Frage gestellt. Der Souverän, also die Volksvertretung und die durch sie bestellte Regierung, hatte demnach in jedem Falle seine Unabhängigkeit und seine Prärogativen gegenüber dem Druck der Straße zu wahren. Maßnahmen wie politisch motivierte Generalstreiks aber stellten ebenso verwerfliche und für das Gemeinwohl schädliche Aktionen dar, wie etwa Akte der Selbstjustiz verfeindeter politischer Gruppen. Im Rahmen eines erweiterten Gewaltbegriffs waren beide Vorgehensweisen gleichermaßen als nicht hinnehmbare, gewalttätige Attacken auf das Prinzip staatlicher Souveränität zu werten. ${ }^{20}$ Interessenvertretungen der Arbeiter, die die ihnen billigerweise zukommende "normale Rolle“ der Artikulation berufsgebundener Anliegen ihrer Mitglieder verließen und sich dauerhaft auf politisches Terrain begaben, um Einfluß auf die staatliche Willensbildung zu nehmen, stellten als potentieller „Staat im Staate" das Gemeinwesen insgesamt in Frage. Im Ergebnis könne aus solcher Machtprobe nur nach britischem Vorbild die völlige Entmachtung der syndikalistischen Bewegung einerseits oder, wie in Italien, die autoritäre Degenerierung des herausgeforderten Staatswesens andererseits resultieren: „[...] une démocratie forte dompte le syndicalisme qui veut la conquérir. Une démocratie faible en proie aux envahissements du syndicalisme fait place à un Etat dictatorial où le pouvoir s'hypertrophie pour "digérer" les forces syndicales. " 21

$\mathrm{Daß}$ er die letztere Alternative im Falle Frankreichs für die wahrscheinlichere hielt, hatte er bereits im Jahr zuvor deutlich gemacht, als er auf strukturelle Ähnlichkeiten zwischen den Regierungsstilen in Italien und in Frankreich hingewiesen hatte. Hier wie dort erwuchsen seiner Meinung nach aus dem gleichen Grund-

19 Mayeur, Troisième République, S. 352.

20, „...] une grève générale, déclenchée pour une raison d'ordre politique, est, elle aussi, un acte de violence politique de particuliers réunis, utilisant leur masse pour peser sur les pouvoirs publics. C'est un acte de violence insidieuse, comme l'inondation, mais qui peut être souveraine." (Paul Reynaud, "La leçon de la nuit tragique de Clichy“, in: Paris-Soir, 27. 3. 1937).

21 Ebenda. 
übel - dem überstarken Einfluß der „Massen“ auf die Willensbildung der Staatsführung - die gleichen negativen Folgeerscheinungen:

„[...] le gouvernement français d'aujourd'hui et le gouvernement italien sont plus proches qu'ils ne le pensent l'un et l'autre. Même appel aux „masses“ qui est la négation même de la légalité républicaine, mêmes mesures socialisantes, mêmes erreurs économiques et monétaires conduisant à l'anémie et à l'isolement dans un monde où les démocraties renaissent à la prospérité."22

Die Parallelsetzung des faschistischen Italien mit dem Frankreich der Volksfront war zweifellos polemisch überspitzt und unterschätzte den Legalismus und das Demokratieverständnis Blums und der radikalsozialistischen Volksfrontführer. Unbestreitbar aber war tatsächlich, daß Blums Wirtschaftsexperiment in wesentlichen Punkten erst auf breiten außerparlamentarischen Druck hin jene Schärfe und Unflexibilität angenommen hatte, die sein Scheitern vorbereitet und das Verhandlungsklima zwischen Arbeitgebern und Gewerkschaften entscheidend belastet hatten. So war insbesondere die 40-Stunden-Woche ab Sommer 1936 erst auf Verlangen der Streikenden und ihrer gewerkschaftlichen Vertretung hin in die Regierungspläne aufgenommen worden. Sie wurde explizit weder in den Plänen der SFIO gefordert, wo man kurz vorher davon abgerückt war, noch im eigentlichen Volksfrontprogramm, das lediglich allgemein von Arbeitszeitverkürzung sprach. 23

Insofern entsprach es durchaus einer tieferen Logik, wenn ein bürgerlicher Kritiker der Blumschen Wirtschaftspolitik in seiner Ursachenforschung die konstatierten ökonomischen Fehlentwicklungen mit der "schleichenden“24 Veränderung des politischen Systems in Zusammenhang brachte. Reynauds Gegenposition war eine grundsätzliche: Wo Blum versuchte, die Konsolidierung der Wirtschaft mit der stärkeren Integration der Arbeiterschaft in den ökonomischen Kreislauf und in die soziale Ordnung in Einklang zu bringen, favorisierte Reynaud ein getrenntes, zweistufiges Vorgehen unter Zurückstellung sozialreformerischer Belange: „il fallait, d'abord, sauver l'économie française pour pouvoir, ensuite, accorder aux masses des avantages durables [...]"25.

In Reynauds Verständnis bildete die Wirtschafts- und Sozialverfassung des Landes keine Variable, sondern eine Konstante, auf die sich sein Reformwille nicht erstreckte. Selbst rigoroseste Maßnahmen wie die Abwertung der Währung dienten in diesem Zusammenhang der Systemstabilisierung, nicht seiner Überwindung. Die feste Überzeugung von der Perfektibilität des „kapitalistischen“ Systems, von der Steuerbarkeit volkswirtschaftlicher Mechanismen und von nur begrenztem staatlichem Regelungsbedarf auch auf wirtschaftlichem Gebiet lag diesem Reformansatz zugrunde. So eingeschränkt diese leitenden Interventionen im Interesse des "natürlichen“ Spiels der Marktmechanismen auch zu bleiben hatten - prinzipiell waren die Eingriffsrechte des Staates Ausfluß seiner Souveränität

22 Paul Reynaud, „Le régime des „masses“ en France et en Italie. Ce qu’il a déjà coûté. Ce qu’il menace de coûter encore“, in: Paris-Soir, 22. 8. 1936.

23 Margairaz, L'Etat, les finances et l'économie, S. 218-221; Jackson, Popular Front, S. 279 f.

24 Paul Reynaud, "La leçon de la nuit tragique de Clichy“, in: Paris-Soir, 27. 3.1937

25 Paul Reynaud, "Ouvrier français, veux-tu partager l'abondance ou la misère?“, in: Paris-Soir, 17. 7. 1936. 
und entsprechend nur durch die bestehende Gesetzgebung gebunden. Wie Reynaud auf allgemeinpolitischem Gebiet die Implantation plebiszitärer Elemente als Deformation des Repräsentativsystems französischer Tradition ablehnte, so begegnete er auch auf sozial- und wirtschaftspolitischem Terrain all jenen Revisionsansätzen mit grundsätzlichem Vorbehalt, die die theoretischen staatlichen Prärogativen einschränken konnten. Dazu gehörte in erster Linie das quasi-plebiszitäre Element des Generalstreiks, das er anders als Blum nicht als "Sicherheitsventil“ und damit als legitimes politisches Mittel zu rechtfertigen bereit war. Dazu gehörte ebenso die politische Rolle von Wirtschaftsvertretungen, die sich in Form intermediärer Gruppierungen zwischen die staatliche Leitungsebene und die Gemeinschaft der Arbeitenden zu schieben drohten. Den Gewerkschaften wies er nicht wie Blum eine Emanzipations-, sondern eine Integrations- und Kanalisierungsfunktion zu und zeigte sich damit einem traditionalistischen Verständnis verhaftet, das sich letztlich kaum von jenem unterschied, das er bereits vor dem Ersten Weltkrieg in Anlehnung an die politische Praxis Waldeck-Rousseaus entwickelt hatte. ${ }^{26}$

Eine Regierung, die sich allzusehr auf Forderungen solcher nichtlegitimierter Vertretungen einließ, lief deshalb Gefahr, den „Instinkten leidenschaftlich erregter", rationaler Argumentation unzugänglicher Massen nachzugeben und damit jenes Verfahren zu negieren, das alleine "republikanischer Legalität“ entspreche: das Handeln von Staatsmännern, die aus der frei gewählten Volksvertretung hervorgegangen waren und im rationalen Diskurs ihre Politik zu verteidigen und durchzusetzen wüßten: „Régime des masses ou régime parlementaire? Voilà le péril qu'il y a à substituer à l'action d'hommes d'Etat relevant d'assemblées librement élues et susceptibles de s'imposer à elles par le raisonnement, qui est sans prise sur les foules, les instincts de ces minorités passionnées s'imposant même à des chefs qui ont le prestige, l'autorité et les dons magnifiques de M. Mussolini." $" 27$

Das beschriebene, elitäre Politikmodell hinderte Reynaud nun keineswegs daran, seinerseits die Zusammenarbeit mit den tragenden Schichten der Volksfront anzustreben. In einer Art Doppelstrategie lehnte er zwar den Kontakt mit den Gewerkschaften ab, suchte aber auf der anderen Seite durchaus das direkte öffentliche Gespräch mit der Arbeiterschaft. Sein Argumentationsschema war einfach: Zwar trage die "classe ouvrière" keineswegs Schuld an der vergangenen „unvernünftigen“"Wirtschaftspolitik; auch habe sie in ihrer Präferenz für die 40Stunden-Woche aus „Altruismus“ und Solidarität mit arbeitslosen Kollegen gehandelt. Die neuerlangte Verantwortung für die Gesamtnation erlege ihr aber die Pflicht auf, sich endlich der volkswirtschaftlichen Einsicht zu öffnen, daß aus einer produktionsfeindlichen Haltung nicht die erhoffte Steigerung des Wohlstands resultieren könne. Ihre noble solidarische Haltung habe die Arbeiterschaft des-

26 Vgl. hierzu Kapitel III.3.a) dieser Arbeit.

27 Paul Reynaud, "Le régime des "masses“ en France et en Italie. Ce qu'il a déjà coûté. Ce qu'il menace de coûter encore ${ }^{\prime}$, in: Paris-Soir, 22. 8. 1936. 
halb auf die Gesamtnation auszudehnen: „Je suis sûr qu'en tenant franchement ce langage à la classe ouvrière, on doit être compris. " 28

Diese zweigleisige und in sich nicht widerspruchsfreie Argumentationsstrategie verfolgte Reynaud bis Frühjahr 1938 in ihrem Kern kaum verändert weiter. Je mehr allerdings der schon unter Blum einsetzende Reorientierungsprozeß voranschritt, in dessen Verlauf sich die Volksfrontregierungen stufenweise von ihrer Wirtschaftsdoktrin abwandten, desto deutlicher trat neben seine wirtschaftstheoretische Kritik der Appell zur „Union aller Kräfte der Nation“. So wie noch niemals in seiner politischen Laufbahn bemühte er sich nun um intellektuellen Einfluß auf die Arbeiterschaft, einen der Schlüsselfaktoren in seiner Doktrin des „redressement ". ${ }^{29}$ In dem Maße, in dem sich letztere als Funktion seiner außenpolitischen Lageeinschätzung verfestigte, verdichtete sich in seinen Äußerungen die Einheitsrhetorik in der Art eines „basso continuo“, der fortan seine wirtschaftstheoretische Überzeugungsarbeit begleitete. Es ist geradezu frappierend, wie sehr Reynauds Konzeption der innergesellschaftlichen Sozialbeziehungen, seine Sicht des Verhältnisses von Kapital und Arbeit über die Jahrzehnte hinweg gleichgeblieben war: In einer Krisensituation der Republik, geprägt von äußerer Bedrohung sowie von der Uneinsichtigkeit der Regierenden und der drohenden Entfesselung irrationaler Massen im Inneren, hatte der Rückgriff auf die republikanische Solidarität an der Basis des Wiederaufschwungs zu stehen. Die Restauration der Einheit der Nation unter dem Vorzeichen eines überparteilichen Konsensus blieb ihm unter den veränderten Voraussetzungen der späten dreißiger Jahre noch ebenso ein anzustrebendes Ideal und ein erfolgversprechendes Palliativ wie vor dem Ersten Weltkrieg, als er seine politischen Maximen zum erstenmal in ausführlicherer Form niedergelegt hatte.

Dabei stand er mit solcher Instrumentalisierung des Republikbegriffs keineswegs alleine. Von der sozialistischen Linken bis zur außerparlamentarischen Rechten pflegte man zwischen den Weltkriegen den Mythos von der „Republik“ als umfassender identitätsstiftender Kraft, wobei die konnotierten Inhalte je nach Selbstdefinition und politischer Wirkabsicht der Gruppen stark variierten. Reynauds Interpretation war 1913 wie 1936/38 von der liberalen Grundüberzeugung dominiert, wonach nicht der Klassenkampf, sondern der pluralistische Ausgleich im natürlichen Spiel der Kräfte den Anfang gesellschaftlicher Erneuerung zu bilden hatte. Der Appell an den staatsbürgerlichen Geist der Arbeiterschaft stand im Einklang mit diesem liberalen Credo, da deren wirtschaftliche Interessen nach seinem Dafürhalten eng mit jenen der Arbeitgeber, ihr Wohlstand eng mit einer prosperierenden Gesamtwirtschaft verknüpft waren: „Il n'y a pas de conflit entre les intérêts profonds des diverses classes. [...] Lorsqu'il y a un an, en pleine crise, on a accru les charges des producteurs et des commerçants français, on a décrété, sans le savoir, le chômage partiel qui recommence à sévir. Par là, on a atteint la

28 Paul Reynaud, „Ouvrier français, veux-tu partager l'abondance ou la misère?“, in: Paris-Soir, 17. 7. 1936; Ders., "Comprenons que nous nous sommes trompés“, in: Paris-Soir, 6. 7. 1937.

29 Vgl. beispielsweise Paul Reynaud, „Le coup de théâtre de Rambouillet permet d'espérer l'union de toutes les forces de la nation“, in: Paris-Soir, 6. 10. 1937. 
classe ouvrière. [...] Il est vain de prétendre servir un secteur de la nation au détriment des autres." 30

Die Kontinuität dieses harmonisierenden Gesellschaftsmodells im Denken Reynauds verbietet es, seine forcierte Hinwendung zur Arbeiterklasse als bloß taktisches, angesichts äußerer Bedrohungslagen kurzfristig eingeleitetes Manöver abzutun. Der direkte Appell war vielmehr in Inhalt und Form genuiner Ausdruck seines an Waldeck-Rousseau geschulten, reformerischen Republikverständnisses. Aufgabe der bürgerlichen Schichten war es demnach, die Arbeiterschaft über tiefere sozio-ökonomische Zusammenhänge aufzuklären und so in den Schoß der republikanischen Einheit zurückzuführen. Wenn nötig hatte das auch unter Umgehung jener intermediären Instanzen zu geschehen, die durch haltlose Komplotttheorien von der Obstruktion der Besitzenden einen Gegensatz zwischen Kapital und Arbeit zu konstruieren versuchten. Bis dato war es allerdings die politische Öffentlichkeit im allgemeinen, die bürgerliche Führungselite im speziellen gewesen, die als privilegierter Adressat der Reynaudschen Appelle fungiert hatte. Erst das Zusammentreffen der außenpolitisch verschärften Sicherheitslage Frankreichs mit den produktionshemmenden sozialpolitischen Maßnahmen der Volksfront hatte sein Interesse neu aktiviert - ein Interesse, das in erster Linie ein funktionales, kein emanzipatorisches war. So war seine von einem wirtschaftsliberalen Verständnis geprägte Rollenzuweisung an die Arbeiterschaft durch strikt sozialkonservative Wertvorstellungen bestimmt. Angesprochen war in erster Linie der Arbeiter in seiner Eigenschaft als "citoyen“, d.h. als mit bestimmten staatsbürgerlichen Rechten wie Pflichten begabtes Mitglied der republikanischen Gemeinschaft, der seiner aus dieser Eigenschaft sich ergebenden Verantwortung für das Gemeinwohl nachzukommen hatte. Die Zuweisung eines neuen Maßes an sozialer Teilhabe in Verbindung mit der geforderten wirtschaftlichen Leistung war im Konzept Reynauds nicht vorgesehen. Auch wenn Reynauds Rhetorik dem oberflächlichen Beobachter „volksfrontfreundlich“ erscheinen mochte - im Kern war sie gegen deren Grundlagen gerichtet.

\section{Liberale Wirtschaftspolitik und Staatskrise: Reynaud als Minister im Kabinett Daladier 1938-1940}

Die dritte Regierung Edouard Daladiers besaß in mehrfacher Hinsicht prägenden Eigencharakter in der Entwicklung der späten Dritten Republik. Bereits in ihrer ungewöhnlichen Dauerhaftigkeit setzte sie einen Kontrapunkt gegenüber fast zehn Jahren politischen Lebens in Frankreich, in deren Verlauf kein Kabinett deutlich länger als ein Jahr im Amt geblieben war. ${ }^{31}$ In den knapp zwei Jahren zwischen dem Sturz des zweiten Kabinetts Blum im April 1938 und dem Regierungsantritt Paul Reynauds im März 1940 leitete sie die zunächst noch vorsichtige, ab Herbst 1938 endgültige Beendigung des Volksfrontexperiments ein, nicht ohne

30 Paul Reynaud, „Comprenons que nous nous sommes trompés“, in: Paris-Soir, 6. 7. 1937.

31 Zuletzt hatte das zweite Kabinett Poincaré zwischen Juli 1926 und November 1928 länger als ein Jahr amtiert. 
die noch unter Blum begonnenen energischen Rüstungsanstrengungen fortzuführen. Unter dem Eindruck des hegemonialen Ausgreifens Hitlers auf nicht-deutsche Gebiete setzte sie um den Preis der politischen Ausschaltung der Arbeiterbewegung erfolgreich ein ökonomisches Konsolidierungsprogramm in Gang, das die französische Wirtschaft bis Sommer 1939 aus der Krise führte. Unter ihrer Ägide vollzogen sich Ausarbeitung, Höhepunkt und Ende einer eigenständigen französischen Politik des „apaisement" gegenüber Hitler. Sie führte Frankreich aber auch in die halluzinierende Atmosphäre der "Drôle de guerre“, deren demoralisierende und den gesellschaftlichen Zerfall beschleunigende Wirkung kaum zu überschätzen ist. Insgesamt bietet das komplexe Erscheinungsbild wenig Anlaß, das politische Regime der letzten Friedensmonate in Frankreich als bloßen Zwischenakt oder als Vorstufe für die katastrophale Niederlage und die darauffolgende Auflösung des parlamentarischen Systems anzusehen. ${ }^{32}$

Auf den Grundlagen des politischen, wirtschaftlichen wie mentalen Erbes der Volksfront und gleichzeitig gegen sie agierte das neue Kabinett, was ihm nach auBen hin zunächst ein wenig eindeutiges Aussehen gab. Wie 1926 und 1934 hatte eine parlamentarische Mehrheitsverschiebung während der Legislaturperiode den Regierungswechsel bewirkt, und zum dritten Mal hatten die Radikalsozialisten ein Linksbündnis verlassen, um in eine zur Mitte hin gerückte Koalition einzutreten. Anders als bei den vorausgegangenen Verschiebungen dieses Musters mündete der Machtwechsel diesmal nicht in ein durch die rechte Mitte geführtes Kabinett. ${ }^{33}$ Die Gründe dafür lagen nicht nur in der Bedeutung der radikalsozialistischen Kammergruppe, die nach den Sozialisten die zweitstärkste Gruppierung stellte $^{34}$, oder im Beharrungsvermögen der Volksfrontidee, deren Anhängerschaft sich in der Bevölkerung trotz der Änderung der Mehrheitsverhältnisse im Parlament kaum vermindert hatte. ${ }^{35}$ Selbst wenn die Mitte-Rechts-Formationen dies beabsichtigt hätten, wären sie nach dem Rückzug Tardieus aus der aktiven Politik kaum in der Lage gewesen, einen Alternativkandidaten aufzubieten, der auch nur

32 Historiographisch lag die Periode lange Zeit im Windschatten von Volksfront und militärischer Niederlage Frankreichs, die sie an polarisierender Symbolkraft einerseits, an erkenntnisfordernder Rätselhaftigkeit andererseits zu übertreffen schienen. Ein Kolloquium an der Pariser „Fondation nationale des sciences politiques" leitete im Dezember 1975 eine Wende ein, deren Folgen bis heute spürbar sind. Vgl. deshalb zur Regierung Daladier von April 1938 bis Kriegsausbruch die Beiträge in dem bereits genannten Sammelband: René Rémond/Janine Bourdin ( $\mathrm{Hg}$.), Edouard Daladier, Chef de gouvernement, avril 1938 - septembre 1939, Paris 1977; daneben: Serge Berstein, Le parti radical-socialiste arbitre du jeu politique français, in: René Rémond/Janine Bourdin ( $\mathrm{Hg}$.), La France et les Français en 1938/1939, Paris 1978, S. 275-306. Zur Phase der „Drôle de guerre“ in breitem Ansatz: Hans-Jürgen Heimsoeth, Der Zusammenbruch der Dritten Französischen Republik. Frankreich während der „Drôle de Guerre“ 1939/1940 (Pariser Historische Studien 30), Bonn 1990; unter dem Blickwinkel der deutsch-französischen diplomatischen Beziehungen: Hans F. Bellstedt, „Apaisement“ oder Krieg. Frankreichs Außenminister Georges Bonnet und die deutsch-französische Erklärung vom 6. Dezember 1938 (Pariser Historische Studien 37), Bonn 1993.

33 René Rémond, Introduction, in: Ders./Bourdin (Hg.), Edouard Daladier, S. 9-21; Mayeur, Troisième République, S. 360 f.

${ }^{34}$ Rémond, Introduction, S. 18.

$35 \mathrm{Zu}$ diesem Ergebnis kommt François Goguel anhand der akribischen Auswertung von 18 parlamentarischen Nachwahlen zwischen April 1938 und September 1939: Neuwahlen hätten während dieser Periode höchstens eine Rechtsverschiebung von etwa 4\% der Wählervoten ergeben (François Goguel, Les élections législatives et sénatoriales partielles, in: Rémond/Bourdin (Hg.), Edouard Daladier, S. 45-54). 
annähernd über das nationale Prestige eines Edouard Daladier verfügte. Selbst Paul Reynaud konnte hier nicht konkurrieren.

Der neue Ministerpräsident, seit Januar 1936 wieder Parteichef der Radikalsozialisten, hatte als Wehrexperte seiner Partei ab 1933 in verschiedenen Kabinetten das Amt des Kriegsministers innegehabt. Unter Léon Blum mit der Koordination der drei Teilministerien beauftragt, denen die Organisation der Landesverteidigung unterstand, war er die treibende Kraft hinter dem Rüstungsprogramm der Volksfront vom September 1936 gewesen, das in Umfang und Schnelligkeit seiner Durchsetzung mit der bis dahin üblichen Praxis brach. ${ }^{36}$ Daß dabei der Schwerpunkt zwar auf Modernisierung und Motorisierung lag, daß sich diese jedoch an den Vorstellungen des Generalstabs über die Verwendung der Panzerwaffe orientierten, ohne Rücksicht auf die Alternativideen Reynauds und de Gaulles zu nehmen, hatte der Popularität Daladiers keinen Abbruch getan - im Gegenteil. Durch fachliche Kompetenz und bewußte Beschränkung auf den Aufgabenbereich seines Ministeriums hatte er sich in Partei und Öffentlichkeit vielmehr den Ruf eines vertrauenswürdigen, seriösen Politikers erworben, der sich abseits allen politischen Tagesgeschäfts und im Einklang mit der Armeeführung dem Aufbau der Landesverteidigung widmete. ${ }^{37}$ In Verbindung mit der Machtbasis, die ihm die Schlüsselposition der radikalen Partei im politischen Kräftespiel verschaffte, lag hierin die Wurzel des nahezu einmütigen Votums von 587 der abgegebenen 593 Stimmen, mit dem die Kammer der neuen Regierung ihr Vertrauen aussprach. ${ }^{38}$

Das neue Kabinett stellte eine radikalsozialistisch dominierte, zentristische Regierung der "concentration" unter Ausschluß der Sozialisten dar, die die Zusammenarbeit verweigert hatten. Anzeichen für eine Abwendung vom Volksfrontexperiment waren also durchaus erkennbar, doch eindeutig stellte sich die Orientierung der neuen Formation zunächst noch keineswegs dar. Immerhin konnte sie sich vorerst auf die Tolerierung durch die Sozialisten sowie die Mitarbeit ehemaliger Volksfrontminister stützen und wurde geführt von einem Politiker, der der Volksfront seit Juni 1936 an maßgeblicher Stelle gedient hatte. ${ }^{39}$ Der Wille zur Umorientierung manifestierte sich zunächst nur personell. Drei Abgeordnete aus den Reihen der "moderés“ gehörten ihr an, denen allesamt eine bekanntermaßen kritische Haltung gegenüber den diktatorischen Regimen in der Nachbarschaft Frankreichs zu eigen war: Georges Mandel im Kolonialministerium, der Vorsitzende des christdemokratischen „Parti Démocrate Populaire“, Champetier de Ribes, als Minister für die „Anciens Combattants“ und Paul Reynaud als Justizminister.

Der neue "Garde des Sceaux “ war zunächst als Finanzminister vorgesehen gewesen, hatte es dann aber nach Rücksprache mit Léon Blum vorgezogen, das Alternativangebot Daladiers zu akzeptieren, um den Bestand des neuen Kabinetts nicht zu gefährden. Denn der Sozialistenführer hatte klargemacht, daß seine Partei den Eintritt des bekannten Gegners der 40-Stunden-Woche in eine Schlüsselposition nicht akzeptieren würde; zur Übernahme eines Regierungsamtes riet Blum

36 Ausführlich zum „programme Daladier“: Frankenstein, Prix du réarmement, S. 71-77.

37 Berstein, Parti Radical II, S. 535 f.

38 Ebenda, S. 536.

${ }^{39}$ Zum Charakter der neuen Kabinettsformation auch: Berstein, Parti Radical II, S. 536-538. 
dennoch dringend. Das Amt des Kriegsministers, das Reynaud daraufhin von Daladier gefordert hatte, war dem militärtheoretischen Häretiker dagegen erwartungsgemäß verweigert worden..$^{40}$

Auf den ersten Blick erstaunt die Berufung des Volksfrontkritikers Reynaud in eine Regierung, die zunächst keineswegs eine klare Neuorientierung erkennen ließ und überdies von einem Mann geführt wurde, mit dem Reynaud in einer „Überlebensfrage“ seit Jahren im Dissens stand. Bei Daladier spielte dabei die Sorge um die parlamentarische Absicherung seines Kabinetts nach Verlust der sozialistischen Unterstützung sicherlich eine große Rolle; darüber hinaus manifestierten sich in der hier eingeleiteten Interessenkoalition der beiden Politiker Ansätze für eine „konservative Wende“ im politischen Denken des Radikalsozialisten, die für seine weitere Politik und die Zusammenarbeit mit Reynaud von großer Bedeutung werden sollten.

Ohne sich während seiner knapp zweijährigen Ministerzeit zu sehr durch allgemeinpolitische Stellungnahmen zu exponieren, hatte Daladier doch bis Frühjahr 1938 in zunehmendem Maße Themen aufgegriffen, die ihn dem rechten, volksfrontfeindlichen Flügel seiner Partei annäherten: Der Schutz mittelständischer Belange zählte ebenso dazu wie Aufrufe zur Steigerung der Industrieproduktion, zur Wiederherstellung des sozialen Friedens und von Recht und Ordnung. ${ }^{41}$ Vor dem Hintergrund einer erneuten, vorwiegend kommunistisch inspirierten Streikwelle, die im April 1938 über 130000 Arbeiter zu Arbeitsniederlegungen und Fabrikbesetzungen getrieben hatte, konnten diese Äußerungen als programmatisch verstanden werden..$^{42}$ Eine gewisse Interessenidentität zeichnete sich also schon im Frühjahr 1938 zwischen Daladier und dem wortgewaltigsten parlamentarischen Vertreter einer Politik des „redressement“ ab. Die daraus resultierende politische Annäherung der folgenden Monate blieb jedoch stets vielschichtig und erreichte als Zweckbündnis niemals jenen Grad an politischer Affinität, der etwa Reynauds Verhältnis zu André Tardieu in seiner konfliktfreien Phase bestimmt hatte. Sie blieb sektoral beschränkt, war aber innerhalb bestimmter Grenzen durchaus entwicklungsfähig. So kam es in Fragen der Militärdoktrin während der gesamten gemeinsamen Regierungstätigkeit zu keinerlei Annäherung der Positionen, was sich in der bereits beschriebenen Aussparung des Themas durch Reynaud niederschlug. ${ }^{43}$ In außenpolitischer Hinsicht zeichnete sich eine nach außen sichtbare Angleichung der Sehweisen erst ab Frühjahr 1939 ab, nachdem Daladier von seiner diesbezüglichen konzeptionellen Zurückhaltung nicht zuletzt unter dem Druck der Sudetenkrise abgegangen war. ${ }^{44}$ Allerdings drückte die Berufung Reynauds, der sich den Ruf erworben hatte, eine harte Linie gegenüber dem Expansionsstreben der Diktatoren zu vertreten, das Bestreben Daladiers aus, ein

40 Vgl. hierzu die Darstellung Reynauds: Reynaud, Mémoires I, S. 200 f.; Ders., Au coeur de la mêlée, S. 201. Zur Berufung Reynauds auch: Susan B. Butterworth, Daladier and the Munich Crisis. A Reappraisal, in: Journal of Contemporary History 9/3 (1974), S. 191-216, hier: S. $200 \mathrm{f}$.

41 Berstein, Parti Radical II, S. 535 f.

42 Zum prekären sozialen Klima des Frühjahrs 1938: Jean-Pierre Azéma, De Munich à la Libération, 1938-1944 (Nouvelle Histoire de la France Contemporaine 14), Paris 1979, S. 23.

43 Siehe dazu oben Kapitel IX.3 dieser Arbeit.

44 Zu frühen außenpolitischen Stellungnahmen Daladiers vor dem Münchener Abkommen und zum Verhältnis Reynaud-Daladier in treffendem Überblick: Bellstedt, „Apaisement“, S. 133-144. 
Gegengewicht zu dem bekannt deutschfreundlichen Außenminister Bonnet zu setzen. ${ }^{45}$ Im Hinblick auf die wirtschaftspolitische Reorientierung und die damit verbundenen sozialpolitischen Grundsatzentscheidungen herrschte dagegen weitestgehende Übereinstimmung, die im Sommer 1938 manifest wurde.

So unbestimmt sich das Kabinett in allgemeinpolitischer Hinsicht zunächst präsentierte, so wenig eindeutig fiel vorerst die Finanz- und Wirtschaftspolitik aus, die auf halbem Wege zwischen den Vorgaben der Volksfrontzeit und den Forderungen von Arbeitgebern und Kapitalinteressen innehielt. In Abstimmung mit Daladier nahm der radikalsozialistische Finanzminister Marchandeau als einschneidendste Maßnahme Anfang Mai die erneute Abwertung des Franc in Angriff. So sollte über die Wiederherstellung von Gewinnmöglichkeiten bei Transfergeschäften die seit Beginn der Volksfront grassierende Kapitalflucht eingedämmt werden. Im Zuge einer Vereinbarung mit Großbritannien wurde der Franc zudem vom Goldstandard gelöst und an den Kurs des britischen Pfunds gebunden. Der Erfolg blieb zunächst nicht aus: Bis Sommer 1938 kehrten knapp 18 Milliarden Francs expatriierten Kapitals auch als Folge der beruhigten innenpolitischen Lage nach Frankreich zurück. Sie konnten bis zu einer Höhe von 16 Milliarden als Staatsanleihen nutzbar gemacht werden - ein Resultat, das die Rückkehrbewegungen der Jahre 1936 und 1937 klar übertraf. Die Entwicklung der internationalen Situation und das Wiederaufleben interner sozialer Spannungen ab Frühjahr 1938 bewirkten dann eine erneute Umkehrung der Tendenz, die den erzielten Effekt bis September praktisch wieder zunichte machte. Bezeichnenderweise erreichte der Kapitalabzug aus Banken und "Caisses d'Epargne" ein massives und überstürztes Maß ab dem 24. September, dem Tag der teilweisen Mobilisierung der französischen Streitkräfte. Erst im Oktober, nach Abschluß des Münchener Abkommens, wandte sich die Situation wieder in ihr Gegenteil, und nahezu die Gesamtheit des Kapitals kehrte zurück. ${ }^{46}$

Der Wiederbewaffnung räumte Daladier die von Blum bereits vorgegebene hohe Priorität ein, blieb gegenüber den Gewerkschaften jedoch bemüht, eine flexible Lösung zur Ausweitung der Produktion zu finden. Das Scheitern der Verhandlungen im Sommer 1938 war bestimmend für die Einleitung eines Kurswechsels, den er in einer Rede am 21. August publik machte: Frankreich habe sich an-

45 Vgl. dazu unten Kapitel X.2.b).

46 "Note de la Trésorerie“, 21 Novembre 1938 (AEF, B 33196). Bislang hat die wirtschaftshistorische Forschung noch keine einheitliche Interpretation der Kapitalbewegungen des Jahres 1938 vorgelegt. Da die Frage für die Bewertung der Finanzpolitik Reynauds ab November 1938 von Bedeutung ist, muß sie hier kurz erörtert werden.

Laut Frankenstein, Prix du réarmement, S. $193 \mathrm{f}$. verließen in der Hochphase der Sudetenkrise, zwischen Juni und Oktober 1938, circa 15 bis 16 Milliarden Francs den französischen Markt, so daß von den zurückgekehrten 18 Milliarden im Oktober nurmehr 2 Milliarden zur Verfügung standen. Ohne sich überhaupt auf Frankenstein zu beziehen, sieht Margairaz diese erneute $\mathrm{Ab}$ wanderungsbewegung zwar, hält aber im Widerspruch dazu die psychologische Konsolidierung des Kapitalmarkts bereits im Frühjahr 1938 für gegeben. Das bei ihm zitierte Quellenmaterial reicht jedoch nicht hin, um diese Behauptung zu belegen. (Vgl. Margairaz, L'Etat, les finances et l'économie, S. $444 \mathrm{f}$. und $462 \mathrm{f}$.).

Beide Autoren übergehen somit einen Teil der Gesamtbewegung und gelangen zu einem unvollständigen Bild: zu einem übermäßig optimistischen bereits für das zweite Quartal 1938 im Falle Margairaz'; zu einem übermäßig pessimistischen im Falle Frankensteins, der die Rückkehrbewegung von Oktober 1938 unterschätzt. 
gesichts der drohenden äußeren Gefahren wieder „an die Arbeit zu machen“, und dies insbesondere durch die flexiblere Handhabung der 40-Stunden-Woche. Die solchermaßen klar formulierte Attacke auf eine zum Symbol gewordene Errungenschaft der Volksfront wurde von Gewerkschaften und Linksparteien als "Kriegserklärung" aufgefaßt, zumal sie einherging mit weitreichenden Versprechen auf Lastenerleichterungen an die Arbeitgeberseite. ${ }^{47}$ Trotz der unwiderruflich aufgebrochenen Fronten bedurfte es eines außenpolitischen Schlüsselereignisses, des Abschlusses des Münchener Abkommens im September, um Daladier definitiv auf einen Konfrontationskurs zur Durchsetzung seiner Wirtschaftspolitik festzulegen. Der eingegangene „Waffenstillstand mit der Gewalt" ${ }^{48}$ erst beseitigte seine letzten $Z$ weifel, daß der Bruch mit den Verbündeten der Volksfrontzeit gleichermaßen "nötig und möglich" 49 geworden war. Die dringlichen Rüstungsanstrengungen für die zu erwartende militärische Konfrontation mit Hitler ${ }^{50}$ konnten nach München, gestützt auf den immensen Popularitätsgewinn des Ministerpräsidenten und deshalb mit Aussicht auf positive Resonanz in der Bevölkerung, in die Wege geleitet werden. ${ }^{51}$ Der geeignete Fachmann zur Durchsetzung der Wende aber war Paul Reynaud.

Reynaud hatte im April ohne Illusionen über seine begrenzten Wirkungsmöglichkeiten das Amt des Justizministers angenommen. Er schrieb der Position mehr "dekorative“ Funktion als tatsächliche Macht zu und richtete seine Hoffnungen offenbar von Anbeginn auf einen Wechsel ins Finanzressort. ${ }^{52}$ Die Spur, die er in seiner neuen Funktion hinterließ, blieb denn auch an Nachdrücklichkeit hinter dem von ihm Gewohnten zurück, und er selbst maß dem Bewirkten im Rückblick kaum Bedeutung zu: die Fortführung laufender Untersuchungen gegen die terroristische Geheimorganisation "Cagoule“, einzelne Änderungen im Zivilrecht, unter anderem zum Erbrecht bei landwirtschaftlichen Betrieben - das war im wesentlichen die Bilanz seiner Tätigkeit. ${ }^{53}$

Dagegen hatte er unverzüglich begonnen, Daladier seine Vorstellungen zur ökonomischen Krisenbehebung zu unterbreiten. Am 26. April und 3. Mai trug er im Anschluß an Kabinettssitzungen brieflich in wenig geschönter Form seine Kritik an den beschlossenen Maßnahmen vor, ohne indes Gehör zu finden. Gegen-

47 Zu Daladiers Rede vom 21.8. 1938 und zu den Reaktionen darauf: Berstein, Parti Radical II, S. 542-544 (Zitat: S. 542).

48 Klaus Hildebrand, Krieg im Frieden und Frieden im Krieg. Über das Problem der Legitimität in der Geschichte der Staatengesellschaft 1931-1941, in: Historische Zeitschrift 244 (1987), S. 1-28, hier: S. 28; Bellstedt, „Apaisement“, S. $135 \mathrm{f}$.

49 So die treffende Formulierung bei Jackson, Popular Front, S. 187.

50 Daladier war zu diesem Zeitpunkt bereits von der Unausweichlichkeit eines Krieges überzeugt; vgl. Du Réau, Edouard Daladier, S. 187.

51 Eine knappe Darstellung dieser Zusammenhänge bei: Ebenda, S. $187 \mathrm{f}$.; ausführlicher dazu: Berstein, Parti Radical II, S. 545-560; Frankenstein, Prix du réarmement, S. 187-199; Margairaz, L'Etat, les finances et l'économie, S. $467 \mathrm{ff}$.

52 Vgl. dazu die Schilderung seiner Justizministerzeit in: Reynaud, Mémoires II, S. 200-223, hier: S. 201.

53 Vgl. zur "Cagoule“, einem vermutlich im Mai 1936 gegründeten, militärisch organisierten rechtsextremen Geheimbund, der bis Frühjahr 1938 Staatsstreichvorbereitungen traf und bis zu seiner

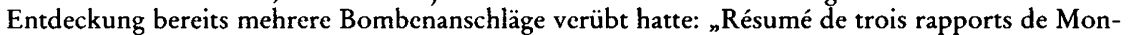
sicur le Procureur Général à Paris des 31 Janvier, 30 Mai et 23 Juin 1938“, o.D. (AN, 74 AP 16). Im Überblick auch: Philippe Bourdrel, La Cagoule. Histoire d'une société secrète du Front populaire à la Ve République, Paris 1992. Zur Zivilrechtsfrage: Reynaud, Mémoires II, S. 202. 
stand seiner Warnungen war die vorgesehene Abwertung des Franc, der er prinzipiell zustimmte, nicht ohne sie jedoch - mit Konsequenzen für ihre Ausführung konzeptionell aus dem anvisierten, vorwiegend finanztechnischen Zusammenhang zu lösen und in ein erweitertes, wirtschaftspolitisches Programm einzubetten. Anstelle der mit Blick auf Spekulantenkreise geplanten, etwa 10prozentigen „dévaluation" des Franc ${ }^{54}$ regte er eine höhere Abwertung an, die im Zusammenspiel mit der Aufhebung der 40-Stunden-Woche von dauerhafterer Wirkung über die bloße Sanierung des Staatshaushalts hinaus sein sollte. Seine Voraussage war präzise: Die beschlossene Variante würde gerade hinreichend sein, um den kurzfristigen Bedarf des Staates zu decken; Impulse auf die Wirtschaft blieben so aus, die sich einstellen könnten, wenn ein längerfristiger Rückzug des Staates vom Kapitalmarkt das Vertrauen in die Währung vorantreiben und ein der Industrie zugute kommendes Sinken des Zinsniveaus fördern würde. Eine "halbherzige“ Abwertung in Kombination mit neuen Staatsanleihen werde letztlich noch vor Ende des laufenden Jahres entweder einen erneuten Währungseingriff oder die Zwangsmaßnahme der Devisenkontrolle zur Folge haben. ${ }^{55}$

Eben vor diese letzte Alternative sah sich Daladier in der Tat bereits im Herbst 1938 gestellt. Bis Oktober hatte die gegen den Rat Reynauds umgesetzte Politik weder auf finanz- noch auf wirtschaftspolitischem Gebiet die gewünschten Erfolge gebracht. Das Bemühen, das für die Wiederbewaffnung so nötige Kapital über eine Politik des „Vertrauensgewinns“ zurückzuholen, war gescheitert - vorwiegend allerdings an politischen Gegebenheiten, die auch Reynaud in seinen rein technisch gehaltenen Ausführungen nicht in Rechnung gestellt hatte. So waren stimulierende Effekte auf die Industrieproduktion insbesondere im Rüstungsbereich tatsächlich ausgeblieben, wo fehlende Mittel sogar die Zurückstellung bereits vorgesehener Ausgaben erforderlich gemacht hatten. ${ }^{56}$ Zumindest im ministeriellen Umkreis Marchandeaus, möglicherweise auch im Denken des Ministers selbst, trat infolge einer neuerlichen Spekulationskrise gegen den Franc der Gedanke des Rückgriffs auf Devisenkontrollmaßnahmen zunehmend in den Vordergrund. Als Marchandeau in einer Kabinettssitzung am 30. Oktober diesbezügliche Absichten kundtat, kam es zum Eklat. Nach der Rücktrittsdrohung Reynauds, der erklärte, bei Fortführung dieser Politik seine Mitarbeit aufzukündigen, nahm Daladier eine personelle Umgruppierung vor: Während Marchandeau ins Justizministerium wechselte, übernahm Reynaud nun selbst das Finanzressort. ${ }^{57}$

Der Tausch hatte tiefere Ursachen als die bloße Ablehnung einer dirigistischen Maßnahme durch den Ministerpräsidenten: Er hatte nichts weniger als programmatischen Charakter. Die Ablösung eines Ministers, dessen Politik versagt hatte, gehörte keineswegs zu den unter der Dritten Republik unüblichen Verfahren. Hier aber stand die Person des Amtsnachfolgers für eine nötigenfalls unortho-

54 Tatsächlich belief sich die am 4. Mai 1938 durchgeführte Abwcrtung auf $12 \%$ und fixierte den Franc auf einem Stand von 179:1 gegenüber dem englischen Pfund. Im Verhältnis zum „Franc Poincaré“ machte die Abwertung 58\% aus (Frankenstein, Prix du réarmement, S. 189).

55 Reynaud an Daladier, 26. 4. 1938, bzw. 3. 5. 1938 (Zitat) (AN, 74 AP 16).

56 Frankenstein, Prix du réarmement, S. 193-197.

57 Zum Verlauf der entscheidenden Kabinettssitzung vgl. Reynaud, Mémoires II, S. 225-227; Jean Zay, Carnets secrets (De Munich à la guerre), Paris 1942, S. 29; Bonnefous, Histoire politique VI, S. 357. 
doxe, in ihren Grundzügen wirtschaftsliberale Politik, die bekanntermaßen das „redressement" von Ökonomie und Produktion dem Erhalt sozialpolitischer Errungenschaften überordnete. Auch Marchandeau hatte sich bereits im Sinne einer Liberalisierung des Kapitalmarkts orientiert. ${ }^{58} \mathrm{Als}$ jedoch nach dem Scheitern seiner kapitalfreundlichen Abwertungspolitik die Entscheidung anstand, entweder in den Zugeständnissen noch weiter zu gehen und damit den Bruch mit Gewerkschaften und Linksparteien zu riskieren oder aber Kapitalabfluß, nachfolgende Währungsinstabilität und wirtschaftliche Stagnation durch dirigistische Eingriffe zu Lasten der Besitzenden aufzuhalten, da hatte er sich zugunsten der zweiten Option entschieden. Daß die Forderung nach Devisenkontrolle ins Standardrepertoire des PCF gehörte und zudem noch im April zum Sturz des letzten reinen Volksfrontkabinetts unter Léon Blum geführt hatte, hemmte seine Entscheidung nicht; ausschlaggebend war sein erschüttertes Vertrauen ins freie Spiel der Marktmechanismen. ${ }^{59}$ Daladier schien zunächst ebenfalls dieser Lösung zuzuneigen, war aber schließlich durch allgemeinpolitische Überlegungen davon abgebracht worden. Auf dem Parteikongreß von Marseille hatten sich die Radikalsozialisten im Oktober 1938 mit großer Mehrheit gegen eine Fortführung der Volksfrontkoalition entschieden. Diese von Daladier mitgetragene und für die Dauer der ausgehenden Dritten Republik definitive Rechtswendung der Partei blieb nicht ohne Auswirkung auf die Orientierung des Kabinetts: Dirigistische Eingriffe, die im Geruch „linker“ Z Zwangsmaßnahmen standen, paßten nun nicht mehr ins Profil der neuen Politik. ${ }^{60}$ Dem Zeugnis eines Kabinettskollegen zufolge hatte Reynaud seinem Ministerpräsidenten am 30. Oktober eben dies vor Augen zu führen versucht: „Il y a une impossibilité politique à appliquer le remède communiste contre les droites qui nous ont soutenues. Ce serait un suicide. A droite, on nous dirait: ,Vous, mais pas cela'. A gauche: ,Cela, mais pas vous'. Il n'y a qu'un remède pour sauver la monnaie, c'est d'agir sur la production. “61

\section{a) „Le miracle français" 62 - Möglichkeiten und Grenzen einer liberalen Wirtschaftspolitik}

Am 1. November 1938 begann Paul Reynaud seine Tätigkeit in der Rue de Rivoli, am 12. November bereits wurde jene Serie von Dekreten veröffentlicht, die eine liberale Wende auf den Gebieten der Kreditpolitik, der staatlichen Preiskontrolle und der Arbeitszeitregelung einleitete. ${ }^{63}$ Oberster Grundsatz der in Angriff genommenen Maßnahmen war es, die ökonomische Wirksamkeit zentraler marktwirtschaftlicher Kategorien wiederherzustellen: „esprit d'entreprise“, „risque“ und "profit ${ }^{\text {" }}{ }^{64}$ Zur unverzichtbaren finanzpolitischen Abstützung dieser wirt-

58 Margairaz, L'Etat, les finances et l'économie, S. 445.

59 Zum Argument der „désagrégation nationale“: Frankenstein, Prix du réarmement, S. 197.

60 Zur Haltung Daladiers: Berstein, Parti Radical II, S. 561; Jackson, Popular Front, S. 187. Zur Rechtswendung der radikalsozialistischen Partei: Berstein, Parti Radical II, S. 535-557.

61 Zay, Carnets secrets, S. 29 (Tagebucheintrag vom 30. 10. 1938).

62 Le Monde, 3. 12. 1978.

63 Eine Sammlung der Dekrete Reynauds findet sich in: AN, F60, Karton 474.

64 Zitiert aus dem wirtschafts- und finanzpolitischen Rechenschaftsbericht, den die Regierung nach fünf Monaten vorlegte: „Le Bilan économique et financier des cinq premiers mois du plan de trois 
schaftspolitischen Neuorientierung zielten die Erlasse deshalb zunächst auf die dauerhafte Erholung des Kapitalmarkts. Um das Abwandern und das Horten von Kapital zu unterbinden, mußte, so die Überlegung Reynauds, die Währung stabilisiert und die Konkurrenz eines „hypertrophen Staates“ am Kapitalmarkt zurückgenommen werden: Die nachfolgende Entspannung des Marktes würde dann der privaten Kreditaufnahme und der Investitionstätigkeit zugute kommen.65 Noch am Tage der Verkündung der ersten Dekrete erklärte Reynaud deshalb den Verzicht auf jegliche Devisenkontrollmaßnahmen.66 Es lag überdies in der Logik dieser Politik, den staatlichen Rückgriff auf längerfristige Anleihen über einen größeren Zeitraum hinweg zu unterbinden. Wenn Reynaud also gleichzeitig anknüpfte an die deflationistische Grundhaltung der Regierungen Doumergue, Laval und Flandin der Jahre 1934/35, so lag seine Absicht zwar durchaus in der Bekämpfung von Staatsdefizit, Inflation und Währungsabwertung. Die dekretierte Minderung der Staatsausgaben - insbesondere bei zivilen Großvorhaben und im öffentlichen Dienst - stand jedoch zusammen mit der Erhöhung direkter und verbrauchsabhängiger Steuern darüber hinaus in engstem Konnex mit dem kapitalund produzentenfreundlichen Grundcharakter seiner Politik. In dieser Linie lag es auch, daß als Gegengewicht zu den Lastenerhöhungen die Wiederherstellung größerer Gewinnspannen bei Produzenten und im Handel gefördert wurde: Ihnen vor allem diente die Milderung der staatlichen Preiskontrolle, die für den Bereich der Großhandelspreise per Dekret umgesetzt wurde.

Die sukzessive Aufweichung der 40-Stunden-Woche bildete, wie zu erwarten, das schwerste Geschütz im Arsenal Reynauds. Mittels dreier Dekrete, die sich mit dem Themenkomplex befaßten, wurde das Mitspracherecht der Arbeiterorganisationen bei der Festlegung zusätzlicher Arbeitsstunden weitestgehend beschnitten. Auch die staatlichen Vorgaben über die Bezahlung der geleisteten Überstunden wurden gelockert, so daß beispielsweise bis zur achtundvierzigsten wöchentlichen Arbeitsstunde nurmehr ein Zuschlag von 15 Prozent verpflichtend war; bis zur fünfundvierzigsten Arbeitsstunde lag der Satz in Betrieben mit über 50 Mitarbeitern bei nurmehr 10 Prozent. Damit war eine der dringendsten Forderungen der Unternehmer erfüllt worden, die eine völlige Aufhebung der Arbeitszeitverkürzung wegen der zu leistenden Überstundentarife nicht immer befürwortet hatten. Schmerzhafte Sanktionen erwarteten zudem diejenigen Arbeiter, die geforderte Überstunden in der Rüstungsproduktion verweigerten; Aufrufe dazu wurden mit Gefängnisstrafe bedroht. ${ }^{67}$

Mit dem Maßnahmenbündel war ein entscheidender Schritt vollzogen. Zwar war es bereits im Dezember 1937 im Anschluß an die Untersuchungen des „Co-

ans. 12 novembre 1938 - 31 mars 1939, Paris 1939“, S. 1 (AEF, B 21848). Zu den im folgenden analysierten Maßnahmen auch: Margairaz, L'Etat, les finances et l'économie, S. 467-492; Frankenstein, Prix du réarmement, S. 201-217; Sauvy, Histoire économique II, S. 325-346.

65 Senatsrede Reynauds am 28. 12. 1938, abgedruckt in: Paul Reynaud, Courage de la France, Paris 1939, S. 113-137.

66 Rundfunkrede Paul Reynauds, 12. 11. 1938, abgedruckt in: Reynaud, Mémoires II, S. 492-495, hier: S. 493; ebenso in: Ders., Courage de la France, S. 23-39. Vgl. auch: "Le plan de redressement", in: Le Temps, 14.11. 1938.

67 JO, Chambre des Députés, Lois et décrets, 13 novembre 1938, S. 12862-12866; Ministère des Finances, Bulletin de statistique et de législation comparée, Novembre 1938, S. 1134-1139. 
mité d'Enquête sur la Production" zu einer Neuregelung in der Anwendung der „Loi de 40 heures" vom Juni 1936 gekommen. Doch umfaßte der bis November 1938 im wesentlichen gültige Kompromiß, auf den sich die Vertreter von Regierung, Arbeitgebern und Gewerkschaften geeinigt hatten, lediglich Modifikationen, die den Gehalt des Gesetzes unangetastet ließen: Ausnahmebestimmungen erlaubten Mehrarbeit zeitweise und in begrenztem Umfange, allerdings nur, wenn Aufsichtsbehörden und Arbeitnehmervertreter ihre Zustimmung erteilten. Insbesondere war an der Regel des 25prozentigen Zuschlags für Mehrarbeit festgehalten worden. 68

Der Wegfall dieser Beschränkungen wurde in den Linksparteien und Gewerkschaften zu Recht als vollkommener Bruch mit den wirtschafts- und sozialpolitischen Vorgaben der Volksfront verstanden. Es hätte unter solchen Umständen der herausfordernden Rhetorik Reynauds nicht bedurft, um Widerstand zu provozieren. Knapp eine Woche nachdem der Finanzminister am Abend des 12. November in einer Rundfunkrede verkündet hatte, daß in Frankreich „die Woche der zwei Sonntage" abgeschafft sei69, kam es in mehreren Unternehmen, die die neuen Bestimmungen bereits umgesetzt hatten, zu Streiks, Fabrikbesetzungen, Aussperrungen, Polizeiaktionen und Massenverhaftungen. ${ }^{70}$ Der Aufruf der CGT zum Generalstreik für den 30. November endete in einem Debakel für die Gewerkschaftsbewegung. Nicht daß die Appelle zum Ausstand nicht befolgt worden wären - vor allem in der Privatindustrie fanden sie ein breites Echo. Doch im entscheidenden öffentlichen Sektor kam das erzielte Ergebnis einer völligen Niederlage gleich. Aufgrund einer massiven Einschüchterungskampagne der Regierung, die fünf Tage Zeit für die minutiöse Vorbereitung von Gegenmaßnahmen gehabt hatte, erreichten die Arbeiterorganisationen noch nicht einmal annähernd jenen nachhaltigen politischen und psychologischen Effekt, den der letzte Generalstreik vom 12. Februar 1934 seinerzeit hinterlassen hatte. Bei öffentlichen Diensten, Post, Eisenbahn und Métro hielten sich die Beeinträchtigungen wegen der vorausgegangenen Zwangsverpflichtungen von Bediensteten und der über Rundfunk verbreiteten amtlichen Sanktionsdrohungen in engen Grenzen; wo dennoch Beschäftigte zuhause geblieben waren, wurden sie durch Soldaten ersetzt. ${ }^{71}$ Anders als noch vier Jahre zuvor reagierten Unternehmer und Staatsgewalt im Herbst 1938 mit massiven Repressionsmaßnahmen, die in mehr als 1731 Gerichtsverfahren und 806 ausgesprochene Gefängnisstrafen mündeten. Über 10000 Arbeiter wurden in den betroffenen Unternehmen bis Anfang Januar 1939 definitiv entlassen. ${ }^{72}$

68 Elisabeth Du Réau, L'aménagement de la loi instituant la semaine de quarante heures, in: Rémond/ Bourdin (Hg.), Edouard Daladier, S. 129-149; zur Arbeit und zu den Ergebnissen des "Comité d'enquête sur la production“: Margairaz, L'Etat, les finances et l'économie, S. 389-428, bes. 418$421,474$.

69 Rundfunkrede Reynauds, 12. 11. 1938, abgedruckt in: Reynaud, Mémoires II, S. 492-495, hier: S. 495.

70 Zum Ausmaß der Streiks und zu den Reaktionen von Unternehmern und Regierung: Antoine Prost, Le climat social, in: Rémond/Bourdin (Hg.), Edouard Daladier, S. 99-111, hier: 105-110; Heimsoeth, Zusammenbruch, S. 46.

7 Ebenda.

72 Prost, Le climat social, S. 107-110. 
Erst nach der Niederlage der Streikenden zeigte Daladier wieder Kompromißbereitschaft. Im Interesse der Entspannung des sozialen Klimas bemühte sich die Regierung in den Folgemonaten, die Wiedereinstellung der Entlassenen zu erreichen. So fand bis Sommer 1939 vermutlich die Mehrzahl in anderen als ihren ursprünglichen Betrieben wieder Arbeit. ${ }^{73}$ Eine dauerhafte Folge der Kraftprobe blieb jedoch bis auf weiteres die Ausschaltung der Arbeiterbewegung als politischer Kraft. Während des gesamten Jahrs 1939 kam es zu keinen neuerlichen Streiks mehr: Die Verankerung der Gewerkschaften in den Unternehmen war dafür seit der Neutralisierung der Streikführer zu nachhaltig gestört worden, die Zahl der Mitglieder in der größten Einzelgewerkschaft CGT im Gefolge der Repressalien zu rapide zurückgegangen. ${ }^{74}$ Nach der parlamentarischen Niederlage vom April 1938 hatten die Anhänger der Volksfront im Verlauf der Arbeitskämpfe vom November ihre zweite, entscheidende Niederlage hinnehmen müssen.75

Die tiefere Bedeutung der personellen Rochade vom November 1938 lag in der Vorbereitung und Durchführung dieses Prioritätenwechsels auf allgemein-, wirtschafts- und sozialpolitischem Feld. Es wäre deshalb auch verfehlt, Reynaud als Alleinverantwortlichen für die Entscheidung zugunsten wirtschaftlicher Mobilisierung und gegen den Erhalt sozialer Errungenschaften anzusprechen. ${ }^{76}$ Zweifellos war er der Motor der neuen Wirtschaftspolitik, und der eher kollegiale als autoritäre Führungsstil Daladiers kam ihm dabei zugute. Ohne dessen loyale Rückendeckung aber wäre der Konfrontationskurs bereits an den Widerständen im Umfeld des Ministerpräsidenten gescheitert, ganz zu schweigen von den Schwierigkeiten seiner parlamentarischen Durchsetzung. ${ }^{77}$ Am 9. Dezember verteidigten beide gemeinsam ihr Vorhaben in der Kammer; am gleichen Tag mißlang der Versuch der sozialistischen Kammerfraktion, die Regierung Daladier über einen Artikel des neuen Finanzgesetzes stürzen zu lassen, nur knapp. ${ }^{78}$ Neben der persönlichen Autorität Daladiers und der technischen Kompetenz Reynauds waren es die im Frühjahr 1939 bereits klar erkennbaren, positiven volkswirtschaftlichen Effekte der Maßnahmen, die das ihre dazu beigetragen hatten, die Akzeptanz der sozialpolitischen Begleiterscheinungen zu erhöhen.

Die Dekrete vom 12. November 1938 waren in der gemäßigten und der rechten Presse zunächst mit Vorbehalten aufgenommen worden, da man eine unnötige Kraftprobe mit den Gewerkschaften fürchtete, doch hatten sich diese Bedenken nach dem Ausgang der Streikbewegung verflüchtigt. Anders als Reynaud selbst behauptet, der von "allgemeiner Feindseligkeit der Presse" spricht, waren die Reaktionen zumindest geteilt. ${ }^{79}$ Eindeutig positiv reagierten dagegen die Kapital-

73 Hierzu aufgrund von Quellenrecherchen in Prozeßakten: Heimsoeth, Zusammenbruch, S. 48.

74 Jean Bruhat, La CGT, in: René Rémond/Janine Bourdin (Hg.), La France et les Français en 1938/ 1939, Paris 1978, S. $175 \mathrm{ff}$.

75 Frankenstein, Prix du réarmement, S. 203.

76 So geschehen bei Prost, Le climat social, S. $110 \mathrm{f}$.

77 Zur Zusammenarbeit Reynaud/Daladier im Herbst 1938: René Rémond, Introduction, in: Ders./ Bourdin (Hg.), Edouard Daladier, S. 14 f.; Berstein, Parti Radical II, S. 563.

78 Reynaud, Mémoires II, S. 249; JO, Chambre des Députés, Débats parlementaires, $1^{\text {re }}$ Séance du 9 décembre 1938, S. 1691-1699 (Reynaud); Ebenda, 2e Séance du 9 décembre 1938, S. 1708-1714 (Daladier).

79 Reynaud, Mémoires II, S. 227 f.; dagegen: Frankenstein, Prix du réarmement, S. 204; Margairaz, L'Etat, les finances et l'économie, S. $474 \mathrm{f}$. 
eigner. Zwischen November 1938 und August 1939 kehrte Gold im Wert von über 26 Milliarden Francs zurück, was Frankreich schon ab Frühjahr 1939 den Status des Landes mit den weltweit zweitgrößten Goldreserven hinter den USA gab. Allein in den Tagen nach dem 12. November 1938 war über eine Milliarde repatriiert worden; nach einem leichten Rückgang während der Streikwelle waren es im Monat Dezember über 7,5 Milliarden. ${ }^{80}$ Das Neue an der Rückkehrbewegung war neben ihrem Umfang und ihrer Konstanz die dahinterstehende neue Haltung der Investoren, die nach Einschätzung des Gouverneurs der „Banque de France“ im Gegensatz zur Kapitalbewegung vom Mai erstmals Dauerhaftigkeit versprach: „[...] c'est la première fois depuis trois ans qu'un mouvement de rentrée se produit sans dévaluation préalable. Ce qui peut attirer les capitaux, ce n'est plus l'appât d'un bénéfice à réaliser sur les cours, mais l'espoir de la stabilité recouvrée“ ".81

Die Reaktion dieses sensiblen Indikators macht klar, wie sehr sich das wirtschaftspolitische Prestige Reynauds innerhalb von wenigen Jahren gewandelt hatte. Hätte noch 1934 der Amtsantritt des "dévaluateurs“ mit großer Wahrscheinlichkeit Panikreaktionen auf dem Kapitalmarkt und den nachfolgenden Kursverfall des Franc bewirkt, so stand seine Person vier Jahre später für die Rückkehr von Stabilität und Vertrauen in die weitere wirtschaftliche Entwicklung. ${ }^{82}$ Dies lag freilich weniger daran, daß sich seine Ansichten über die anzuwendenden Mittel zur ökonomischen Erholung grundlegend gewandelt hätten. Ein ganzes Bündel persönlicher und überpersönlicher Faktoren mußte zusammentreffen, um den Wiederaufschwung in die Wege zu leiten, der Frankreich bis Frühjahr 1939 endgültig aus der Weltwirtschaftskrise herausführte: die vorläufige Entspannung der internationalen Krisenlage nach Abschluß des Münchener Abkommens, die Anbindung des Franc an das britische Pfund, welche seine weitere Abwertung unwahrscheinlich machte, schließlich die innenpolitische Wende, die einer kapitalfreundlichen Politik den Weg bereitete. ${ }^{83}$ Nur vor diesem Hintergrund konnten die Ideen Reynauds zur Entfaltung kommen und eine Kaskade von Folgewirkungen in Gang setzen, die ihrerseits dem Vertrauenszuwachs Stabilität verliehen.

80 Dieser Angabe liegt die Berechnung von Frankenstein zugrunde: Prix du réarmement, S. 204f. Die Zahlen für November 1938 legte Reynaud gegenüber der Finanzkommission der Kammer der Abgeordneten vor: Archives de la Chambre des Députés, Procès-verbaux de la Commission des Finances, Séance du 22 novembre 1938.

81 Die Protokolle des engeren Leitungsgremiums der Bank von Frankreich, des „Comité Permanent", zeigen klar, daß man auch dort die profitorientierte Kapitaloperation der Regierung vom Mai 1938 sehr skeptisch beurteilte: Sobald der realisierte Gewinn als ausreichend erachtet werde, würden die Gelder wieder ins Ausland abwandern (Comité Permanent, Séance du 12 Mai 1938; Archives de la Banque de France, Série Politique monétaire, Carton 25: Procès-verbaux du Conseil Général et du Comité Permanent, 1934-1945). Zitat: Comité Permanent, Séance du Jeudi 17 Novembre 1938, Ebenda. (Zum Zeitpunkt der Einsichtnahme in den Quellenbestand war dieser weder durch ein Findbuch noch durch eine einheitliche Signatur erschlossen).

82 Vgl. dazu etwa den Bericht des Finanzattachés an der französischen Vertretung in New York, wonach man in amerikanischen Finanzkreisen den Amtsantritt Reynauds als Vorzeichen für eine Hausse des Franc betrachtete (Leroy-Beaulieu an Finanzministerium, 3. 11. 1938; AEF, B 21848). Auch in englischen Wirtschaftskreisen wurden die Ernennung und die ersten Ergebnisse der Arbeit Reynauds mit Wohlwollen aufgenommen; siehe hierzu die Analysen des Botschafters in London, Corbin, vom 3. 11. - 5. 12. 1938 und 22. 5. 1939 (AEF, B 31732).

83 Frankenstein, Prix du réarmement, S. 203. 
Wegen des zurückgekehrten und des im Inland mobilisierten Kapitals war man tatsächlich während eines halben Jahres imstande, zur Deckung der Staatsausgaben auf die Auflage neuer, längerfristiger Staatsanleihen zu verzichten. Die Folge war eine Senkung des Zinsniveaus für längerfristige Kredite, die im Zusammenspiel mit den Impulsen, die von der gesteigerten Rüstungsproduktion ausgingen, einen allgemeinen Wiederaufschwung bewirkte. Der Produktionsindex erreichte im Juni 1938 wieder den Stand von 1928. Während der Anstieg für den Zeitraum zwischen Oktober 1938 und Juni 1939 durchschnittlich bei $20 \%$ lag, wurde dieser Wert in einigen Schlüsselbereichen wie der rüstungsnahen Metallindustrie (26\%), der Textil- $(23 \%)$ und der Bauindustrie (36\%) noch überschritten. ${ }^{84}$ Die Arbeitslosenzahl ging ab Juni 1939 leicht zurück, fiel allerdings nicht unter das Niveau von 1937. In vielen Bereichen war verstärkte Aktivität zu beobachten, so nahm etwa der Schiffahrts- und Eisenbahnverkehr um $8 \%$ bzw. um $13 \%$ zu. 85

Der Einfluß der verlängerten Arbeitszeit auf diese positive Entwicklung hielt sich allerdings wohl in engeren Grenzen, als dies Reynauds ehemaliger Mitarbeiter Alfred Sauvy im nachhinein herauszustellen versuchte. ${ }^{86} \mathrm{Zwar}$ arbeitete man im Juni 1939 in wichtigen Bereichen wie der Metall-, Kunststoff- und Textilproduktion über 40 Stunden, doch betrug die durchschnittliche Arbeitszeit insgesamt lediglich 41,2 Wochenstunden. So wichtig die Flexibilisierung der Arbeitszeit insbesondere für die Rüstungsindustrie und das Saisongewerbe gewesen war - in der Praxis stieß die freigesetzte Arbeitskraft dann an andere, strukturell bedingte Grenzen wie z.B. den Mangel an modernen Maschinen. Zusätzlicher Einfluß auf die wirtschaftliche Erholung ging von den gesteigerten Rüstungsanstrengungen und von der Konsolidierung etwa der Automobilindustrie aus. ${ }^{87}$

Auch hatte Reynaud im Hinblick auf die positive Gesamtbilanz seines Aufbauwerks, die er in regelmäßigen Stellungnahmen recht öffentlichkeitswirksam vertrat $^{88}$, durchaus von den Früchten der Arbeit seines Vorgängers profitiert. Was Marchandeau nach der Franc-Abwertung vom Mai 1938 unterlassen hatte, holte Reynaud im November nach: In Angleichung an die neue Parität des Franc nahm er eine Neubewertung des Gold- und Devisenvorrats der Bank von Frankreich vor und gelangte damit zu einem rein buchhalterischen Zugewinn von 31,581 Milliarden Francs in den Staatskassen. Dieser wiederum erlaubte ihm die publikumswirksame Rückzahlung von gewährten Vorschüssen an das Emissionsinstitut in gleicher Höhe. Die gleichzeitige Neubewertung des „ständigen Vorschusses“ der Zentralbank erhöhte die Disponibilitäten des Finanzministers auf über 10 Milliarden Francs, ohne daß zu einer andernfalls unvermeidlichen, beträchtlichen Erhöhung der vorgestreckten Beträge Zuflucht genommen werden mußte. Das Verfahren trug entscheidend dazu bei, den Rückzug des Staates vom Kapitalmarkt über

84 Die Zahlen nach: Alfred Sauvy, L'évolution économique, in: Rémond/Bourdin (Hg.), Edouard Daladier, S. 87-98; etwas abweichende Zahlen in: Sauvy, Histoire économique II, S. $338 \mathrm{f}$.

85 Ebenda.

86 Etwa in: Sauvy, De Paul Reynaud à Charles de Gaulle, S. 80.

87 Margairaz, L'Etat, les finances et l'économie, S. 480-482.

88 Reynaud nutzte dazu systematisch die Möglichkeiten, die ihm die Rundfunktechnik bot: Vgl. etwa seine Rundfunkreden vom 26. November, vom 1. und 27. Dezember 1938, vom 28. Januar, 6. März, 21. April, 12. Mai und 25. Mai 1939 (abgedruckt in: Ders, Courage de la France, S. 49-59, 61-66, 107-111, 143-152, 157-173, 189-210). 
sechs Monate hinweg zu finanzieren und so den Grundstein für den Vertrauenszuwachs in die staatliche Finanzpolitik zu legen.89

Welche Umstände aber auch immer der Arbeit Reynauds zugute gekommen waren - das ökonomische Resultat war ohne Zweifel ein positives. Dies war keineswegs selbstverständlich gewesen, und viele seiner Vorgänger waren an der gleichen Aufgabe gescheitert. Es hatte einer gewissen Kühnheit bedurft, um gegen die vorhersehbaren Widerstände in ein „liberales Experiment“ einzutreten, das angesichts der krisenhaften Entwicklung in Europa und der bekannt seismographischen Reaktionen des französischen Kapitalmarktes darauf ein zumindest riskantes Manöver darstellte. Das Kalkül Reynauds hatte sich als richtig erwiesen: Es gelang tatsächlich, die fatale Verknüpfung von innenpolitisch motivierten Umsturzängsten und außenpolitisch begründeter Kriegsfurcht in Anlegerkreisen zu lösen. Sobald die innenpolitische „Hypothek “ 90 eines denkbaren Wiedererstehens von Inhalten der Volksfrontpolitik aufgehoben war, verlor das außenpolitische Moment weitgehend seine Wirkkraft als dynamisierender Faktor auf dem Kapitalmarkt. ${ }^{91}$

Daß die Finanzprobleme im Rahmen des demokratischen Systems gelöst worden waren, konnte zu Recht als Prestigegewinn für das Prinzip des wirtschaftlichen Liberalismus verstanden werden. ${ }^{92}$ Wiederholt hatte Reynaud in eigennütziger Absicht dirigistische Maßnahmen wie die Devisenkontrolle mit totalitärer Zwangsstaatlichkeit in Verbindung gesetzt, als es darum gegangen war, Vertrauen in seine wirtschaftsliberale Haltung zu erzeugen. Zweifellos aber stand hinter dem deutlichen Verweis auf die deutschen Verhältnisse auch die aufrichtige Überzeugung vom engen Konnex zwischen wirtschaftlicher und politischer Freiheit: „Pour que le contrôle [des changes, A.d.V.] fonctionne, il faut qu'il y ait la chemise brune au village, la peine de mort en haut de l'édifice et la délation partout." ${ }^{93} \mathrm{Im}$ Verständnis Reynauds bildete die Konkurrenz der Wirtschaftssysteme das Pendant zur politischen Auseinandersetzung zwischen den „fordernden“ Diktaturen und den „bewahrenden“ Demokratien Europas. ${ }^{94}$ Der Erfolg auf wirtschaftlichem Gebiet stellte die Probe aufs Exempel für die Leistungsfähigkeit der französischen Demokratie dar und rechtfertigte die weitgehenden Opfer, die der Bevölkerung abzuverlangen waren. Ob Reynaud selbst diese Bewährungsprobe in den Jahren 1938/1939 als bestanden beurteilte, ist angesichts des allgegenwärtigen und für seine wirtschaftspolitischen Ziele konstitutiven Optimismus, den er öffentlich zur Schau trug, schwer zu beurteilen. Produktionssteigerung, Währungsstabilisierung und Konsolidierung der Staatsfinanzen - diese Bilanz schrieb er im Frühjahr 1939 gleichermaßen den mobilisierten Widerstandskräften wie der eigenen Innovationsfähigkeit zu: „Que dans le désarroi général des esprits et des choses, la

89 Vgl. hierzu: „Note sur la réévaluation de l'encaisse de la Banque de France“, 22. 11. 1928 (AEF, B 33196); erläuternd hierzu auch: Frankenstein, Prix du réarmement, S. 202; Reynaud, Mémoires II, S. $231 \mathrm{f}$.

90 Margairaz, L'Etat, les finances et l'économie, S. 475.

91 Frankenstein, Prix du réarmement, S. 205.

92 So nach der Ansicht "gutinformierter Beobachter" aus amerikanischen Bankiers- und Geschäftskreisen: Leroy-Beaulieu an Finanzministerium, 17. 1. 1939 (AEF, B 21848).

93 JO, Sénat, Débats parlementaires, Séance du 28 décembre 1938.

94 Paul Reynaud, Le problème militaire français, Paris 1937, S. III. 
France ait pu reconstituer et accroître ses forces, cela prouve sans doute la robustesse de son organisme économique, la solidité de sa structure sociale et la souplesse de ses institutions. Mais cela démontre en outre l'efficacité des méthodes que nous avons suivies et la justesse des principes qui ont guidé notre action."

In bezug auf das umfassendere Ziel, das er vor und nach Antritt seiner ministeriellen Funktion wiederholt öffentlich formuliert hatte - das "redressement“ Frankreichs, gestützt auf die Einheit der Nation und mit Blick auf die Stärkung ihrer Wehrhaftigkeit nach außen -, hinterläßt sein Werk allerdings einen eher zwiespältigen Eindruck.

Der ökonomische Aufschwung und die „Wohlhabenheit"96 des Fiskus im Gefolge der Maßnahmen Reynauds verschafften Frankreich zweifellos erst die volkswirtschaftliche Basis, um die enorme Steigerung der Verteidigungsausgaben von 8,6\% des Nationaleinkommens im Jahr 1938 auf 23\% im Jahr 1939 in Angriff zu nehmen. ${ }^{97}$ Der Goldvorrat der Bank von Frankreich hatte sich bis Sommer 1939 auf über 2800 Tonnen erhöht, was dem Doppelten der Reserven entsprach, über die Frankreich im August 1914 verfügte. Damit hatte der Finanzminister jenen „trésor de guerre" wiederhergestellt, den der französische Generalstab im Sommer 1936 als Mindestmaß für das erfolgreiche Durchstehen einer kriegerischen Auseinandersetzung fixiert hatte. ${ }^{98}$ Auch nach September 1939 trieb Reynaud die Vorbereitung der französischen Wirtschaft auf einen Kriegseintritt systematisch voran: Neue Steuererhöhungen und Kriegsanleihen dienten ab Herbst 1939 zur Deckung der massiv gewachsenen Belastungen des Budgets. Gegen den anfänglichen Widerstand Daladiers und eines Teils des Kabinetts konnte Reynaud im Frühjahr 1940 eine weitere Verschärfung seiner Austeritätspolitik durchsetzen. Die Prinzipien der Konsumbeschränkung und Produktionssteigerung, der Inflationsbekämpfung und der mentalen Vorbereitung der Bevölkerung auf mögliche Entbehrungen der Kriegszeit gingen in eine Serie neuer Décrets-lois ein, die unter anderem die Rationierung von Grundnahrungsmitteln und kriegswichtigen Verbrauchsgütern festschrieben. 99

95 "Le bilan économique et financier des cinq premiers mois du plan de trois ans. 12 novembre 31 mars 1939, Paris 1939“, S. 27 (AEF, B 21848).

96 "Note de la Trésorerie“, 21. 11. 1938 (AEF, B 33196).

97 Die Zahlenangaben bei Frankenstein, Prix du réarmement, S. 35. In einer Rede vor dem Senat erklärte Daladier am 17.4.1940 in bezug auf die Auswirkungen der Kapitalrückkehr: „A partir de cette date, $j$ 'ai pu prodiguer - je dis prodiguer - à l'aviation française non pas les 2 milliards primitifs, mais plus de 11 milliards pour une seule année"; zitiert nach: Ebenda, S. 207.

98 Die Armeeführung hatte den erforderlichen Staatsschatz auf 50 Milliarden Franc geschätzt, eine Summe, die im Verlauf der Jahre 1937 und 1938 unterschritten und erst im Verlauf des Sommers 1939 wieder erreicht wurde; vgl. dazu: Robert Frankenstein, Le financement français de la guerre et les accords avec les Britanniques (1939-1940), in: Français et Britanniques dans la Drôle de guerre. Actes du Colloque franco-britannique tenu à Paris du 8 au 12 décembre 1975, Paris 1979, S. 461-487, hier: S. 463 f.; Ders., Prix du réarmement, S. $205 \mathrm{f}$.

99 Hierzu und zu den Bedenken im Kabinett angesichts möglicher psychologischer Folgen einer forcierten Politik der Konsumbeschneidung in der Bevölkerung: Jean-Louis Crémicux-Brilhac, Les Français de l'an 40. Band I: La guerre oui ou non?, Paris 1990, S. 442-455. Reynaud formulierte seine Überlegungen zur Stärkung des „Opfergeists“ der Franzosen gegenüber Oberst de Villelume, seit Oktober 1935 Verbindungsoffizier zwischen dem Quai d'Orsay und dem Generalstab Gamelins: Paul de Villelume, Journal d'une défaite (23 août 1939 - 16 juin 1940), Paris 1976, S. 116 f. (1.12.1939). 
Obwohl am 10. September 1939 die so lange offiziell abgelehnte Devisenkontrolle auf der Basis monatelanger, geheimer Vorarbeiten eingeführt worden war, brachte dies keinen wirklichen Bruch mit der liberalen Ausrichtung seiner Politik mit sich. Die Kontrollmechanismen waren bewußt vergleichsweise schwach gehalten und hinderten deshalb keineswegs den weiteren Kapitalrückfluß. Von einem Überhandnehmen dirigistischer Wirtschaftsführung seitens des Staates konnte keine Rede sein, vielmehr blieben wesentliche Elemente des liberalen finanzpolitischen Credos Reynauds weiterhin wirksam: das Vertrauen auf die unternehmerische Privatinitiative als Basis für die Steigerung der Rüstungsproduktion; die anleger- und produzentenfreundliche Grundhaltung; die Zusammenarbeit mit den beiden Kammern, die seine Finanzpolitik im wesentlichen unterstützten; schließlich nicht zuletzt das Beharren auf einer gemäßigten Ausgabenpolitik, als er die Kapazität des Landes, einen längeren Krieg zu führen, gefährdet sah. Überraschend hatte er zwar noch im November 1938 der Gewährung von 25 Milliarden Francs neuer Militärkredite zugestimmt; im Dezember verweigerte er sich jedoch hartnäckig der durch Daladier gewünschten Aufstockung dieser Summe zum Kauf amerikanischen Kriegsmaterials. Gegen Jahresende erst war er zu Zugeständnissen bereit, die deutlich geringer ausfielen, als von Daladier und den Militärs gewünscht. ${ }^{100}$ Diese Haltung verrät sehr viel weniger „innere Widersprüche“ oder "Unentschlossenheit" 101 bei Reynaud denn ein durchaus wahrnehmbares Konzept für die Organisation der Staatsfinanzen in Kriegszeiten. Reynaud verlor - wie auch leitende Beamte seines Ministeriums - über allen prinzipiell mitgetragenen Verteidigungsvorbereitungen nicht die Nachkriegssituation in Frankreich und Europa aus den Augen. Die neue Ordnung sollte Frankreich nicht wieder in die finanziellen wie diplomatischen Engpässe der Zeit nach 1918 führen, und die Grundlagen dafür mußten schon während des Krieges gelegt werden: über eine solide Haushaltsführung entgegen der Versuchung zum massiven Einsatz der staatlichen Goldreserven; durch die baldmöglichste Rücknahme dirigistischer oder restriktiver Maßnahmen; schließlich über die wirtschaftlich gestützte Zusammenarbeit mit Großbritannien, vorweggenommen in der französisch-britischen Wirtschaftsvereinbarung vom 4. Dezember 1939.102

100 Vgl. zu den Umständen dieser Verhandlungen die Erinnerungen Jean Monnets, der von Daladier als Unterhändler in den USA vorgesehen war: Jean Monnet, Mémoires, Paris 1976, S. 143; Frankenstein, Prix du réarmement, S. 208. Siehe auch Reynauds Stellungnahme in diesem Sinne während der Sitzung des obersten Verteidigungsrates "Comité Permanent de la Défense Nationale“ vom 5. 12. 1938 (DDF, 2e série, Band XIII, Doc. 37, S. 69-76).

101 So die allzu negativen Urteile Frankensteins (Ders., Prix du réarmement, S. 208) und Monnets (Ders., Mémoires, S. 143).

102 Vgl. zu diesen Grundsätzen die Senatsrede Reynauds vom 28. 12. 1939, seine Rundfunkrede vom 29. Februar 1940 (abgedruckt in: Ders., Courage de la France, S. 113-137 und Ders., Finances de guerre (29 juillet 1939 - 29 février 1940), Paris 1940, S. 205-225). Dazu auch eine Note des Generalsekretärs im Finanzministerium, Yves Bouthillier, der sich gegen den Gedanken des massiven Einsatzes der staatlichen Gold- und Devisenvorräte für die Rüstungsanstrengungen aussprach: „La guerre va profondément appauvrir le pays. L'assurance du pays contre cet appauvrissement, quelle est-elle? En dehors de la production générale qu'il faudra intense dès la fin des hostilités, le gage sur lequel pourra être édifié la monnaie française après la victoire consistera dans les réserves d'or, d'une part, de devises et de valeurs étrangères d'autre part “ („Mesures à prendre pour assurer le financement des dépenses publiques en 1940. Note pour le ministre", 4. 1. 1940; AEF, B 33196). Zur französisch-englischen Finanzvereinbarung vom 4. 12. 1939 (unterzeichnet am 13.12. 1939): Frankenstein, Le financement français, S. $472 \mathrm{f}$. und 482-487. 
Eine solcherart verantwortlich geführte Wirtschafts- und Finanzpolitik stand natürlich in eklatantem Gegensatz zu einer totalitären Kriegswirtschaft, die in ihrer Ausrichtung auf das militärische Ziel hin die Bereinigung der anfallenden Lasten den Nachkommen überließ. Die Beibehaltung des liberalen Rahmens machte demgegenüber die moralische und auf längere Sicht auch ökonomische Überlegenheit der Reynaudschen Politik aus, begründete mittelfristig aber ihre wirtschaftsmobilisatorische Unterlegenheit: Mit großer Wahrscheinlichkeit hätte die rigorosere Umwandlung der ökonomischen Struktur des Landes in Richtung einer „économie de guerre" noch umfangreichere Rüstungsanstrengungen erlaubt. Der Anteil der Militärausgaben am Nationaleinkommen in Frankreich erreichte nach 1935 bis zum Kriegsbeginn nie jenen Prozentsatz, der im nationalsozialistischen Deutschland für die Rüstung aufgewendet wurde. ${ }^{103}$ Zweierlei darf bei der Bewertung dieser Tatsache allerdings nicht übersehen werden. Zum einen gelang es nach Jahren erst wieder unter der Ägide Daladier/Reynaud, den seit Mitte der dreißiger Jahre ständig gewachsenen Abstand bei den relativen Aufwendungen zu vermindern: Im Jahr 1939 hatte sich die Differenz mit einem Prozentanteil von $23 \%$ in Frankreich und 30\% in Deutschland im Vergleich zum Vorjahr verringert. Zum anderen schnitt Frankreich neben der zweiten bedeutenden europäischen Demokratie, Großbritannien, durchaus nicht schlechter ab, da dort die relativen Aufwendungen bis Kriegsausbruch stets leicht unter den französischen lagen. Insofern erscheint es unangemessen, die Reynaudsche Wirtschafts- und Finanzpolitik unter dem Aspekt ihres rüstungspolitischen Ertrags grundsätzlich zu kritisieren. 104

Bedenklicher war allerdings der sozialpolitische Preis, mit dem der unbezweifelbare Erfolg erkauft wurde. Weniger von ihrer öffentlichen Präsentation denn von ihrer praktischen Umsetzung her kam die neue Wirtschaftspolitik einer "Ghettoisierung" 105 der Arbeiterbewegung gleich, die umso gravierender empfunden wurde, als sie den Ansätzen auf verstärkte politische Teilhabe der Arbeiterklasse unter der Volksfront ein abruptes Ende bereitete. Das Auseinanderklaffen von unitarischer Rhetorik und tatsächlicher Aktion hatte sich am 30. November 1938 augenfällig gezeigt und setzte sich bis in die Kriegsjahre fort. Von Anbeginn und wiederholt hatte Reynaud eine gleichmäßige Aufteilung der Lasten versprochen ${ }^{106}$, die Evolution der Steuergesetzgebung wies bis 1940 dann allerdings in eine andere Richtung. Der Vergleich der Belastungen der Steuerjahre 1938/39 und 1939/40 macht deutlich, daß Reynauds Reformen zur Abschöpfung des Zu-

103 Im Jahr 1935 übertraf der Anteil der deutschen Rüstungsaufwendungen am Nationaleinkommen mit $6 \%$ zum erstenmal seit Ende des Ersten Weltkriegs denjenigen der französischen Seite, der bei 5,8\% lag. Der Abstand zwischen den prozentualen Aufwendungen wurde trotz Anwachsens auch der französischen Anstrengungen immer größer, bis im Jahr 1938 in Deutschland mit 17,2\% des Bruttoeinkommens anteilmäßig mehr als das Doppelte in die Rüstung investiert wurde als in Frankreich (8,6\%) (vgl. dazu die Zahlenangaben bei Frankenstein, Prix du réarmement, S. 35).

104 Ebenda. Die diesbezügliche Kritik bei Frankenstein widerspricht dessen eigenen Einsichten zum wirtschaftlichen Mobilisationsvermögen der französischen Demokratie (Frankenstein, Prix du réarmement, S. 35 f.; zur Kritik an Reynaud: S. 207-209 und passim).

105 Jackson, Popular Front, S. 188.

$106 \mathrm{Vgl}$. etwa seine Runkfunkrede vom Abend des 12. November 1938 (Reynaud, Mémoires II, S. 492-495); Entsprechendes versicherte er in: „Le bilan économique et financier des cinq premiers mois du plan de trois ans“, S. 27 (AEF, B 21848). 
gewinns aus kriegsbedingten Mehreinnahmen keineswegs unter dem Imperativ sozialer Gerechtigkeit konzipiert waren. Zur (Mit)finanzierung der Rüstungsausgaben wurden Einkommenssteigerungen aus geleisteter Mehrarbeit sowie der allgemeine Konsum der Bevölkerung in deutlich höherem Maße herangezogen als die zusätzlichen Gewinne der Unternehmer; die Besteuerung von Kapitalbesitz wurde im Verhältnis zur Periode 1938/39 sogar reduziert. Während die Erwerbstätigen also über direkte und indirekte Besteuerung erfaßt wurden, stand es dem Kapitalbesitz weiterhin frei, sich durch die Zeichnung von Anleihen am Aufbauwerk zu beteiligen. ${ }^{107}$

Weit davon entfernt, willkürlich konzipiert zu sein, spiegeln die Maßnahmen eine wirtschaftspolitische Grundsatzentscheidung wider, die in einer Linie mit den Dekreten vom November 1938 stand und zur Konjunkturbelebung in erster Linie auf die Aktivierung der Investitionstätigkeit zielte. Das Vorgehen Reynauds als Finanzminister zwischen November 1938 und März 1940 zeigt die Möglichkeiten und Grenzen seines liberalen Politikverständnisses. In erster Linie auf das wirtschaftliche Feld gerichtet, konnte es sich dort in effektiver Weise entfalten, weil als Ergebnis einer zweifellos schwierigen Gratwanderung des Ministers soziale Ansprüche und Mitspracherechte hinter dem nationalen Ziel hatten zurückstehen müssen. Daß eine flexiblere Lösung möglich gewesen wäre, die etwa jenen Ergebnissen Rechnung getragen hätte, die die Beratungen zwischen Regierung, Arbeitgebern und Gewerkschaften im "Comité d'Enquête sur la Production“ bis Ende 1937 zutage gefördert hatten, kann im nachhinein mit guten Gründen vermutet werden. In jedem Falle bot die französische Gesellschaft auch aufgrund der Wirtschafts- und Finanzpolitik der Regierung Daladier im Frühjahr 1940 ein weniger geeintes Bild als noch im Jahr 1938. ${ }^{108}$

Reynaud hatte durch seine wirtschafts- und finanzpolitischen Maßnahmen in ein komplexes Beziehungsgeflecht eingegriffen und es charakteristisch verändert. Stabilisierende wie in gewissem Maße auch destabilisierende Effekte hatten sich daraus ergeben. In der Folge blieb es jedoch weder bei den rein ökonomischen Wirkungen der Neuorientierung noch bei den beschriebenen sozial- und rüstungspolitischen Implikationen. Bis auf das außenpolitische Feld strahlte der „technische“ Erfolg seiner Wirtschaftspolitik aus, entzog er doch auf indirektem Wege einer genuin französischen Politik des „apaisement“ gegenüber Hitlerdeutschland noch im Frühjahr 1939 die Basis.

\section{b) „Réarmement et conciliation" - Paul Reynaud und die Deutschlandpolitik Edouard Daladiers}

Naturgemäß war der außen- und deutschlandpolitische Handlungsspielraum Reynauds als Minister im Kabinett Daladier zunächst begrenzt. Allein schon aufgrund der Ressortverteilung war ihm weitgehende Abstinenz auferlegt, so daß sich sein Einfluß bis November 1938 praktisch nur mittelbar manifestieren

107 Frankenstein, Le financement français, S. $467 \mathrm{f}$. und $476 \mathrm{f}$.

108 Margairaz, L'Etat, les finances et l'économie, S. 483 und 389-428. Zur Auseinanderentwicklung der französischen Gesellschaft während der „Drôle de guerre“ allgemein: Heimsoeth, Zusammenbruch, S. 102-137. 
konnte. Auch wenn ihm seine vorerst zweitrangige Funktion mehr Einfluß verliehen hätte, wäre er aber wohl kaum mit energischer Kritik an der Politik seines Ministerpräsidenten an das breite Publikum getreten. Während der Sudetenkrise und nach seinem Wechsel ins Finanzministerium vermied er es, sich in öffentlichen Gegensatz zu Daladier zu stellen. ${ }^{109}$ Nichtsdestoweniger war sein außenpolitisches Koordinatensystem klar abgesteckt, als er im April 1938 in die Ministerverantwortung berufen wurde. Er hatte sich den Ruf des unkonventionellen ,Hardliners' gegenüber den europäischen Diktaturen erworben, seit er sich im Dezember 1935 öffentlich für Sanktionen gegen Italien ausgesprochen hatte, das im Oktober des gleichen Jahres in Äthiopien eingefallen war. ${ }^{110}$ Ebenso wie mit seinem energischen Eintreten für eine weitere französisch-russische Annäherung auf der Basis der Zusammenarbeit der jeweiligen Generalstäbe hatte er sich damit weite Teile des rechten Lagers entfremdet, wo man Lavals Lavieren in der Sanktionsfrage unterstützte und aufgrund antikommunistischer Ressentiments ein Bündnis mit der Sowjetunion ablehnte.111 Mit André Tardieu war es über diesen Fragen im Jahr 1935 zum Zerwürfnis gekommen.112

In der rhetorischen Konsequenz, mit der er insbesondere seine Position deutschlandpolitischer „fermeté" im Kabinett und außerhalb vertrat, hob er sich deutlich von seinem Regierungschef $a b$. Er hatte dabei allerdings die günstigere Ausgangsposition: Wenn es ihm im Gegensatz zu Daladier gelang, sich auch nach September 1938 in der Öffentlichkeit als Mann der Entschlossenheit und der Härte gegenüber den europäischen $Z$ wangsregimen zu profilieren, dann kam ihm ganz wesentlich gerade die faktische Beschränkung seiner außenpolitischen Wirkungsmöglichkeiten zugute. Anders als der Ministerpräsident, dessen außenpolitisches Agieren sich zumindest bis zur Jahreswende 1938/39 oft unvorteilhaft von seinen wiederholten Entschlossenheitsbekundungen abhob, konnte Reynaud seinen ostentativ zur Schau getragenen Willen zur Tat weitgehend unbeirrt von den Zwängen beispielsweise der interalliierten Beziehungen präsentieren. Es hieße den politischen Ehrgeiz Reynauds zu unterschätzen, wollte man dahinter nur den Ausdruck von konzeptioneller Geradlinigkeit und nicht auch ein gehöriges Maß an persönlicher Profilbildung und Karriereplanung vermuten.

Vor dem Hintergrund des Berchtesgadener Ultimatums Hitlers an Schuschnigg vom 12. Februar und der allmählich sich verdichtenden Gewißheit des „Anschlusses" Österreichs hatte in der Pariser Kammer der Abgeordneten am 25. und 26. Februar eine wichtige außenpolitische Debatte stattgefunden. Die gemäßigte

109 So hatte er Daladier keineswegs vor den übrigen Kabinettsmitgliedern wegen seiner Finanzpolitik attackiert und hierfür den Briefweg vorgezogen (vgl. Reynaud an Daladier, 26. 4. 1938; AN, 74 AP 16).

110 Vgl. JO, Chambre des Députés, Débats parlementaires, Séance du 27 décembre 1935, S. 2815 f.; wiederholt in: Paris-Soir, 22. 8. 1936. Zum diplomatischen Hintergrund der Äthiopienfrage in der „Ära Laval“: Duroselle, La décadence, S. 123-152; zur Haltung der Rechten gegenüber der Italienpolitik Lavals: Micaud, French Right, S. 52-66.

111 Vgl. die Artikel Reynauds in: L'Oeuvre, 16. 4. 1936; L'Echo de Paris, 21. 11. 1936; Ce Soir, 21. 3. 1938; siehe auch: JO, Chambre des Députés, Débats parlementaires, Séance du 4 décembre 1936, S. 3325; ebenda, Séance du 26 février 1938, S. 647. Allgemein: Bartel, Frankreich und die Sowjetunion, S. 38; zur Haltung der Rechten: Micaud, French Right, S. 46-50 und 67-84.

112 Monnet, Refaire la République, S. 372-375. Vgl. dazu auch den Briefwechsel zwischen Reynaud und Tardieu (AN, 324 AP 14). 
und die äußerste parlamentarische Rechte war dabei im Hinblick auf die einzuschlagende Deutschland- und Ostpolitik in eben jenen drei Strömungen präsent gewesen, die sich in ihren Reihen seit 1936 herauskristallisiert hatten. Paul Reynaud exponierte sich in der Debatte als Vertreter "bedingungsloser Unnachgiebigkeit“. ${ }^{113}$ In einer programmatischen Kammerrede entfaltete er am 26. Februar seine im Kern unveränderten Vorstellungen anhand der beiden Alternativen, die er im Prinzip bereits im Dezember 1936 als einzig logische Fortentwicklungsmöglichkeiten der französischen Außenpolitik präsentiert hatte: die aktive Aufrechterhaltung des europäischen Gleichgewichts einerseits oder die „Abdankung“ als Großmacht und der Rückzug hinter die Maginot-Linie andererseits. ${ }^{114}$ Der Verteidigung der ersten Option als allein wirklich friedenssichernder Politik galten im Kern seine Ausführungen. Nur eine Position der Festigkeit gegenüber der deutschen Expansionslust in Zentral- und Osteuropa könne auf Dauer immer neuen Forderungen vorbeugen und eine kriegerische Auseinandersetzung abwenden: „Hitler [...] veut germaniser l'Europe centrale. Une fois ce formidable bloc germanique constitué, l'Allemagne nous réclamerait des colonies, l'Alsace et la Lorraine, l'accès à l'Atlantique. La ligne Maginot suffira-t-elle alors? Nous serions entraînés dans une guerre sans honneur - et sans l'appui d'un ami."115

Reynauds Konzept des rückhaltlosen Widerstands gegen das deutsche Vordringen baute auf die Unterstützung durch die Sowjetunion, durch Großbritannien und die kleineren östlichen Verbündeten. Daß diesem Kalkül im Frühjahr 1938 bereits ein hohes $\mathrm{Maß}$ an Wunschdenken innewohnte, war ihm vermutlich klar: Nur sehr zurückhaltend verwies er noch auf eine mögliche militärische Zusammenarbeit mit der Sowjetunion. Die im Rückblick entscheidende Wegmarke in der Einleitung der englischen Appeasement-Politik - die Entlassung Edens im Februar 1938 - interpretierte er zwar optimistisch als kaum ausschlaggebend für eine Veränderung in der englischen Haltung. Daß er dennoch ein englisches „désengagement" in Zentraleuropa fürchtete, läßt sich indirekt ablesen. In einer Art „Vorwärtsstrategie" sollte Frankreich in der Region die führende Schutzmachtrolle übernehmen und so Großbritannien, das den großen Festlandsverbündeten nicht im Stich lassen werde, mitziehen: „Certes, la Grande-Bretagne n'a jamais voulu prendre d'engagement ferme en Europe centrale, mais elle a toujours laissé planer une menace salutaire envers un agresseur éventuel. A cet égard, malgré le départ de M. Eden, la politique anglaise ne changera pas. Sa formule est: réarmement et conciliation. Elle ne peut laisser écraser la France, mais, en ce qui concerne l'Europe centrale, c'est à nous de prendre la tête." ${ }^{116}$

Eine Minderheit nur der parlamentarischen Rechten und der Mitte trug diese Position bedingungsloser „fermeté" mit. ${ }^{117}$ Reynauds Vorstoß richtete sich deshalb in erster Linie gegen die Träger der beiden alternativen Vorstellungen aus den eigenen politischen Reihen, gegen jene, die wie Louis Marin und Jean Ybarnéga-

113 Vgl. Micaud, French Right, S. 136-144 (Zitat: S. 137).

114 JO, Chambre des Députés, Débats parlementaires, Séance du 26 février 1938, S. 646-649; zum Verlauf der Debatte auch: Reynaud, Mémoires II, S. 186-191.

115 JO, Chambre des Députés, Débats parlementaires, Séance du 26 février 1938, S. 648.

116 Ebenda, S. 649.

117 Micaud, French Right, S. 143 f. 
ray eine Erneuerung der Stresa-Politik unter Einschluß Italiens wünschten, und insbesondere gegen die Befürworter einer „Politik der freien Hand“ für Deutschland in Zentraleuropa. Sein eigener Parteichef, Pierre-Etienne Flandin, stand im Februar 1938 wie bereits in den Debatten von Dezember 1936 für diese Option. ${ }^{118}$ Außerhalb des Parlaments wurde die Konzessionspolitik seit 1937 unter anderem mitgetragen von Reynauds späterem außenpolitischen Antagonisten im Kabinett Daladier: Georges Bonnet.119 In allen wesentlichen Punkten herrschte Dissens zwischen den beiden Extrempositionen Reynauds und Flandins: Widerstand gegen deutsche Hegemoniebestrebungen, diplomatische Einflußnahme auf Großbritannien im Sinne offensiver Einhaltung der westlichen Beistandsverpflichtungen in Ost- und Südosteuropa sowie Förderung einer internationalen Gleichgewichtspolitik unter Einbezug der russischen Allianz standen auf der einen Seite; vorzugsweises "rapprochement" an Deutschland und Italien, Annäherung an die interventionsfeindlichen Strömungen in der englischen Politik, Vertrauen in das sicherheitspolitische Faustpfand der Maginot-Linie auf der anderen. ${ }^{120}$

Als Edouard Daladier sein Ministerpräsidentenamt im April 1938 antrat, ließ er zunächst wenig Entschiedenheit erkennen, intensiv auf außenpolitische Fragen Einfluß zu nehmen. ${ }^{121}$ Der Mann, der 1933 gegenüber Hitler auf einer Doppelstrategie von direkter Gesprächsdiplomatie und Gleichgewichtspolitik beharrt hatte, entwickelte unter den veränderten Umständen des Jahres 1938 zunächst kaum eindeutiger konturierte Vorstellungen. Zwar beharrte er in den ersten englisch-französischen Regierungsgesprächen vom April 1938 auf den französischen Verpflichtungen gegenüber der Tschechoslowakei; daneben aber erging er sich gegenüber Chamberlain und Halifax nur in recht unkonkreten Äußerungen über eine einzuschlagende Politik der "Weisheit" und der "Vernunft" gegenüber Hitler. ${ }^{122}$ Die nachfolgende Konzentration des Ministerpräsidenten auf die Problematik der wirtschaftlichen Konsolidierung Frankreichs als Voraussetzung seiner Aufrüstung ließ Außenminister Bonnet weiten Spielraum, den dieser bereits ab Sommer im Sinne seiner Konzessionspolitik nutzte. ${ }^{123}$

In der Sudetenkrise des Jahres 1938 bot die französische Regierung wie der Ministerpräsident selbst ein ambivalentes Bild. ${ }^{124}$ Im Handeln Daladiers verschränkten sich entschlossene Absichtserklärungen zur Bündnistreue, die er gegenüber seinen britischen Verhandlungspartnern, im französischen Ministerrat und vor der eigenen Öffentlichkeit vertrat, mit dem schrittweisen Zurückweichen vor den

118 JO, Chambre des Députés, Débats parlementaires, Séance du 26 février 1938, S. 639-646. Zwischenzeitlich hatte er in verschiedenen öffentlichen Stellungnahmen seine Haltung dargelegt, so unter anderem am Parteikongreß der "Alliance“ vom November 1937 (Vgl. Pierre-Etienne Flandin, Paix et liberté. „L'Alliance Démocratique“ à l'action, Paris 1938, S. 173-175 und S. 190-192).

119 Bellstedt, „Apaisement“, S. 218-220.

120 Vgl. die Rede Flandins: JO, Chambre des Députés, Débats parlementaires, Séance du 26 février 1938, S. 639-646.

121 Vgl. René Girault, La décision gouvernementale en politique extérieure, in: Rémond/Bourdin (Hg.), Edouard Daladier, S. 209-227, hier: S. 222; übernommen bei Bellstedt, "Apaisement“, S. $134 \mathrm{f}$.

122 Vgl. Du Réau, Edouard Daladier, S. 234-239; Bellstedt, „Apaisement“, S. 135.

123 Du Réau, Edouard Daladier, S. 239; Bellstedt, „Apaisement“, S. 173 f.

124 Im Zusammenhang dieser Arbeit ist es nicht von Interesse, die komplexe Vorgeschichte des Münchener Abkommens in ihren Einzelheiten darzulegen, zumal Paul Reynaud nicht als verantwortlicher Entscheidungsträger involviert war. 
englischen Wünschen. Nach außen hin stellte sich die Zusammenarbeit Daladiers mit seinem Außenminister wenig harmonisch dar. Bonnet versuchte bereits ab Juli 1938, die Ansätze des Regierungschefs zur „fermeté“ teils hinter dessen Rücken zu unterlaufen. Diese Uneinigkeit schwächte wiederum die Position der französischen Seite gegenüber dem Gespann Chamberlain/Halifax, das mehr und mehr die Führung im diplomatischen Abtausch mit Hitler übernahm. Spätestens in der eigenmächtigen Zusage Chamberlains auf eine Viererkonferenz in München - bereits die Berchtesgadener Aussprache mit Hitler war ohne Rücksprache mit Daladier erfolgt - zeigte sich das Auseinandertreten von französischem Großmachtanspruch, von prätendierter internationaler Schlichterrolle und tatsächlich einsetzbarem Potential. Wenn sich Daladier im September 1938 zum schmerzlich empfundenen Arrangement mit dem Diktator bereitfand, dann stand dahinter nicht einfach mangelnde Kompetenz oder blinde Anpassung an die Führung durch die britische „Gouvernante“125, sondern eben auch die Einsicht in strukturelle Schwächen Frankreichs auf rüstungstechnischem und wirtschaftlichem Gebiet, die eine Atempause zur Konsolidierung der Kräfte der Nation notwendig machten. ${ }^{126}$ Vor der Kammer der Abgeordneten faßte Daladier am 4. Oktober 1938 seine pessimistische Lageeinschätzung und die daraus resultierende Aufgabe knapp zusammen: „Il n'y a pas une heure à perdre: il faut faire appel à ce sursaut des énergies françai-

125 François Bédarida, La "gouvernante anglaise“, in: Rémond/Bourdin (Hg.), Edouard Daladier, S. 228-240.

126 Auf solch multikausale Erklärungsmodelle einigte sich die seriöse neuere Forschung mittlerweile. Als neueste, breit angelegte Darstellung der französischen Haltung ist heranzuziehen: Yvon Lacaze, La France et Munich. Etude d'un processus décisionnel en matière de relations internationales (Collections contacts, Série II: Gallo-Germanica 8), Bern 1992. Die jüngste eingehendere Darstellung des diplomatischen Prozesses aus der Sicht Daladiers und unter Auswertung bislang unveröffentlichten Materials aus dem Nachlaß bietet: Du Réau, Edouard Daladier, S. 234-287. Zur Einordnung in die Außenpolitik Frankreichs im fraglichen Zeitraum: Jean Baptiste Duroselle, La décadence 1932-1939, Paris 1979, S. 325-366; aufschlußreich zur Reaktion der französischen Öffentlichkeit: Yvon Lacaze, L'opinion publique française et la crise de Munich, Frankfurt u.a. 1991; Ders., L'opinion publique française et la crise de Munich, in: Francia 18/3 (1991), S. 73-83.

Die Entstehung des Münchener Abkommens, die Motive der führenden französischen Staatsmänner, allen voran Daladiers, und die Aufteilung der Verantwortlichkeit für das Zustandekommen gehören bis in die Gegenwart zu den am heftigsten diskutierten Themen der französischen Zeitgeschichte. Erklärbar ist die emotional aufgeladene Vehemenz der schon unter Zeitgenossen einsetzenden Debatte aus der gedanklichen Verbindungslinie, die die Gegner des Abkommens zwischen einer im September 1938 angeblich eingeleiteten „politique de l'abandon“ und der Niederlage Frankreichs im Juni 1940 knüpften. Die objektive Widerlegung, die die Politik der „Munichois“ im März 1939 erfuhr, schließlich die traumatisierende Wirkung des Desasters von 1940 verstellten zunächst den Blick auf historische Zusammenhänge und Motivstrukturen der Handelnden, die geeignet sein konnten, die rasch erhobenen Vorwürfe von allgemeiner "Dekadenz" oder fehlender Weitsichtigkeit des politischen Personals zu relativieren. Auch in dieser Hinsicht stellte das bereits erwähnte Kolloquium an der "Fondation nationale des sciences politiques" von 1975 eine Wende dar, die sich in den obengenannten Arbeiten fortsetzte.

$\mathrm{Daß}$ die ideologisch geprägte Wahrnehmung des Abkommens zumindest in den Randbereichen von historischer Forschung und politischer Literatur weiterhin Konjunktur hat, zeigt sich an zwei Darstellungen, die aus Anlaß des 50. Jahrestages des Münchener Abkommens publiziert wurden. Die Arbeit von Colonel Pierre Le Goyet, Munich. Un traquenard?, Paris 1988, greift die alte These vom eigensüchtigen englischen „Verrat" an französischen Interessen wieder auf; die Studie von François Paulhac, Les accords de Munich et les origines de la guerre de 1939, Paris 1988, versucht eine Exkulpierung Daladiers und Bonnets auf der Basis einer nur allzu unrühmlich bekannten, revisionistischen Interpretation des Kriegsausbruchs als Werk „unverantwortlicher" westlicher Politiker. 
ses sans lequel le pays ne pourra faire face aux événements redoutables que je sens venir dans un avenir beaucoup plus proche peut-être que nous ne le voyons." 127

Im Ministerrat hatte sich schon Anfang September grundsätzlichere Uneinigkeit über das weitere Vorgehen manifestiert. Um zwei personelle Pole gruppierten sich jene Kabinettsmitglieder, die einen dezidierten Standpunkt einnahmen: um Außenminister Bonnet einerseits, um Justizminister Reynaud und den Minister für die Kolonien, Georges Mandel, andererseits. ${ }^{28}$ Die Differenzen blieben auch Außenstehenden nicht verborgen. Am 10. September notierte der englische Botschafter Phipps: „Mon impression est que Bonnet, peut-être plus que Daladier et certainement plus que Mandel et Reynaud, est désespérément anxieux de trouver un moyen pour sortir de cette impasse sans être obligé de se battre." 129 Offener Widerstand seitens der Fraktion der "durs" stellte sich dann zum erstenmal ein, als Daladier nach den englisch-französischen Regierungsgesprächen vom 18. September gezwungen war, vor seinem Kabinett erste Konzessionen an das „Appeasement"-Konzept Chamberlains zuzugeben. Die Londoner Beschlüsse sahen definitiv die Übergabe der mehrheitlich deutsch besiedelten tschechischen Gebiete an das Deutsche Reich vor, und zwar unter Einschluß der Möglichkeit eines Plebiszits - eine Option, die Daladier bis dahin strikt abgelehnt hatte. ${ }^{130}$ Die erläuternden Hinweise des Regierungschefs im Ministerrat vom 19. September auf den französischen Rüstungsrückstand, die unverzichtbare Rücksichtnahme auf den englischen Verbündeten und den unsicheren englischen Beistand im Falle eines französischen Vorgehens konnten die Fraktion der "durs" nicht überzeugen. ${ }^{131}$ Reynaud, Mandel und der Minister für die „Anciens combattants“, Champetier de Ribes, gaben ihre Absicht zu erkennen, zurückzutreten. Erst die Argumente eines illustren Verbündeten, der aus London herbeigeeilt war, trugen dazu bei, sie von ihren Plänen abzubringen. Winston S. Churchill, zu diesem Zeitpunkt einer der profiliertesten britischen Kritiker der Europapolitik Chamberlains, war im März 1938 bereits mit bekanntermaßen anglophilen französischen Politikern zusammengetroffen: Paul Reynaud, Edouard Herriot, auch Léon Blum, Joseph Paul-Boncour und der Generalsekretär des Quai d'Orsay, Alexis Léger, hatten damals zu seinen Gesprächspartnern gezählt. ${ }^{132}$ Sein erneuter Besuch, zu dem er am

127 JO, Chambre des Députés, Débats parlementaires, Séance du 4 octobre 1938, S. 1526-1529.

128 Zu den erklärten „Hardlinern“" im Kabinett gehörten die drei Radikalsozialisten Jean Zay, César Campinchi und Albert Sarraut; aus den Reihen der "modérés“ zählte dazu neben den beiden Genannten insbesondere der Christdemokrat Auguste Champetier de Ribes.

Da wie bereits in der Einleitung zu dieser Arbeit bemerkt, keine offiziellen Kabinettsprotokolle für die Ministerratssitzungen der Dritten Republik existieren, ist die Forschung auch in diesem Fall stark auf die rückblickenden Darstellungen oder im nachhinein veröffentlichten Notizen von Beteiligten angewiesen. Am wertvollsten sind in dieser Hinsicht die Tagebücher des radikalsozialistischen Erziehungsministers und "Anti-munichois“ Jean Zay, Carnets secrets, Paris 1942.

129 Phipps Papers, Churchill College, 1-120, 61, 72; zitiert nach Du Réau, Edouard Daladier, S. 254 (dort bereits in französischer Übersetzung).

130 Du Réau, Edouard Daladier, S. 257-259.

131 Zur Kabinettssitzung vom 19. 9. 1938: Zay, Carnets secrets, S. 4-6.

132 Vgl. die Nachweise über die Gespräche vom 25. und 26. 3. 1938 bei Martin Gilbert, Winston S. Churchill. Band V (1922-1939), London 1976, S. 928; im September 1936 bereits hatte Churchill in Paris Reynaud, Herriot und Flandin getroffen, im Dezember des gleichen Jahres hatte Reynaud in Anwesenheit des englischen Politikers vor der "Anglo-French luncheon“ gesprochen (Ebenda, S. 787 und 821; Winston S. Churchill, The Second World War. Band I: The Gathering Storm, London 1948, S. 280; Reynaud, Mémoires II, S. 125-127). 
20. September 1938 in Paris eintraf, hatte demonstrativen Charakter. Mit den Rücktrittsplänen seiner „Freunde“ Reynaud und Mandel konfrontiert, riet er zum Verbleib: „Both these Ministers were in lively distress and on the verge of resigning from the Daladier Cabinet. I was against this, as their sacrifice could not alter the course of events, and would only leave the French Government weakened by the loss of its two most capable and resolute men. I ventured even to speak to them in this sense." $" 133$

Daß Churchill Außenminister Bonnet bei seinem Besuch überging, sollte ein Zeichen setzen, sollte die Möglichkeit einer alternativen, inoffiziellen englischfranzösischen Interessengemeinschaft zugunsten einer Position der deutschlandpolitischen Härte aufzeigen. Am 22. September trafen sich Mandel, Champetier de Ribes und Reynaud mit Daladier, um ihren Unmut über den englisch-französischen Druck auf Prag zum Ausdruck zu bringen und gegen den diesbezüglichen Einfluß Bonnets zu protestieren. Nach dem Gespräch, das in unterschiedlichen Versionen überliefert ist, sahen die Minister von einer Demission ab; an die Presse erging ein Dementi der Rücktrittsgerüchte. ${ }^{134}$

Da keine direkten Zeugnisse vorliegen, um den Entscheidungsprozeß Reynauds zu erhellen, können die Gründe für sein Vorgehen nur vermutet werden. Die Episode verdeutlicht in erster Linie die schwache Position jener Fraktion der „durs“ im Kabinett: Vor einem Ministerpräsidenten, der trotz aller Bekenntnisse zur Unnachgiebigkeit zunehmend dem englischen Standpunkt und der Politik Bonnets nachzugeben schien, blieb ganz offensichtlich den Opponenten wenig mehr effektive Einflußmöglichkeit, als sofort auf die schärfste Waffe zurückzugreifen, über die sie in ihrer Lage verfügten. Die Situation war jedoch noch zu offen, das wirkliche Ausmaß des schon eingeleiteten diplomatischen Rückzugs Frankreichs noch zu ungewiß, als daß Daladier genügend Angriffsfläche geboten hätte, um einen eventuellen Regierungssturz in der Öffentlichkeit plausibel zu begründen. Ein solcher Sturz aber gehörte ins Kalkül der dissidenten Minister, die ihre Hoffnungen vergeblich auf den bekanntermaßen einer Politik der "fermetéc zuneigenden Senatspräsidenten Jules Jeanneney als Nachfolger Daladiers gerichtet hatten. ${ }^{135}$

Reynauds „Rücktritt vom Rücktritt“ mag unter solcher Perspektive durchaus geleitet gewesen sein von persönlichem Ehrgeiz, verbunden mit der Hoffnung auf einflußreichere Ämter inner- oder außerhalb der Regierung Daladier. In der aktuellen außenpolitischen Krisensituation hätte ein bloßer Austritt aus der Regierungsmannschaft ohne Hoffnung auf die Bildung eines Alternativkabinetts wohl in der Tat allzu leicht als Zurückweichen vor der nationalen Aufgabe interpretiert werden können - mit fatalen und vermutlich endgültigen Folgen für die politische

${ }_{133}$ Churchill, Gathering Storm, S. 302 f.; zum Parisbesuch Churchills vom 20./21. 9. 1938: Gilbert, Churchill, S. 978. Vgl. auch die Darstellung Reynauds: Reynaud, Mémoires II, S. 209.

$134 \mathrm{Vgl}$. „La politique extérieure du gouvernement français. Les entretiens de M. Daladier“, in: Le Temps, 24. 9. 1938.

135 Dies geht aus der Korrespondenz Jeanneneys mit seinem Privatsekretär Maurain hervor; zitiert bei Lacaze, L'opinion publique, S. 372. Der instinktsichere de Gaulle wandte sich am 24. September erneut an Reynaud, um ihm eine zukünftige „bedeutende Rolle" vorherzusagen und die eigenen Dienste anzubicten (De Gaulle an Reynaud, 24. 9. 1938, in: Ders., Lettres, notes et carnets. 1919juin 1940, S. 475 f.; abgedruckt auch bei Reynaud, Mémoires II, S. 213 f.). 
Zukunft der so Handelnden. ${ }^{136}$ Dem angestrebten Sprung Reynauds ins Finanzministerium jedenfalls wäre ein Rücktritt keinesfalls förderlich gewesen. Karriereüberlegungen alleine aber können das Verhalten eines Politikers nicht erklären, der in der Vergangenheit bewiesen hatte, daß er die innenpolitische Marginalisierung bei der Durchsetzung seiner Ziele nicht scheute. Vielmehr stand Reynaud zumindest prinzipiell einer Verständigung mit Deutschland unmittelbar vor wie auch noch nach Abschluß des Münchener Abkommens nicht ablehnend gegenüber. In einem Gespräch mit dem Leiter der „Dienststelle Ribbentrop“ in Paris, Otto Abetz, gab er sich im Oktober unter Verweis auf seine einschlägigen Vorstöße vor 1933 durchaus offen für eine Fortsetzung entsprechender Bemühungen. ${ }^{137}$ Er beurteilte die territorialen Regelungen in den Friedensverträgen von Trianon und St.-Germain selbst skeptisch genug, um die Notwendigkeit einer Neuregelung zu sehen, ja er ging sogar so weit, zur Entschärfung der Sudetenfrage im Gespräch mit dem deutschen Botschafter "radikale“ Lösungen unter Einschluß eventueller Bevölkerungsumsiedlungen zu befürworten. ${ }^{138}$ Die Förderung direkter Gespräche zwischen Beneš und Henlein erachtete er wie der neue englische Außenminister Halifax als vordringlich. ${ }^{139}$

Ergänzt man das Bild, das seine parlamentarischen Äußerungen abgeben, durch diese Aussagen, die sämtlich gegenüber nicht-französischen Gesprächspartnern fielen, dann erscheint der Dissens, der ihn von Daladier trennte, keineswegs so grundsätzlich, als daß eine Zusammenarbeit nicht mehr möglich gewesen wäre. Reynauds „Doppelstrategie“ gegenüber Hitlerdeutschland hatte sich seit 1933 zwar inhaltlich angereichert, doch in ihrem Prinzip nicht wesentlich verändert: Echte Verständigung war durchaus zu erreichen, aber nur zwischen annähernd gleich starken Partnern, und die innere Konsolidierung Frankreichs hatte deshalb wie die bündnispolitische Absicherung einer möglichen Annäherung an Deutschland voranzugehen. ${ }^{140}$ Natürlich verurteilte Reynaud die Tatsache wie die Methoden der Hitlerschen Expansionspolitik, insbesondere das deutsche Vorgehen in Südosteuropa; das hatte er nicht zuletzt gegenüber seinen deutschen Gesprächspartnern deutlich gemacht. ${ }^{141}$ An den Defiziten Frankreichs auf ökonomischem

136 Karriereüberlegungen rückt als "main reason“ für das Handeln Reynauds in den Vordergrund: Antony Adamthwaite, France and the Coming of the Second World War 1936-1939, London 1977, S. 122 f.; übernommen bei Lacaze, France et Munich, S. 446.

137 „[...] Paul Reynaud verteidigte sich gegen den Vorwurf, ein Feind der deutsch-französischen Verständigung zu sein und gab eine Schilderung seiner Fühlungnahme mit deutschen Kreisen in den Jahren vor der nationalsozialistischen Machtergreifung." (Abetz an Welczeck, 24. 10. 1938; ADAP D IV, No. 342, S. 384 f.).

138 „Unterredung mit Justizminister Paul Reynaud“, Welczeck an AA, 11. 5. 1938 (ADAP D II, No. 152, S. 210f.).

139 So in einem Gespräch mit Halifax in London am 20. Mai 1938 (Halifax an Phipps, 20. 5. 1938; Documents on British Foreign Policy (künftig: DBFP), 1919-1939, Third Series, Band I, No. 243, S. $325 \mathrm{f}$.).

140 Vgl. dazu die einleitenden Abschnitte zu Kapitel IX.3.a) dieser Arbeit.

$1+1$ „Paul Reynaud warf hierbei ein, [...] wenn wir aber bei der Realisierung unserer völkischen Aspirationen dieselbe oder ähnliche Methoden wie bei der Annexion Österreichs anwenden und den nach einem Aufstande von der tschechischen Regierung bedrängten Sudetendeutschen manu militari oder mit Freiwilligen-Verbänden zu Hilfe eilen würden, so sei die Katastrophe da, von der Europa, vielleicht mit Ausnahme des abgelegenen und bereits im Kommunismus lebenden Rußlands, sich nie mehr erholen würde. Man müßte alles tun, um einer Vernichtung der zivilisierten alten Welt vorzubeugen." (Welczeck an AA, 11. 5. 1938; ADAP D II, No. 152, S. 210f.). 
und rüstungstechnischem Gebiet aber konnte eine „feste Sprache in Berlin“142 allein nichts ändern, und der Wirtschaftsexperte Reynaud mußte sich darüber genauso im klaren sein wie der Militärreformer. „Réarmement et conciliation“: Diese Formel, die er im Februar 1938 zustimmend - und allzu optimistisch bezüglich ihrer weiteren Ausgestaltung - als das Kennzeichen der Politik Chamberlains aufgegriffen hatte ${ }^{143}$, entsprach tatsächlich seiner eigenen Haltung auch noch unmittelbar nach Abschluß des Münchener Abkommens in höherem Maße, als er dies rückblickend zu suggerieren versuchte. In den einschlägigen Abschnitten seiner Memoiren geht Reynaud nicht auf den „Verständigungs“-Aspekt seiner deutschlandpolitischen Vorstellungen von 1938 ein, sondern bietet im wesentlichen eine aus der Rückschau gefertigte Analyse und Kritik der französischen Außenpolitik während der Sudetenkrise. In ihrer Tendenz zielen die Ausführungen darauf, ihren Verfasser zum hellsichtigen und hartnäckigen Verfechter einer unnachgiebigen Haltung gegenüber Deutschland zu stilisieren - ein Befund, der, wie gesehen, stark zu differenzieren ist. ${ }^{144}$

Reynauds warnende Interventionen im Ministerrat spiegelten im Verlauf der Sudetenkrise seine aufrichtige Sorge vor dem französischen Vertragsbruch, vor dem Verlust des tschechischen Bundesgenossen und einem Prestigegewinn Hitlers, der diesem weitere Vorstöße erleichtern mußte. ${ }^{145}$ Seine Rücktrittsdrohung aber hatte stark taktischen Charakter: zum Zeitpunkt des englisch-französischen Ultimatums gegenüber Prag an einem ersten klar erkennbaren Kulminationspunkt des französischen Einlenkens formuliert, erstrebte sie eine Rejustierung der Haltung Daladiers im Sinne des anders gewichteten, aber keineswegs diametral entgegengesetzten deutschlandpolitischen Konzepts Reynauds. Sie stand damit in erster Linie in Konkurrenz zu den gegenteiligen Bemühungen der dezidierten Verständigungsanhänger um Bonnet und Flandin. Der Abbruch seines Vorstoßes zeigte dann vor allem, daß eine Position bedingungsloser deutschlandpolitischer Härte zu diesem Zeitpunkt weder als sachliche Alternative im Kabinett noch als Kristallisationspunkt für eine kabinettspolitische Neuformation mehrheitsfähig war. Sich in das implizierte Verdikt über die eigene Anschauung zu fügen, fiel Reynaud umso leichter, als sein Widerstand gegen eine Verzichtspolitik in der

142 So Reynaud gegenüber Halifax am 20. Mai 1938 (Halifax an Phipps, 20.5. 1938; DBFP, Third Series, Band I, No. 243, S. 326).

${ }_{143}$ Reynaud hatte die Begriffskombination in der oben erwähnten Kammerrede vom 26. Februar geprägt und sie in einem Rundfunkvortrag wenige Tage später wiederholt: „Ceux qui avaient affirmé si imprudemment que $\mathrm{M}$. Chamberlain s'était rallié à leur politique dont les deux bases sont „faiblesse et abdication " ont pu constater qu'ils s'étaient trompés. Les deux bases de la politique de $\mathrm{M}$. Chamberlain sont „Réarmement et conciliation.“ Formule excellente que, pour ma part, j'adopte pleinement et qui exprime aussi la politique du gouvernement français." (Paul Reynaud, Manuskript für: Radio-Cité, 29. 2. 1938; AN, 74 AP 16).

In inhaltlich entsprechendem Sinne hatte er sich bereits in einem Vortrag vor der „Société des Conférences" geäußert: „M. Paul Reynaud parle de la situation internationale“, 4.2. 1938 (Ebenda); vgl. auch das Interview der rumänischen Zeitung Universul mit Reynaud, 21. 3.1938 (Ebenda).

144 Vgl. Reynaud, Mémoires II, S. 200-223, bes. S. 219-223. Auf die Diskrepanz zwischen der Memoiren-Darstellung Reynauds und seinem tatsächlichen Verhalten weist auch Adamthwaite, France and the Coming of the Second World War, S. 122 hin.

145 In einem Telephonat mit Botschafter Phipps nach der Berchtesgadener Unterredung zwischen Chamberlain und Hitler vom 15. September hatte er neben Glückwünschen für den englischen Premierminister eine entsprechende Befürchtung geäußert (vgl. Phipps an Halifax, 15.9. 1938; DBFP, Third Series, Band 2, No. 894, S. 337). 
Sudetenfrage nicht von grundsätzlichen Ressentiments gegenüber Deutschland im Stile eines Louis Marin und auch nicht in erster Linie von ideologischen Erwägungen getragen war, sondern vorwiegend auf einer staatsmännisch-machtpolitischen Sicht beruhte. Das Münchener Abkommen verstand er als Zwischenetappe auf dem Wege zu einer energischeren, doch prinzipiell immer noch ausgleichsbereiten Deutschlandpolitik Frankreichs, in deren Rahmen der eigenen Person größerer Einfluß zuwachsen mochte. Seine Entschlossenheitsbekundungen gegenüber der französischen Öffentlichkeit besaßen in diesem Zusammenhang auch instrumentalen Charakter, um die Grundlagen für eine Annäherung von gleich zu gleich zu legen. Verblüffend offen äußerte er sich dahingehend gegenüber Abetz: „Er [Paul Reynaud, A.d.V.] ließ durchblicken, daß Frankreich zu seiner inneren Stärkung des Gespenstes einer deutschen Gefahr bedürfe, weil sonst die Wehrwilligkeit und die Bereitschaft der Bevölkerung, dafür Opfer zu bringen, völlig abhanden käme. Er stehe auf dem Standpunkt, man könne eine Verständigung nicht mit „mous" (womit er offenbar Flandin meinte), sondern mit „durs" (mit einem deutlichen Seitenblick auf sich selbst) machen. Er gab vor, die öffentliche Meinung Frankreichs werde in Bälde Männer wie Bonnet desavouieren und den Gegnern der Münchner Vereinbarung zustimmen." ${ }^{146}$

Nachdem mit dem Abkommen vom 30. September die Entscheidung zumindest vorläufig zugunsten der Verständigungspartei gefallen war, leistete Reynaud keineswegs öffentlichen Widerstand, sondern war bereit, sich wiederum weitgehendes Stillschweigen aufzuerlegen. Daß er nicht zum Empfang Daladiers am Flughafen Le Bourget erschien, blieb zwar augenfälliges Zeichen für eine abweichende Haltung. ${ }^{147}$ Auch trat er aus seiner Partei, der "Alliance“, aus, nachdem Parteichef Flandin ein Glückwunschtelegramm an die Unterzeichner des Münchener Abkommens, unter anderem also auch an Hitler, gesandt hatte. ${ }^{148}$ In der außenpolitischen Debatte um die Ratifizierung des Münchener Abkommens dagegen stimmte Reynaud wie 534 andere Abgeordnete am 4. Oktober 1938 für die Annahme. ${ }^{149}$ Henri de Kerillis war es, der sich in der Aussprache als einziger Vertreter des bürgerlichen Lagers neben dem Kommunisten Gabriel Péri eindeutig ablehnend äußerte; die 75 Gegenstimmen stammten denn auch von ihm und den Mitgliedern der kommunistischen Fraktion. 150

Die persönliche Rechnung, in die Paul Reynaud seinem Gesprächspartner Otto Abetz Einblick gewährt hatte, ging in der Tat weitgehend auf. Alle Versuche seines deutschlandpolitischen Widersachers im Kabinett, Georges Bonnet, im Rahmen einer allgemeinen Reorientierung der französischen Außenbeziehungen nach „München" eine eigenständige Politik des „Apaisement" gegenüber Hitler in die Wege zu leiten, mißlangen. Als am 6. Dezember 1938 eine deutsch-französische Erklärung über „friedliche und gutnachbarliche Beziehungen"151 unterzeichnet

\footnotetext{
${ }_{146}$ Abetz an Welczeck, 24. 10. 1938; ADAP D IV, No. 342, S. 385.

147 Reynaud, Mémoires II, S. $218 \mathrm{f}$.

148 Wileman, L'Alliance, S. 306.

149 Vgl. zur Debatte: JO, Chambre des Députés, Débats parlementaires, Séance du 4 octobre 1938, S. 1525-1543; Micaud, French Right, S. 176 f.; Lacaze, L'opinion publique française, S. 520-526. 150 Vgl. JO, Chambre des Députés, Débats parlementaires, Séance du 4 octobre 1938, S. 1531 f., 15361539 und $1596 \mathrm{f}$. (Abstimmungsanalyse).

151 Die Erklärung findet sich abgedruckt in: ADAP D IV, No. 369, S. 409 f., hier: S. 409.
} 
wurde, war damit bereits der Höhepunkt der Ansätze Bonnets erreicht. Ihr Scheitern lag begründet im Abflauen jener allgemeinen Erleichterung und Friedenseuphorie, die unmittelbar nach der Rückkehr Daladiers aus München in der Öffentlichkeit und innerhalb der nichtkommunistischen politischen Klasse dominiert hatte. Die Pogrome vom November 1938 in Deutschland ebenso wie die aggressiven Territorialforderungen Italiens wurden ausschlaggebend für die allgemeine Ernüchterung. Innenpolitisch aber waren in hohem Maße die ersten positiven Auswirkungen der Wirtschaftspolitik Reynauds verantwortlich dafür, daß im Gefolge des wiederkehrenden Aufschwungs auch die Bereitschaft zum politischen Widerstand gegen die Ansprüche der Diktatoren auf zunehmenden Rückhalt in der öffentlichen Meinung rechnen konnte. ${ }^{152}$ Damit zeichnete sich eine eklatante Bestätigung der Strategie Reynauds ab.

Entsprechend scheint für Reynaud selbst, der sich im November 1938 wie alle seine Ministerkollegen außer Bonnet offen gegen den geplanten Ribbentrop-Besuch in Paris ausgesprochen hatte, der Erfolg seiner Bemühungen in Kombination mit den genannten Vorgängen und inbesondere dem öffentlichen Meinungswandel entscheidend dafür geworden zu sein, die Verständigungskomponente seines Deutschlandkonzepts vorläufig zurückzustellen. ${ }^{153} \mathrm{Im}$ Kabinett freilich neigte sich die Waage erst allmählich zugunsten der Vertreter einer härteren Gangart gegenüber Deutschland. Gewisse Anzeichen waren durchaus sichtbar: Daladier selbst, der noch in der Parlamentsdebatte vom 4. Oktober 1938 die politische Äquidistanz zu den beiden Hauptströmungen innerhalb der Regierung zur Maxime seines Handelns erklärt hatte ${ }^{154}$, nahm ab Frühjahr 1939 die Leitung der Außenpolitik zunehmend in die eigenen Hände. Nach Abschluß des Münchener Abkommens bereits hatte der Ministerpräsident starkes Mißtrauen gegenüber der Möglichkeit neuer, auf der Basis gegenseitigen Vertrauens stattfindender Verhandlungen mit Deutschland oder Italien an den Tag gelegt. ${ }^{155}$ Die hartnäckig fortgeführten Verständigungsversuche Bonnets bereiteten dann der fortschreitenden politischen Entfremdung zwischen beiden Männern den Weg. Der formellen Ablösung des Außenministers im September 1939 ging so dessen allmählicher Einflußverlust ${ }^{156}$ voraus, der ihn jedoch vorerst noch nicht völlig daran hinderte, weiterhin auf den deutsch-französischen Ausgleich um jeden Preis hinzuwirken.157 Als sich Ende August 1939 im Kabinett jene Fronten neu bildeten, die sich während der Sudetenkrise gegenübergestanden waren, formierte sich die Gruppe der

152 Grundlegend zur Politik Bonnets und zur Erklärung vom 6. Dezember: Bellstedt, „Apaisement“; zu Bonnets Motiven und zu den Gründen für sein Scheitern zusammenfassend bes. S. 233-242.

153 Zur Haltung des Kabinetts im Vorfeld des Ribbentrop-Besuchs vom Dezember 1938: Zay, Carnets secrets, S. 36-38 (Kabinettsrat vom 23. 11. 1938).

154 JO, Chambre des Députés, Débats parlementaires, Séance du 4 octobre 1938, S. 1526-1529.

155 Heimsoeth, Zusammenbruch, S. 61; Bellstedt, „Apaisement“, S. 246.

156 Vgl. zur Entmachtung Bonnets auch die Stellungnahme des Senatspräsidenten Jeanneney gegenüber Herriot vom 6. 9. 1939, kurz vor der Entlassung Bonnets als Außenminister: „Vous me dites Daladier résolu à se séparer de Georges Bonnet. Parfait cela! L'opération lui sera plus facile s'il prend pour lui-même les Affaires Etrangères dont il remplit, en fait, la fonction depuis quelques mois." (Jules Jeanneney, Journal politique. Septembre 1939 - Juillet 1942. Edition établie, présentée et annotée par Jean-Noël Jeanneney, Paris 1972, S. 9).

157 Zur „verdeckte[n] Fortführung des Apaisement " durch Bonnet zwischen Dezember 1938 und Kriegsausbruch vgl. Bellstedt, „Apaisement“, S. 242-254 (Zitat: S. 242). 
verständigungswilligen „mous“ wiederum um den Außenminister, dessen Bereitschaft, „Danzig zu opfern“, geteilt wurde durch Marchandeau und Guy La Chambre. Die Fraktion der „durs" versammelte sich ebenfalls um den bekannten harten Kern: Paul Reynaud und Georges Mandel. Wie Jean Zay, Albert Sarraut und César Campinchi zeigten sie sich bestürzt angesichts der weiterhin bestehenden Konzessionsbereitschaft der „Tauben“, traten darüber hinaus für den „unbedingten Beistand" gegenüber Polen und bereits am 22. August für die Generalmobilmachung ein. ${ }^{158}$ Während das gesamte Kabinett einschließlich des Ministerpräsidenten am 2. September bereit war, die Anregung des italienischen Außenministers Ciano aufzugreifen und das französische Ultimatum auszusetzen, bis die deutsche Antwort auf den italienischen Vorschlag einer internationalen Konferenz eintreffe, lehnten Reynaud und Mandel jedes neuerliche Zurückweichen ab. ${ }^{159}$ Hatte Bonnet noch im September 1938 zwischen dem „kriegsentschlossenen" Mandel und dem vorsichtigeren Reynaud differenzieren können, so war einer solchen Unterscheidung jetzt die Basis entzogen. ${ }^{160}$ Reynaud erachtete den französischen Kriegseintritt nun als unvermeidlich. Die Manöver des Außenministers, um diesen in letzter Stunde noch abzuwenden, erschienen ihm „perfider denn je“. ${ }^{161}$ Im vertraulichen Gespräch mit dem Senatspräsidenten Jules Jeanneney, den er regelmäßig als gleichgestimmten Gesprächspartner und Ratgeber einbezog, hielt Reynaud daneben auch mit Kritik an Daladier nicht mehr zurück. Als „zögernd“, „unentschlossen“ und klaren Entscheidungen ausweichend schätzte er den Ministerpräsidenten ein und drängte Jeanneney wiederholt, seinen persönlichen Einfluß bei Daladier geltend zu machen, um ihn zu entschiedenerem Vorgehen zu bewegen. 162

Bis Sommer 1939 hatte sich Reynauds Position im Kabinett Daladier, in dem er zunächst nur eine zweitrangige Rolle spielte, in mehrfacher Weise gefestigt. Auf inhaltlicher Ebene hatten seine politischen Konzeptionen ihre Bestätigung erfahren: Nicht nur war seine Wirtschaftspolitik nach anfänglichem Zögern schließlich erfolgreich umgesetzt worden; auch bedeutete die Entlassung Bonnets aus dem Außenministeramt am 13. September 1939 die indirekte Bekräftigung einer härteren deutschlandpolitischen Linie, die ganz in seinem Sinne war. Entsprechendes galt in bezug auf Italien, demgegenüber sich Daladier im März/April 1939 nicht die von Bonnet gewünschte Verhandlungsbereitschaft zur Verbesserung des seit

158 Tatsächlich wurde die französische Generalmobilmachung erst am 1. September eingeleitet. Vgl. zur Neubildung der Fronten im Kabinett und zu ihrem Verlauf: Zay, Carnets secrets, S. 60-64 und $66 \mathrm{f}$. (Kabinettssitzungen vom 22. und 24. 8. 1939). Dazu auch die regelmäßigen Klagen des Senatspräsidenten über die Uneinigkeit und den "Defätismus" in den Reihen des Kabinetts: Jeanneney, Journal politique, S. 8, 20, 35 .

159 Zay, Carnets secrets, S. 84-86 (Kabinettsrat vom 2. 9. 1939).

160 So der Bericht Phipps' an Halifax, 2. 9. 1938 (DBFP, Third Series, Band II, No. 751, S. 219f., hier: S. 220).

161 So Reynaud 1. September gegenüber Jules Jeanneney: Jeanneney, Journal Politique, S. 5.

${ }_{162}$ Siehe dazu Reynauds Unterredungen mit Jeanneney vom 1.9. und 5.9. 1939 (Ebenda, S. 5 und 7). Der Senatspräsident teilte nicht nur Reynauds "fermetéc, gegenüber Hitler wie Mussolini, sondern auch dessen Einschätzung Daladiers (siehe hierzu seine Charakteristik vom 21.10. 1939: Ebenda, S. 19f.). Er zögerte deshalb nicht, Reynaud politisch zu unterstützen und ihn wie andere "durs" im Kabinett zur Beibehaltung ihres Engagements zu ermuntern (vgl. etwa die Gespräche Jeanneneys mit Reynaud, mit dem neuen Marineminister Alphonse Rio und Kolonialminister Georges Mandel vom 12. 2., 4. 3. und 19. 3. 1940: Ebenda, S. 27 f., 29f. und 35f.). 
November 1938 getrübten Verhältnisses zu eigen gemacht hatte. ${ }^{163}$ Die Einleitung diplomatischer Verhandlungen mit Sowjetrußland, die die Regierung Daladier im April 1939 unternahm, markierte in diesem Zusammenhang - ungeachtet des Scheiterns der Gespräche im August 1939 - nicht nur ein Anknüpfen der französischen Außenpolitik an die Bündnispolitik Louis Barthous 164 , sondern letztlich auch an Ideen, die Paul Reynaud jahrelang vertreten hatte. ${ }^{165}$

Die Konzeption, die Reynaud verkörperte - Aufrüstung, Bündnispolitik und Härte gegenüber den europäischen Diktaturen, auf der Basis der binnenwirtschaftlichen Konsolidierung Frankreichs über eine entschlossene Austeritäts- und Produktivitätspolitik -, besaß unverwechselbares politisches Profil. Sie hatte zweifellos das Wohl des Landes im Auge, das im Verständnis Reynauds gleichbedeutend war mit seiner innen- und außenpolitischen Wehrfähigkeit. Zugleich fungierte sie aber auch als Vehikel in der persönlichen Karriereplanung des Ministers. Daß Reynaud es geschafft hatte, sich als entschiedener „Anti-Munichois“ zu profilieren, war gewiß der Durchsetzung unpopulärer innenpolitischer Maßnahmen förderlich und kam ihm unter anderem während der Streikwelle vom 30. November 1938 zugute. ${ }^{166}$ Sein tatsächlicher deutschlandpolitischer Dissens mit Daladier aber hielt sich, wie gesehen, sogar im zeitlichen Umkreis des Münchener Abkommens in engen Grenzen. Es kann sogar angenommen werden, daß sich die Wendung beider Politiker zur Intransigenz vor Kriegsausbruch annähernd parallel vollzog: zwischen Herbst 1938 und Frühjahr 1939, als im Gefolge des deutschen Einmarsches in Prag die Mehrheit selbst der rechten „Munichois“ alle Ausgleichshoffnung fahren ließ.167 Dies hinderte Reynaud zudem keineswegs daran, nach Ende des deutschen Polenfeldzugs, in der Hochphase der "drôle de guerre“, wiederum eine Verhandlungslösung ins Auge zu fassen. Als der amerikanische Unterstaatssekretär und Präsidentenberater Sumner Welles auf seiner Europareise im März 1940 auch in Paris haltmachte und dabei zu Unterredungen mit führenden Politikern zusammentraf, gab sich Reynaud ausgleichsbereit. Unter explizitem Verweis auf seinen Ruf des „Anti-Munichois“ stellte er sich als besonders legitimiert dafür dar, nun eine „objektive Politik“ deutsch-alliierter Unterredungen zur Klärung strittiger territorialer und allgemeinpolitischer Fragen zu empfehlen.168

163 Bellstedt, „Apaisement“, S. $249 \mathrm{f}$.

164 Jean-Pierre Azéma, Die französische Politik am Vorabend des Krieges, in: Wolfgang Benz/Hermann Graml (Hg.), Sommer 1939. Die Großmächte und der Europäische Krieg, Stuttgart 1979, S. 280-313, hier: S. 288.

$165 \mathrm{Zu}$ den Verhandlungen im einzelnen: Bartel, Frankreich und die Sowjetunion, S. 164ff.; Duroselle, La décadence, S. $416-435$.

166 Reynauds Kabinettskollege Anatole de Monzie spricht von einer gewissen „Immunität“ gegen Kritik aus der Bevölkerung, die sich der Finanzminister durch seine prononcierte Skepsis im Umfeld des Münchener Abkommens im Gegensatz zu Daladier erworben habe (Anatole de Monzie, Ci-devant, Paris 1941, S. 61; Eintrag vom 30. 11. 1938).

167 Zur Gruppe der „Munichois“: Micaud, French Right, S. $206 \mathrm{ff}$.

168 In seiner Notiz für Roosevelt vom 9.3. 1940 gab Welles die Ausführungen Reynauds so wieder: "He said that he was rightly regarded as the „hardest“ man in the French Government with regard to french relations with Germany. [...] His well known sentiments on this subject [zum Münchener Abkommen, A.d.V.], and on the general subject of Franco-German relations, made it easier for him to follow an objective policy now. He stated to me quite plainly that he believed the political and territorial issues now at stake could be solved without any considerable difficulty through negotiations between the Allies and Germany." (Foreign Relations of the United States. Diplomatic Papers (FRUS) 1940, Band I, S. 70-72, hier: S. 71). Zu den Hintergründen des Europabesuchs 
Das zeigt einmal mehr, daß die hartnäckige, öffentlichkeitswirksame Selbstpräsentation Reynauds als kompromißloser "Hardliner" keineswegs von Anfang an berechtigt war. Sie diente vielmehr auch der geduldigen Konstruktion eines auf längerfristige Wirkung angelegten Politikerprofils, das sich als bewußt gesetzte Alternative zur Person des Ministerpräsidenten darbot.

Bezeichnend für die Effektivität der Taktik und für das Verhältnis zwischen Daladier und Reynaud war es, daß ernste Unstimmigkeiten dann aufkamen, als Mythos und Realität der Reynaudschen Erfolgsgeschichte zu einer überzeugungsstarken Einheit verschmolzen waren. Nicht Daladier, sondern Reynaud hinterließ im Frühjahr 1940 bei Sumner Welles den nachhaltigsten Eindruck. ${ }^{169} \mathrm{Zu}$ diesem Zeitpunkt war der Politiker an einem Höhepunkt seines politischen Erfolgs als Finanzminister angelangt. Sein überzeugendes Auftreten während der großen Budgetdebatte vom Dezember, auch sein erfolgreiches Engagement zur Sicherung der englisch-französischen Zusammenarbeit in Wirtschafts- und Währungsfragen hatte seine Reputation in Parlament und Öffentlichkeit in solchem Maße erhöht, daß er bei Beobachtern bereits als „Dauphin“ gehandelt wurde. ${ }^{170}$ In der Tat war er zum aussichtsreichsten Konkurrenten Daladiers avanciert, seitdem mit Georges Bonnet nicht nur der Vertreter einer konkurrierenden Deutschlandpolitik, sondern auch ein gewichtiger Aspirant auf das Ministerpräsidentenamt in politische Ungnade gefallen war. ${ }^{171}$ Der Regierungschef, der sich spätestens seit den politischen Kabalen von September 1938 um die Lancierung Jeanneneys als Nachfolger darüber im klaren gewesen sein mußte, daß seiner Position seitens der Fraktion der „Falken“ Gefahr drohte, reagierte auf den Einflußgewinn Reynauds mit Mißtrauen. Als dieser im Parlament attackiert wurde, gab er Zeichen

Welles': Bernd Martin, Friedensinitiativen und Machtpolitik während des Zweiten Weltkrieges 1939-1942, Düsseldorf 1974, S. $207 \mathrm{ff}$.

169 „In my judgment M. Paul Reynaud has a greater grasp of Foreign Relations, and has a keener mind, than any other member of the present French Government. [...] During our conversation in his office, and at lunch, the Minister discussed in an exceedingly temperate, moderate and constructive fashion the present situation, the problems created by the actions of Germany in the past three or four years, and the post-war settlements which would arise after the war." (FRUS 1940, I, S. 70 f.). Vgl. Heimsoeth, Zusammenbruch, S. 227.

170 Vgl. zur Debatte: JO, Chambre des Députés, Débats parlementaires, $2^{\mathrm{e}}$ Séance du 13 décembre 1939, S. 2257-2263. Reynaud und der britische Schatzkanzler Simon hatten sich am 13. Dezember 1939 in einem Abkommen unter anderem darauf geeinigt, anfallende gemeinsame Kriegskosten im Verhältnis von drei zu zwei zwischen Großbritannien und Frankreich aufzuteilen, Handelshemmnisse abzubauen und weitgehende Währungssolidarität zu praktizieren. Beide Länder konnten sich von da an mit kriegswichtigen Gütern aus dem jeweils anderen Kolonialreich versorgen, ohne dazu ihre Gold- oder Devisenvorräte antasten zu müssen. Zum Abkommen: Jean-Baptiste Duroselle, L'abîme 1939-1945, Paris 1982, S. 66 f.; Robert Frankenstein, Le financement français, S. 461-487, hier: S. 483-487.

Zitat: Jeanneney, Journal politique, S. 27 (Eintrag vom 12. 2. 1940). In gleichem Sinne die Tagebucheinträge von Jacques Bardoux: Ders., Journal d'un témoin de la Troisième, ler septembre $1939-15$ juillet 1940, Paris 1957, S. 165 und 169 (24.12. und 30.12. 1939). De Gaulle bemerkte in seinem Glückwunschbrief unter anderem: „Je mesure et salue vos magnifiques succès. Sans doute valent-ils dans le domaine particulier où vous les avez remportés. Mais, en outre, ils ont pour effet de rapprocher du sommet du pouvoir un homme d'Etat par excellence digne et capable de conduire cette guerre, la plus grave de notre Histoire." (De Gaulle an Reynaud, 15. 12. 1939, in: Ders., Lettres, notes et carnets, 1919-juin 1940, S. 488).

$171 \mathrm{Zu}$ den Ambitionen Bonnets: Bellstedt, „Apaisement“, S. $179 \mathrm{f}$. 
nachlassender Loyalität und plante offenbar bereits eine Umbildung der Regierung unter Ausschluß Reynauds. ${ }^{172}$

Die außenpolitische Lage, insbesondere die Bemühungen Daladiers, über französisch-britische Verhandlungen der stagnierenden alliierten Kriegführung neue Impulse zu geben, banden seine Energien vorerst allerdings in anderen Bereichen. Die innenpolitischen Folgen des sowjetisch-finnischen Winterkriegs, der seit Anfang 1940 die Debatten in der Kammer der Abgeordneten prägte, setzten dann seiner knapp zwei Jahre währenden Amtszeit ein Ende.

\section{Die Katastrophe: Ministerpräsidentenamt und Gefangenschaft}

„21 mars 1940 - je prends le pouvoir“. - Die knappe Formel, auf die Reynaud seine Berufung zum Ministerpräsidenten Frankreichs in der Rückschau brachte, suggeriert einen kraftvollen Akt, getragen von unabweisbarer persönlicher Autorität oder zumindest weitreichendem Konsens in der politischen Klasse des Landes. ${ }^{173}$ Nichts weniger als das lag indessen vor, als Staatspräsident Lebrun den mittlerweile 61jährigen Politiker zum Chef der 107. Regierung der Dritten Republik ernannte. Der Wechsel im Regierungsamt unterschied sich kaum von der unrühmlichen Art und Weise, in der Kabinettskrisen seit 1919 bereits unzählige Male vor sich gegangen waren. Ungewöhnlich allerdings war die Komplexität der innen- und außenpolitischen Situation, die Reynaud vorfand und in der sich schon traditionelle Probleme der parlamentarischen Demokratie Frankreichs mit neuen, kriegsbedingten Fragestellungen verbunden hatten. Strukturelle Gegebenheiten wie die primär defensiv orientierte Kriegsdoktrin, Schwierigkeiten in den interalliierten Verhandlungen mit Großbritannien, innenpolitische Vorgaben, die Reynaud zwangen, übermäßig auf die parlamentarischen Kräfteverhältnisse Rücksicht zu nehmen, schließlich das Gewicht der Erwartungen in der Öffentlichkeit auf energische Kriegsführung hatten sich zu einem Gespinst verdichtet, das dem neuen Ministerpräsidenten nurmehr wenig wirkliche Bewegungsfreiheit ließ. Es ist nicht nötig, so wie dies vielfach schon in der zeitgenössischen Literatur geschehen ist, auf die ausschlaggebende Rolle charakterlicher Schwächen Reynauds zu

172 Die Reaktionen Daladiers waren Gegenstand eines Gesprächs zwischen Reynaud und Jeanneney am 12. 2. 1940: vgl. Jeanneney, Journal politique, S. $27 \mathrm{f}$.

173 Reynaud, Mémoires II, S. 298 (Zitat). Die schlagwortartige Umschreibung, die Reynaud seinem Amtsantritt von 1940 zukommen ließ, erfuhr in den verschiedenen Ausgaben seiner Erinnerungen eine bezeichnende Zuspitzung. Sprach er in der ersten Fassung von 1947 noch moderat von bloßer "Regierungsbildung“ - „21 mars 1940. Je forme le gouvernement“ (Ders., La France II, S. 13) -, so wurde daraus in der revidierten Version von 1951 bereits ein Akt aktiven Zugriffs - „21 mars 1940. Je prends le gouvernement" (Ders., Au coeur de la mêlée, S. 375). Die in der zitierten letzten Fassung von 1963 in geradezu usurpatorischem Sinne verschärfte Formulierung gewann hier noch zusätzlich an Gewicht durch eine neu eingefügte Zustandsbeschreibung Frankreichs: „La France s'est étendue, passive, sur la table d'opération..." (Ders., Mémoires II, S. 298 und 300). Die Aussageabsicht ist evident und findet sich im weiteren Fortgang seiner rückblickenden Darlegungen ausgeführt: Reynaud stilisiert sich zur Retterfigur, zum aktiven Heilsbringer, der angesichts der verfehlten Politik seiner Vorgänger der daniederliegenden Republik zu Hilfe eilt... (Ders., Mémoires II, S. 298-437). Der weitaus differenziertere historische Befund steht im Mittelpunkt der folgenden Ausführungen. 
rekurrieren, um die insgesamt negative Bilanz seiner Ministerpräsidentenzeit einleuchtend aufzuschlüsseln. Daß sich in den knapp drei Monaten seiner Amtszeit, die sich bei genauem Besehen auf nicht mehr als sieben Wochen echter politischer Wirkungsmöglichkeit reduzierten ${ }^{174}$, natürlich auch persönliche Dispositionen und professionelle Prägungen des Politikers manifestierten, bleibt daneben unbenommen.

Wenige Abschnitte der französischen Zeitgeschichte sind bislang einer so eingehenden Betrachtung in zeitgenössischen Publikationen und in der nacharbeitenden Forschung unterzogen worden wie die ereignisreichen Monate des Frühjahrs 1940; vor allem die letzten Wochen der Dritten Republik hat man buchstäblich Tag für Tag zu rekonstruieren versucht. ${ }^{175}$ Ein dicht gewobenes Geflecht von Fakten und Zusammenhängen bietet sich mittlerweile dem Betrachter, dennoch bleiben insbesondere die Absichten und Motive der Beteiligten in der Regel nur schwer zu fassen. Kaum in den offiziellen Dokumenten zu finden, sind sie oft nur aus der Abfolge der Ereignisse, aus Memoirenbänden oder Tagebüchern zu erschließen, die in der Regel um so mehr mit Vorsicht zu betrachten sind, je näher die Verfasser den Entscheidungszentren standen. So erstaunt es kaum, daß publizistisch-historiographische Plädoyers in eigener Sache die Quellenlage auf diesem Feld ebenso prägen wie bereinigte oder verlorengegangene Nachlässe und die daraus resultierenden Widersprüche, Leerstellen und Ungereimtheiten. Unter politischen Rechtfertigungsdruck waren führende Akteure der späten Dritten Republik bereits unter Pétains „Etat Français“ geraten, stellvertretend für die parlamentarische Demokratie schlechthin. Der ideologisch geprägte Versuch einer politischen Generalabrechnung mit den „Verantwortlichen für die Niederlage“ im Prozeß von Riom mißlang zwar kläglich ${ }^{176}$; ungeachtet dessen wurde die drängende Frage nach den Ursachen des raschen Zusammenbruchs von 1940 nach Kriegsende unter demokratischen Vorzeichen und in breiter angelegter Form neu aufgeworfen. Auch jene Beteiligten, die sich nicht durch die Zusammenarbeit mit Vichy kompromittiert hatten, mußten sich dem selten offen ausgesprochenen, doch latent stets vorhandenen Verdacht persönlicher Versäumnisse stellen: Hätte denn nicht die demütigende Niederlage oder sogar das folgende autoritäre und verbrecherische Regime bei entschlossenerem oder patriotischerem Handeln der demokratischen Staatsführung vermieden werden können?

Die folgenden Abschnitte werden die Ministerpräsidentschaft Paul Reynauds zunächst im Zusammenhang der diplomatischen und innerfranzösischen Diskussions- und Entscheidungsabläufe darstellen; anschließend sollen einige umstrit-

174 Mayeur, Troisième République, S. 389 geht davon aus, daß nach dem deutschen Angriff vom 10. Mai 1940 bis zur französischen Niederlage nicht mehr von wirklichem "politischem Leben“ in Frankreich gesprochen werden kann.

175 Aus der Fülle der vorliegenden Untersuchungen seien als Überblicksdarstellungen herausgegriffen: Duroselle, L'Abîme (von allererster Bedeutung, da unter Benutzung der französischen diplomatischen Akten verfaßt); daneben: Jean-Pierre Azéma, De Munich à la Libération. 1938-1944 (Nouvelle Histoire de la France Contemporaine 14), Paris 1982; ders., 1940. L'année terrible, Paris 1990; ders./François Bédarida (Hg.), La France des années noires. 2 Bände, Paris 1993; Jean-Louis Crémieux-Brilhac, Les Français de l'an 40. 2 Bände, Paris 1990 sowie die im folgenden angegebene Spezialliteratur. Zu zeitgenössischen Äußerungen vgl. auch das folgende Kapitel XI.1.

176 Die beste Überblicksdarstellung zum Prozeßverlauf und zu seinen Hintergründen bietet nach wie vor: Henri Michel, Le procès de Riom, Paris 1979. 
tene Aspekte seiner Amtszeit in den Blick genommen werden. Es wird dabei nicht darum gehen, die bekannten Zusammenhänge noch einmal in aller Ausführlichkeit aufzurollen. Maß und Ziel der Betrachtungen wird weiterhin die Einschätzung seiner politischen Persönlichkeit sein und hier speziell der Versuch, sein politisches Verhalten im Frühsommer 1940 daraus zu verstehen.

\section{a) Die Ausgangslage}

Der Berufung Reynauds war keineswegs eine große, Stabilität verheißende Mehrheitsverschiebung im Parlament vorangegangen, und die Kritik der Abgeordneten an Daladiers Kriegführung, die den radikalsozialistischen Ministerpräsidenten zum Rücktritt bewogen hatte, hatte ihn formal noch nicht einmal eindeutig in die Minderheit gesetzt. Die Haltung der Regierung im finnisch-sowjetischen Winterkrieg war unmittelbarer Anlaß für die politische Vertrauenskrise gewesen, der Daladier Tribut zollen mußte. Letztlich aber war er Opfer der fatalen innen- und außenpolitischen Begleiterscheinungen der „drôle de guerre“ geworden, deren Wirkungen sich in der Folge auch sein Nachfolger nicht entziehen konnte. ${ }^{177}$

Nach der französischen Kriegserklärung an Deutschland vom 3. September 1939 hatten sich Regierung und Generalstab auf eine vorwiegend defensive Strategie verständigt, die in ihren Grundzügen den Absprachen zwischen der britischen und französischen Militärführung seit März 1939 entsprach. Demnach richtete man sich seitens der Alliierten auf einen längerdauernden Krieg ein, in dessen Verlauf es gelingen werde, die noch bestehende Überlegenheit Deutschlands zu Lande und in der Luft aufgrund des letztlich größeren Umfangs der eigenen Ressourcen schließlich aufzuheben. Bis dahin aber hatten offensive Aktionen hinter verstärkten Rüstungsanstrengungen und der defensiven Sicherung der eigenen Position zurückzustehen. Die französische Hilfe für Polen beschränkte sich im Rahmen dieses Konzepts und unter Bruch der französisch-polnischen Militärvereinbarungen vom Mai 1939 auf zeitlich und räumlich begrenzte Aktionen an der deutschen Grenze. ${ }^{178} \mathrm{Zu}$ ersten Divergenzen zwischen Briten und Franzosen war es gekommen, als man nach Verlauf einiger Kriegsmonate vorwiegend auf französische Initiative hin Pläne aufgriff, die die Langzeitstrategie durch kleinere offensive Aktionen an der Peripherie des europäischen Kriegsschauplatzes anreichern sollten: Die Errichtung einer zweiten Front am Balkan, schließlich die Unterstützung des angegriffenen Finnland durch die Bombardierung kaukasischer Erdölfelder oder die Unterbrechung schwedischer Eisenerzlieferungen nach Deutsch-

177 Wegweisend für die Interpretation der „Drôle de guerre“ und ihre Auswirkungen auf den Zustand der französischen Gesellschaft am Vorabend des deutschen Angriffs: Heimsoeth, Zusammenbruch. Eine Zusammenfassung wichtiger Ergebnisse findet sich in: Ders., Frankreich im Krieg mit Deutschland: Der Zerfall der Dritten Französischen Republik während der „Drôle de guerre“, in: Claude Carlier/Stefan Martens (Hg.), La France et l'Allemagne en guerre. Septembre $1939-N_{0-}$ vembre 1942, Paris 1990, S. 49-67. Als ältere Darstellungen zum Thema noch nicht unverzichtbar: Guy Rossi-Landi, La Drôle de guerre. La vie politique en France, 2 septembre 1939 - 10 mai 1940, Paris 1971; Henri Michel, La drôle de guerre, Paris 1971.

178 Zum Verhalten Gamelins in dieser Periode vgl. Alexander, Republic in danger, S. 349-377; zu den britisch-französischen Generalstabsbesprechungen vom 29. März, 4. April, 3. Mai sowie 28., 29., und 31. August 1939: Heimsoeth, Zusammenbruch, S. 202-205. 
land wurden ins Auge gefaßt. ${ }^{179}$ Es zeigten sich nun die Schwächen der britischfranzösischen Aktionsgemeinschaft, die weniger positiv-substantiell denn ihrem Wesen nach negativ-dilatorisch ausgerichtet war. ${ }^{180}$ Bestand mit Rücksicht auf den jeweiligen Rüstungsstand Einigkeit in der Grundsatzentscheidung für die Defensive, so war Chamberlain kaum an einer zweiten kontinentalen Front interessiert und setzte in erster Linie auf wirtschaftliche Stabilisierungsmaßnahmen in Südosteuropa sowie den Seekrieg gegen das Deutsche Reich. Für Daladier und seinen Generalstab rangierten dagegen periphere militärische Entlastungsaktionen an allererster Stelle ihrer Prioritätenliste, da man sich davon die Verlagerung der deutschen Bedrohung weg von der eigenen Nordostfront versprach. ${ }^{181}$ Überlagert wurde diese strategisch-außenpolitische Motivation der französischen Seite allerdings zunehmend von innenpolitischen Überlegungen, nachdem der sowjetische Überfall auf Finnland vom 30. November 1939 eine heftige Sympathiebewegung zugunsten der Angegriffenen in der Öffentlichkeit des Landes ausgelöst hatte. Der auch in politischen und militärischen Führungszirkeln ausgreifenden Forderung nach Sanktionsmaßnahmen gegen den Aggressor zollte Daladier schließlich Tribut: Konkrete Pläne für ein alliiertes Landeunternehmen in Nordfinnland und die Zerstörung kaukasischer Erdölquellen wurden auf seine Initiative hin ausgearbeitet; im Parlament gab der Ministerpräsident am 9. Februar die indirekte Zusicherung, daß Frankreich militärisch eingreifen werde.182 Trotz wiederholten Drängens konnte sich Daladier jedoch mit seinen Vorstellungen gegenüber den Briten nicht durchsetzen, die den Konflikt mit der Sowjetunion scheuten und am militärischen Sinn der Unternehmung zweifelten. ${ }^{183}$ Der finnisch-sowjetische

${ }_{179} \mathrm{Als}$ grundlegende, mit ausführlicher Einleitung versehene Quellenedition zu den interalliierten Regierungsgesprächen zwischen dem 12. September 1939 und dem 27. April 1940 liegt vor: François Bédarida, La stratégie secrète de la drôle de guerre. Le Conseil Suprême Interallié, septembre 1939 - avril 1940, Paris 1979; in knappem inhaltlichem Überblick zu den Sitzungen des Rates im Mai/Juni 1940 unter dem Aspekt des englisch-französischen Bruchs: Ders., La rupture franco-britannique de 1940. Le Conseil Suprême Interallié, de l'invasion à la défaite de la France, in: Vingtième Siècle 25 (1990), S. 37-48.

Vgl. bes. die Sitzungen des „Conseil Suprême Interallié" vom 12.9.1939 - 5. 2. 1940, in: Bédarida, Stratégie secrète, S. 90-276; Heimsoeth, Zusammenbruch, S. 243-270; Ders., Frankreich im Krieg, S. $62 \mathrm{f}$. Allgemein zu den verschlungenen Wegen des britisch-französischen Verhältnisses 1939/40: Eleanor M. Gates, End of the Affair. The Collapse of the Anglo-French Alliance, 1939-40, Berkeley/Los Angeles 1981; Brian Bond, Britain, France and Belgium 1939-1940, London u.a. 21990; Klaus-Jürgen Müller, Das Ende der Entente Cordiale. Eine Studie zur Entwicklung der englischfranzösischen Beziehungen während des Westfeldzuges 1940 (Beihefte der Wehrwissenschaftlichen Rundschau 3), Frankfurt a.M. 1956. Aufschlußreich sind auch die Beiträge des Sammelbandes: Français et Britanniques dans la Drôle de guerre. Actes du colloque franco-britannique tenu à Paris du 8 au 12 décembre 1975, Paris 1979; zu den strategischen Absprachen: W.B.R. Neave-Hill, L'évolution de la stratégie franco-anglaise (1939-1940), in: Ebenda, S. 333-358; François Bédarida, Convergences et divergences stratégiques franco-britanniques, in: Ebenda, S. 359-378.

180 Antony Adamthwaite, Grandeur and misery. France's bid for power in Europe 1914-1940, London u.a. 1995, S. 226.

181 Zur britischen Position: Elisabeth Barker, British Policy in South-East Europe in the Second World War, London 1976; für die französische Seite: Heimsoeth, Frankreich im Krieg, S. 63.

182 Vgl. zur Debatte JO, Chambre des Députés, Débats parlementaires, Comité secret du 9 février 1940, Numéro spécial du 7 avril 1948, S. 40-43; vgl. Rossi-Landi, Drôle de guerre, S. 42 f.

183 Vgl. zum Finnlandkrieg vor dem Hintergrund der französisch-sowjetischen Beziehungen nach Abschluß des deutsch-sowjetischen Nichtangriffspaktes: Heinrich Bartel, Frankreich und die Sowjetunion 1938-1940. Ein Beitrag zur französischen Ostpolitik zwischen dem Münchener Abkommen und dem Ende der Dritten Republik, Stuttgart 1986, S. 265-314; René Girault, Les relations franco-soviétiques après septembre 1939, in: Français et Britanniques, S. 263-279; R.A.C. 
Waffenstillstand vom 13. März 1940 beendete die Phase des alliierten Tauziehens abrupt. Daladier, der sich einer empörten Öffentlichkeit gegenübersah ${ }^{184}$, verlor zum erstenmal, seit Frankreich in den Krieg eingetreten war, seine parlamentarische Mehrheit: Nachdem bereits am 15. März im Senat die obligatorische Vertrauenserklärung an die Regierung nur 236 Befürworter neben 60 Enthaltungen gefunden hatte ${ }^{185}$, überwogen in der Nacht vom 19. zum 20. März in der Kammer der Abgeordneten die Stimmenthaltungen bereits die zustimmenden Voten. ${ }^{186}$ Der vom Verhalten der britischen Alliierten enttäuschte, in der Debatte wenig kämpferisch auftretende Daladier interpretierte das Ergebnis als Niederlage und trat noch am gleichen Tag zurück. ${ }^{187}$

Vor dem Hintergrund des allgemeinen Wunsches in der Kammer nach energischerer Kriegführung führte nun kein Weg mehr an der Person Reynauds vorbei. Zwar hätte der einflußreiche „Königsmacher“ im Hintergrund, Senatspräsident Jules Jeanneney, Georges Mandel als Exponenten der neuen Politik bevorzugt; der Kolonialminister aber hatte unter Verweis auf seine umstrittene Position abgelehnt. ${ }^{188}$ Jeanneney empfahl Staatspräsident Lebrun daraufhin Paul Reynaud als Nachfolger. ${ }^{189}$ Dieser erntete jetzt die Früchte seiner ausdauernden Profilierungsarbeit, mußte aber rasch die Fragilität seiner parlamentarischen Position erkennen. Eine allzu heterogene Koalition von Gegnern hatte den Sturz Daladiers bewirkt, und sie sollte sich in der Folge als brüchig erweisen. $\mathrm{Zu}$ jenen Abgeordneten vor allem auf der parlamentarischen Rechten, die enttäuscht waren über den außenpolitischen Mißerfolg Frankreichs im allgemeinen, über die verpaßte Gelegenheit einer Aktion gegen die Sowjetunion im speziellen, traten diejenigen, denen das Vorgehen Daladiers seit längerem entweder als zu zögerlich oder zu

Parker, Grande-Bretagne, France et Scandinavie en 1939-1940: la politique, les hommes et la stratégie, in: Ebenda, S. 561-582 und Ronald Wheatley, La guerre russo-finlandaise, les plans d'intervention alliés et les relations britanniques avec la Russie, in: Ebenda, S. 245-261.

${ }_{184}$ Ausführlich zu den Reaktionen der französischen Öffentlichkeit auf die finnische Niederlage: Heimsoeth, Zusammenbruch, S. 192 f. und 276-279.

185 JO, Sénat, Débats parlementaires, Comité secret du 15 mars 1940, Numéro spécial du 2 août 1948, S. $45 \mathrm{ff}$.

186 Der Ministerpräsident erhielt 239 Ja-Stimmen gegenüber 300 Enthaltungen; JO, Chambre des Députés, Débats parlementaires, Séance du 19 mars 1940, S. 584 f. Vgl. auch Rossi-Landi, Drôle de guerre, S. 53; JO, Chambre des Députés, Débats parlementaires, Comité secret du 19 mars 1940, Numéro spécial du 7 avril 1948, S. 52-54.

$187 \mathrm{Zu}$ den Umständen des Regierungssturzes: Bonnefous, Histoire politique VII, S. 144-149; Mayeur, Troisième République, S. 383-387; Rossi-Landi, Drôle de guerre, S. 47-55; Heimsoeth, Zusammenbruch, S. 275-279.

188 Auf die indirekte Anfrage Jeanneneys hin hatte Mandel am 19. März keine Bereitschaft zur Übernahme des Ministerpräsidentenamts gezeigt: „Mandel ayant dit que la semaine ne se passerait que difficilement à la Chambre, je lui ai demandé: "Que feriez-vous alors? Vous sentez-vous de force et en mesure?» Il m'a répondu: «Mon heure ne peut être que celle d'un péril plus grand. Ma personnalité serait trop discutée à présent" et il admet que ce serait l'heure de Paul Reynaud." (Jeanneney, Journal politique, S. 36). Die Ablehnung Mandels als Nachfolger Daladiers in der Kammer war nicht frei von antisemitischen Ressentiments. Dem Bericht eines Abgeordneten zufolge kursierte über ihn das Diktum "Mandel scrait peut-être un bon chef, mais juif ... impossible" (Ebenda, S. 22).

189 Es entsprach in der Dritten Republik parlamentarischem Usus, daß der Staatspräsident vor der Bcrufung eines neuen Ministerpräsidenten die Präsidenten der beiden Kammern konsultierte. Die einflußreiche Stellung Jeanneneys resultierte aus dieser beratenden Funktion und aus den weitreichenden persönlichen Beziehungen, die er zu Politikern verschiedenster Couleur unterhielt; vgl. das Gespräch Jeannency-Lebrun vom 20. 3. 1940: Jeanneney, Journal politique, S. 37 f. 
hart erschienen war. Die Enthaltungen der oppositionellen Sozialisten und der noch verbliebenen äußersten Linken hatten zusammen mit jenen der gespalten agierenden Mitte-Rechts-Gruppierungen und den Gegenstimmen auf der extremen Rechten das desaströse Ergebnis vom 19./20. März bewirkt. ${ }^{190}$

Weder die Konstituierung der Nachfolgeregierung Reynaud noch ihre Präsentation in der Kammer der Abgeordneten oder die Regierungserklärung des neuen Ministerpräsidenten am 22. März konnten diese Negativkoalition zu einer überzeugenden neuen Mehrheit umformen. In einer Mischung aus forschem Hinwegsetzen über die seit zwei Jahren etablierte Kräftebalance und der Anwendung altvertrauter Methoden parlamentarischer Kabinettsbildung hatte er eine gezielt "dosierte“ Regierungsmannschaft zusammengestellt. Sie umfaßte nicht weniger als 35 Minister und Staatssekretäre, ausgewählt nach fachlichen, aber auch innenund außenpolitischen Motiven. ${ }^{191}$ Daladier blieb im Amt des Kriegsministers. $\mathrm{Zu}$ groß war sein Gewicht als Vorsitzender der zweitstärksten im Parlament vertretenen Partei, als daß Reynaud es sich hätte leisten können, ihn nicht aufzunehmen; zu bedeutend auch war der Machtfaktor, den die Radikalsozialisten darstellten, als daß sein Kabinett ohne ihre Unterstützung politisch überlebensfähig gewesen wäre. Erstmals seit Beendigung der Volksfront waren daneben sozialistische Minister wieder an einer Regierung beteiligt, ohne daß freilich Léon Blum, die treibende Kraft hinter der Zusage der SFIO, selbst eingetreten wäre. ${ }^{192}$ Reynaud konnte somit seine Basis gegenüber dem Vorgängerkabinett nach links verbreitern, und die Aufnahme zweier Mitglieder der "Alliance Démocratique“ verankerte das neue Kabinett auch innerhalb der rechten Mitte der Kammer. Die Errichtung einer wirklichen, überparteilichen Regierungsformation unter Einschluß der bedeutendsten Gruppen gelang jedoch nicht, da die rechte „Fédération Républicaine" um Louis Marin die Zusammenarbeit mit den Sozialisten verweigerte.

In der ersten Kammerdebatte, die das neue Kabinett im mittlerweile siebten Kriegsmonat zu bestehen hatte, weitete sich dieses Bild überdauernder parteipolitischer Querelen zu einem Panorama jener parlamentarischen Mißstände, die in den zurückliegenden Jahren regelmäßig in die Kritik geraten waren. ${ }^{193}$ Abgeord-

190 Vgl. dazu die Analyse des Abgeordneten Wladimir d'Ormesson (zitiert nach Jean-Louis Crémieux-Brilhac, Les Français de l'an 40. Band I: La guerre oui ou non?, Paris 1990, S. 249). Zur Auswertung der Abstimmungen vom 19. und 22. März 1940: Rossi-Landi, Drôle de guerre, S. 226228; Heimsoeth, Zusammenbruch, S. 278.

191 Laut Pierre Lazareff soll Reynaud geäußert haben: „Je suis obligé de composer avec les forces parlementaires. Chaque nouveau ministre que je prends doit m'assurer un certain nombre de votes. Il me faut amadouer le Parti radical et gagner des voix sur le plus de bancs possibles. Si je veux agir, il faut d'abord que j'en aie les moyens, donc que je reste au pouvoir" (Pierre Lazareff, De Munich à Vichy, New York 1944, S. 219). Die Berufung des als Anhänger einer italienischen Neutralität bekannten de Monzie sollte offenbar wider Erwarten "guten Willen“ gegenüber Italien signalisieren (De Monzie, Ci-devant, S. 203 f.; Einträge vom 20. und 22. 3. 1940).

192 Im einzelnen hatten sozialistische Minister, darunter der Blum nahestehende Georges Monnet, das Justiz- und das Blockadeministerium sowie das Ministerium für die „Anciens Combattants“ übernommen.

193 Vgl. JO, Chambre des Députés, Débats parlementaires, Séance du 22 mars 1940, S. 595-607 (Aufschlüsselung der Abstimmung: S. 615). Noch fast ein Vierteljahrhundert später sprach Reynaud von einem „entwürdigenden Schauspiel“ (Reynaud, Mémoires II, S. 305). Léon Blum schrieb wenige Tage nach der Debatte: "Jetons un voile. Si l'on devait envisager en elle-même la séance de vendredi, elle laisserait une impression par trop humiliante et désolante. Le mieux qu'on puisse faire est d'en chasser le souvenir de son esprit comme celui d'un mauvais rêve." ("Jetons un voile“, 
nete der radikalsozialistischen Partei, die Reynaud die Ablösung Daladiers noch nicht verziehen hatten, und Vertreter der Rechten nahmen den Ministerpräsidenten unter Beschuß. Der Umfang der Regierung, der nicht den Erwartungen an ein konzentriertes, wendiges Kabinett entsprach, und die Einbindung der Sozialisten bildeten die zentralen Topoi der Kritik, die bald auch in der rechten Presse auftauchten. ${ }^{194}$ Ursprünglich von lakonischer Kürze in seiner Regierungserklärung, hatte Reynaud in Reaktion auf die Anwürfe seiner Kritiker ein breiteres, doch wenig präzises Spektrum entworfen. Im Kern sah es die Kontinuität des Begonnenen unter Stärkung der ökonomischen Produktionsanstrengungen vor. Daladier blieb ausgespart von jeglicher Kritik, diente vielmehr als mehrfach zitierter Bezugspunkt für die Fortführung der militär- und außenpolitischen Vorgaben - Festigung der britisch-französischen Allianz unter Beachtung der "solidarité latine“ ebenso wie für innenpolitische Sanktionsmaßnahmen gegen die Mitglieder der aufgelösten kommunistischen Partei. ${ }^{195}$ Nichts verriet deutlicher die prekäre Stellung Reynauds, als diese Referenz vor dem ungeliebten Vorgänger.

Die Verabschiedung des "Ordre du Jour“ zugunsten der Regierung verlief denkbar knapp: Von den 424 abgegebenen gültigen Stimmen sprachen nur 268 Paul Reynaud und seinem Kabinett das Vertrauen aus, 156 Abgeordnete votierten dagegen. Da 111 Deputierte sich enthalten hatten, blieb rechnerisch nur eine einzige Stimme Mehrheit für den neuen Regierungschef. ${ }^{196}$ Lediglich die 153 Sozialisten hatten einhellig für Reynaud gestimmt, so wie ihr Parteichef Léon Blum in der Debatte als einziger Redner für die Regierung eingetreten war. Von den 115 Radikalsozialisten dagegen hatten sich nur 33 zur Unterstützung Reynauds entschließen können. Die Mehrheit der Abgeordneten der "Alliance démocratique“ und der "Fédération Républicaine“ hatte gegen Paul Reynaud gestimmt. ${ }^{197}$

Damit war die paradoxe Situation eingetreten, daß das Kriegskabinett Reynaud entschlossenere Unterstützung seitens der parlamentarischen Linken denn von seiten der Rechten erhielt. Die freundschaftlichen Beziehungen Reynauds zu Blum, die gemeinsame Überzeugung vom notwendigen Widerstand gegen die Diktatoren, die Fähigkeit Blums, staatsmännisch über Parteigrenzen hinauszusehen, und nicht zuletzt der Wunsch der Sozialisten, an die Macht zurückzukehren, waren entscheidend für den Regierungseintritt gewesen. ${ }^{198}$ Auf der anderen Seite

in: Le Populaire, 24. 3. 1940). Dazu Heimsoeth, Zusammenbruch, S. 279; Rossi-Landi, Drôle de guerre, S. 57-63.

194 Vgl. die Stellungnahmen von Lucien Galimand, Vincent Badie, Louis Marin, Fernand Laurent und Léon Blum (JO, Chambre des Députés, Débats parlementaires, Séance du 22 mars 1940, S. 596-598, 598 f., 599 f., 600-602 und 604 f.).

195 JO, Chambre des Députés, Débats parlementaires, Séance du 22 mars 1940, S. 596 und 602-604.

196 Nahe Beobachter wie Parlamentspräsident Herriot äußerten im nachhinein ihre Zweifel, ob Reynaud nach den üblichen „Rektifikationen“ der Voten tatsächlich über die eine fragliche Stimme verfügte (vgl. Charles de Gaulle, Mémoires de guerre. Band I, Paris 1954, S. 25). Reynaud wehrte sich zeit seines Lebens gegen diesen Vorwurf und beharrte darauf, nach fünf Korrekturen des Auszählungsergebnisses noch mehr als eine Stimme Vorsprung besessen zu haben (Reynaud, Mémoires II, S. 309). Die Frage ist im Rückblick nicht mehr zu entscheiden.

197 Zur Auswertung der Abstimmung: Rossi-Landi, Drôle de guerre, S. $62 \mathrm{f}$. Ausführlich dazu: „L'accueil du Parlement", in: Le Temps, 23. 3. 1940; zur Haltung der Radikalsozialisten: „L'attitude du groupe radical socialiste", Ebenda, 24. 3.1940.

198 Bruce D. Graham, Choice and Democratic Order. The French Socialist Party, 1937-1950, Cambridge 1994, S. 242; Grailsammer, Blum, S. 422 f. geht nicht auf das Verhältnis Blums zum Kabinett Reynaud ein. 
des politischen Spektrums hatte Reynaud aufgrund seiner prononcierten öffentlichen Gegnerschaft gegen das Münchener Abkommen die Unterstützung extrem konservativer Kreise verloren. Die Einbindung der Sozialisten, die immer noch als Partei der Volksfront galten, tat ein übriges, um ihn zu diskreditieren. Die Irritation reichte bis in das Milieu der "modérés", wo selbst ein Reynaud wohlwollend gesonnenes Blatt wie Le Temps Vorbehalte anmeldete. ${ }^{199}$ Auch wirkten sich nun die Popularitätseinbußen aus, die Reynauds Austeritätspolitik, insbesondere seine Steuerreformen, mit fortschreitender Wirkungsdauer begleitet hatten. ${ }^{200}$ Abgeschirmt durch das Prestige eines bis zur Jahreswende 1939/40 parlamentarisch noch fest verankerten Ministerpräsidenten Daladier, hatten sich die Unmutswellen zunächst an den schützenden Regierungsdeichen gebrochen, wenngleich erste Warnzeichen bereits sichtbar geworden waren. ${ }^{201}$ Jetzt, da es für Reynaud darauf ankam, ein unabhängiges Sympathiepotential zu mobilisieren, fehlte ihm dieser Rückhalt, um weiter den Protest der Abgeordneten unter anderem vom linken Flügel der radikalsozialistischen Partei abzuwehren. ${ }^{202}$ Zusammen mit seinem insgesamt gesunkenen Ansehen in den Reihen der Partei Daladiers - es hielten sich hartnäckig Gerüchte, Reynaud habe gegen diesen intrigiert -, seiner schlechten Presse in den immens einflußreichen agrarischen Kreisen ${ }^{203}$ und seinem Image des wohlhabenden Pariser Bürgers, das sich von der „Erdennähe“ Daladiers wenig öffentlichkeitswirksam abhob, waren damit eine ganze Reihe von Faktoren vereint, die sein schlechtes Abschneiden erklären können. ${ }^{204}$

199 „L'unité de conception et d'action pourrait se trouver compromise. La question se pose notamment au sujet de la large participation socialiste au nouveau cabinet. Les conditions dans lesquelles est intervenue cette participation ne risquent-elles pas d'enlever à la nouvelle formation ministérielle le caractère d'équipe cohérente armée pour l'action que tout le monde, y compris $\mathrm{M}$. Paul Reynaud lui-même, souhaitait et voulait?" ("Le nouveau ministère", in: Le Temps, 23. 3. 1940). Entsprechende Vorbehalte finden sich auch etwa in der Revue politique et parlementaire (10.5. 1940) und in der Revue des Deux Mondes (15. 4. 1940). Entschiedene Ablehnung schlug Reynaud aus den Spalten der Rechtspresse, vor allem von L'Action française, Le Figaro, Le Petit Journal und Gringoire entgegen. Uneingeschränkt positive Stimmen beschränkten sich auf die sozialistische Presse, auf Le Populaire und L'Oeuvre (vgl. dazu Rossi-Landi, Drôle de guerre, S. 65-67).

200 Vgl. dazu die Analysen von Heimsoeth, Zusammenbruch, S. $131 \mathrm{f}$.

201 In den Kammersitzungen vom 13. Dezember 1939 bzw. 12. Februar 1940 hatten mehrere radikalsozialistische Redner und Marcel Déat die Finanz- und Steuerpolitik des Ministers zuletzt heftig unter Beschuß genommen (JO, Chambre des Députés, Débats parlementaires, Séance du 13 décembre 1939; Ebenda, Comité secret du 10 février 1940, Numéro spécial du 7 avril 1948).

202 Der linke Flügel der Partei hatte bereits im November 1938 nur mit Bestürzung und unter Widerstand die neue Wirtschaftspolitik des Gespanns Daladier/Reynaud sanktioniert. Bezeichnenderweise gehörte einer der Kritiker Reynauds in der Regierungsdebatte vom 22.3. 1940, Lucien Galimand, diesem Flügel an (Berstein, Parti Radical II, S. 311 und $561 \mathrm{f}$.).

${ }^{203} \mathrm{Zu}$ den Reaktionen der Landwirtschaftsverbände auf den Regierungsantritt Reynauds: Heimsoeth, Zusammenbruch, S. $120 \mathrm{f}$.

204 Oliver Harvey, Privatsekretär Edens und Halifax' zwischen 1936 und Dezember 1939, dann ab Jahresbeginn 1940 als Botschaftsmitglied im Ministerrang in Paris, faßte seine Eindrücke so zusammen: "Paul Reynaud got a majority of one only what with abstentions in the Chamber on Friday [...]. He has annoyed the Radicals by his intrigues against Daladier, and the Right by his inclusion of three Socialists (a good move in itself). He is of course a Parisian, a bourgeois and wellto-do, and not the type of French politician who easily becomes a President of the Council." (John Harvey (Hg.), The Diplomatic Diaries of Oliver Harvey 1937-1940, New York 1970, S. 341; Eintrag vom 25.3.1940). 
Nach kurzer Beratung mit seinem Kabinett, in der sich Reynaud der Solidarität seiner zehn radikalsozialistischen Minister und Staatssekretäre versicherte205, entschloß er sich, sein Amt trotz der erheblichen Vorbelastungen, die darauf ruhten, beizubehalten. Die Ausgangslage war klar: Er hatte nur die Wahl, auf dem Feld, das seinem Vorgänger zum Verhängnis geworden war, einen schlagenden Erfolg zu erzielen oder aber seine denkbar knappe Mehrheit mit großer Wahrscheinlichkeit zu verlieren. Bestärkt durch den Rat von Senatspräsident Jeanneney, wandte er sich zwei Hauptgebieten zu: dem Ausbau der Zusammenarbeit mit Großbritannien und der Neubelebung peripherer Aktionen am europäischen Kriegsschauplatz. ${ }^{206}$

\section{b) „Malheureux essai de dynamisme "207: Die Versuche aktiver Kriegführung}

Keines der konkreten Projekte, das Paul Reynaud nach dem 21. März 1940 in die Wege zu leiten versuchte, stellte einen vollkommenen Bruch mit den noch unter Daladier ausgearbeiteten Kriegsplänen und den seit 1939 eingeleiteten interalliierten Verhandlungen dar. Ebensowenig wie der Wechsel an der Regierungsspitze von seinen innenpolitischen Begleiterscheinungen her eine souveräne, gleichsam zwangsläufige Machtübernahme gewesen war, drängte sich das anschließende internationale Agieren Reynauds durch zwingende militärstrategische Originalität auf. Was er bis zum 10. Mai, dem Beginn des deutschen Frankreich-Feldzugs, erreichte, blieb zwiespältig. Nur sechs Tage nach seiner Berufung gelang es ihm, eine britisch-französische Erklärung und den Beschluß des gemeinsamen Vorgehens in den norwegischen Territorialgewässern anzuregen und damit das alliierte Kriegshandeln vordergründig neu zu beleben. Der Innovationscharakter beider Erfolge blieb aber insofern begrenzt, als sie nur allzubald durch den weiteren Verlauf der Ereignisse in ihrer potentiellen Tragweite beschnitten wurden.

In einer Ausarbeitung des Quai d'Orsay, die noch unter Daladier angeregt und von Reynaud übernommen worden war, legte der Ministerpräsident den britischen Alliierten am 25. März sein Konzept vor. Es bestand im wesentlichen in Vorschlägen zum energischeren Vorgehen als bisher in den Gewässern vor der norwegischen Küste, wo bislang ungehindert schwedisches Eisenerz nach Deutschland verschifft wurde. Im Schwarzen bzw. Kaspischen Meer sollte ein Schlag gegen die Gewinnungsstätten und Transportwege sowjetischen Erdöls geführt werden, um so die deutsche Kriegswirtschaft an einer zweiten lebenswichti-

${ }^{205}$ Vgl. seinen Bericht über den Verlauf der Sitzung gegenüber Jeanneney: Ders., Journal politique, S. $38 \mathrm{f}$.

206 Jeanneney notierte bezüglich der Anregungen, die er dem Ministerpräsidenten gegeben hatte: „Dans l'ordre diplomatique, il faut une revanche de l'affaire de Finlande. De même, on ne peut tolérer que, par les eaux territoriales norvégiennes, les minerais suédois continuent à approvisionner l'Allemagne. Le cas des pétroles en mer Noire est semblable. On avait des projets concernant Bakou: ne fait-on rien? Les fabrications de guerre, très en retard, ne progressent pas assez. La collaboration anglaise est à resserrer encore, au besoin par un pacte interdisant la paix séparée. [...] Paul Reynaud est d'accord." (Jeanneney, Journal politique, S. 39; Eintrag vom 24. 3. 1940).

207 Pertinax, Fossoyeurs, Band I, S. 179. 
gen Stelle zu treffen. Zum Abbruch der diplomatischen Beziehungen mit der Sowjetunion zeigte sich Reynaud bereit, auch den Kriegsfall nahm er in Kauf. ${ }^{208}$

Im Verlauf des britisch-französischen Obersten Rats vom 28. März, dem ersten unter Beteiligung Paul Reynauds, kam es zum Ausgleich der zunächst diametral entgegengesetzten Positionen. Die Briten traten für äußerste Zurückhaltung an der Peripherie, also in Norwegen und im Kaukasus ein, favorisierten dagegen einen Plan über die Aussetzung von Minen in deutschen Flüssen, der auf Betreiben des obersten Lords der Admiralität, Churchill, unter dem Codenamen „Royal Marine" seit Anfang März diskutiert worden war. Auf französischer Seite, wo man unter Daladier bislang des Risikos deutscher Gegenschläge wegen direkte Aktionen im Nachbarland gescheut hatte, war man unter Reynauds Verhandlungsführung zum Einlenken bereit. Als Bedingung forderte der neue Ministerpräsident im Gegenzug die Verminung der norwegischen Häfen und die Bombardierung von Erdölquellen im Kaukasus. Nach dem Prinzip des „do ut des“ einigte man sich darauf, die Norwegenaktion in den ersten Apriltagen zu starten. Reynaud sagte als Gegenleistung zu, bestehende Widerstände gegen das Projekt "Royal Marine“ bei der eigenen politisch-militärischen Führung auszuräumen. Die Frage eines Vorgehens gegen die Sowjetunion behandelte man trotz des nachdrücklichen Drängens Reynauds dilatorisch. 209

In der seit September 1939 offenstehenden Frage einer Vereinbarung mit Großbritannien nach dem Muster derjenigen mit Polen vom 4. September 1939 erzielte man ebenfalls einen Durchbruch. Reynaud machte sich das Projekt wieder zu eigen, das aufgrund des französischen Desinteresses liegengeblieben war ${ }^{210}$, und erreichte die Unterzeichnung einer ergänzten Fassung. Darin sagte man sich gegenseitig den Verzicht auf separate Friedensverhandlungen zu; außerdem wurde die Fortführung der britisch-französischen Aktionseinheit über das Kriegsende hinaus und auf Reynauds Initiative die Abstimmung der beiderseitigen Sicherheitspolitik gegenüber Deutschland vereinbart. ${ }^{211}$

Die Verhandlungsergebnisse, die nach der Rückkehr Reynauds nur zum Teil bekannt gemacht wurden, verfehlten die beabsichtigte Öffentlichkeitswirkung zunächst nicht. Abgesehen von der extremen Rechten begrüßte man in der Presse die gemeinsame Erklärung mit Wohlwollen, gelegentlich mit Enthusiasmus. Le Temps sprach von einem Akt „allergrößter Bedeutung“ und dem „Beginn einer neuen Phase des europäischen Kriegs". Der psychologisch ungünstige Moment zwischen dem finnischen Debakel und baldigen neuen Rückschlägen stellte sie

${ }^{208}$ Ein Exemplar der Note findet sich in: MAE, Papiers 1940, Fonds Reynaud, Dossier 2; abgedruckt in: Les événements survenus en France de 1933 à 1945. Rapport de M. Charles Serre, député, au nom de la commission d'enquête parlementaire. 2 Bände, Paris 1947, hier: Band II, S. 351-354.

209 Zum Sitzungsverlauf und den Ergebnissen der Beratungen: Bédarida, Stratégie secrète, S. 312-360; aus englischer Sicht: "War Cabinet: Confidential Annex“, 29. 3. 1940, in: Martin Gilbert (Hg.), The Churchill War Papers. Band I: At the Admiralty (September 1939- May 1940), London 1993, S. 929-931. Vgl, auch Heimsoeth, Zusammenbruch, S. 280-285.

210 Eine vom 25. 3. 1940 datierte Note des Außenministeriums über die Vorteile einer derartigen Erklärung findet sich in: MAE, Papiers 1940, Fonds Dejean, Dossier 1; dazu auch Duroselle, L'Abîme, S. $133 \mathrm{f}$.

211 Zur Vorgeschichte der Erklärung seit September 1939: Duroselle, L'Abîme, S. 131-134. Ein Exemplar befindet sich in: MAE, Papiers 1940, Fonds Reynaud, Dossier 4; zum Wortlaut auch: Le Temps, 30. 3. 1940. 
allerdings unverbunden in den diplomatischen Raum und ließ ihre moralische Wirkung bald verpuffen. ${ }^{212}$

Die diplomatischen Erfolge des neuen Ministerpräsidenten beruhten zudem in hohem Maße darauf, daß er zu Konzessionen bereit gewesen war, auf die sein Vorgänger nicht hatte eingehen wollen. So gab Reynaud sich mit vergleichsweise unpräzisen gemeinsamen Kriegszieldefinitionen zufrieden, die Daladier in Erinnerung an die alliierten Auseinandersetzungen nach dem Ersten Weltkrieg noch in der Sitzung des Obersten Rates vom 19. Dezember 1939 als ungenügend erachtet hatte. ${ }^{213}$ Um des augenfälligen Ergebnisses willen versprach Reynaud dabei wie im Falle der Operation „Royal Marine“ auch mehr, als er halten konnte. Nachdem der nationale französische Verteidigungsrat auf Druck Daladiers sowie des Oberbefehlshabers Gamelin hin „Royal Marine“ abgelehnt und den Ministerpräsidenten desavouiert hatte, blieb Reynaud nurmehr ein peinlicher Rückzug gegenüber der britischen Regierung. Lediglich aufgrund der Unterstützung Churchills und der mittlerweile gereiften englischen Einsicht, daß man dem französischen Regierungschef zur Absicherung seiner innenpolitischen Position entgegenzukommen habe - ein weiterer Faktor, der Reynaud gegenüber seinem Vorgänger begünstigte -, kam die Aktion verzögert auch ohne die vereinbarte französische Gegenleistung zustande. 214

Zum politischen Mißgeschick Reynauds trat das Kriegspech: Als das britischfranzösische Unternehmen in den Hoheitsgewässern Norwegens am 8. April 1940 endlich anlief, stand die Einnahme der anvisierten Häfen durch deutsche Truppen unmittelbar bevor und wurde am nächsten Tag eingeleitet. ${ }^{215}$ Der weitere Verlauf der deutsch-alliierten Kämpfe in dem nordeuropäischen Land trug dann nicht nur entscheidend dazu bei, das ohnehin fragile Prestige Reynauds entscheidend zu schwächen. Er gab darüber hinaus Anlaß zu ernstesten Verstimmungen zwischen Briten und Franzosen und stand letztlich am Ursprung einer internen Krise im französischen Kabinett, die Reynaud bis zum 10. Mai zum Rücktritt führte.

212 Zitate: „La déclaration franco-britannique“, in: Le Temps, 30. 3. 1940. Zur Resonanz allgemein: Jean-Louis Crémieux-Brilhac, L'opinion publique française, l'Angleterre et la guerre (septembre 1939 - juin 1940), in: Français et Britanniques, S.1-50, hier: S. 25 f.; skeptischer: Heimsoeth, Zusammenbruch, S. $285 \mathrm{f}$.

${ }^{213}$ Zur Sitzung des "Conseil Suprême Interallié" vom 19. 12. 1939 vgl. Bédarida, Stratégie secrète, S. 185-232. Selbst aus dem engsten Mitarbeiterkreis Reynauds war Kritik an der beabsichtigten Erklärung lautgeworden; siehe dazu die Aufzeichnungen seines Verbindungsoffiziers zwischen Außenministerium und militärischer Führung: Paul de Villelume, Journal d'une défaite. (23 Août 1939 - 16 Juin 1940), Paris 1976, S. 253 f.

214 Den Verlauf der Beratungen des "Comité de guerre“ vom 30. März 1940 referiert Heimsoeth, Zusammenbruch, S. 286 anhand eines im Nachlaß Daladiers erhaltenen Protokolls. Zu den Widerständen gegen "Royal Marine“ in Frankreich und zur Vermittlung Churchills auch: Diaries of Oliver Harvey, S. $346 \mathrm{f}$. (Einträge vom 4. und 7. April). Zu den englischen Motiven für das Nachgeben: „Sir Ronald Campbell to Lord Halifax: telephone message“, 4. 4. 1940, in: Churchill War Papers I, S. 962 f.; „War Cabinet: minutes“, 5. 4. 1940, ebenda, S. 964-966; Winston S. Churchill: Memorandum, ebenda, S. $972 \mathrm{f}$.

215 Zum deutschen Norwegen-Feldzug als neueste Gesamtdarstellung: Hans-Martin Ottmer, „Weserübung". Der deutsche Angriff auf Dänemark und Norwegen im April 1940 (Operationen des Zweiten Weltkrieges 1), München 1994; zum diplomatischen Hintergrund der Kampfhandlungen in Norwegen: Thomas Munch-Petersen, The Strategy of Phoney War. Britain, Sweden and the Iron Ore Question 1939-1940, Stockholm 1981, bes. S. 211 ff.; François Kersaudy, 1940. La guerre du fer, Paris 1987. 
Das deutsche Vorgehen hatte die Alliierten derart unvorbereitet getroffen, die militärische Lage sich so ungünstig entwickelt, daß die britische Führung bereits am 26. April den Abzug der eigenen Truppen aus Mittelnorwegen ins Auge fassen mußte. ${ }^{216}$ In Paris war man schockiert. Trotz streckenweise geradezu beschwörender Einflußnahme der französischen Regierung, allen voran Reynaud, um den Verbleib der Briten zu bewirken, blieben alle Bemühungen vergeblich. ${ }^{217}$ Noch vor der eilig anberaumten Sondersitzung des Obersten Interalliierten Kriegsrates am 27. April in London war die britische Rückzugsentscheidung intern bereits getroffen. Die hinhaltende Taktik, die Chamberlain und die englische Delegation während der Gespräche gegenüber ihren französischen Gesprächspartnern an den Tag legten, bewirkte dort tiefe Verbitterung und Enttäuschung, als sie im nachhinein offen zutage trat. ${ }^{218}$ Es vertiefte sich der Eindruck, hintergangen worden zu sein, hatte man in Paris doch bereits kurz vorher zur Kenntnis nehmen müssen, daß die britische Regierung die Pläne zur Zerstörung kaukasischer Erdölfelder keineswegs energisch weiterverfolgt, sondern im Gegenteil den Abschluß eines britisch-sowjetischen Handelsabkommens forciert hatte. Besonders Reynaud hatte, anders als er in seinen rückblickenden Stellungnahmen vorgab, größten Wert auf die Bombardierung gelegt und dazu unter anderem am 3. April einen Kabinettsbeschluß herbeigeführt. Wiederum mußte er sich der englischen Zurückhaltung beugen, war aber wohl mit Beginn der Kämpfe in Norwegen bereits aus eigenem Antrieb zunehmend davon abgerückt, einen Krieg mit der Sowjetunion provozieren $\mathrm{zu}$ wollen. ${ }^{219}$

216 Zur Sitzung des englischen Kriegskabinetts vom 26. April und zu den französischen Reaktionen auf die Nachricht: Kersaudy, Guerre du fer, S. 243-246; eine präzise Aufschlüsselung der Ereignisse vom 26. und 27. April in London und Paris auch bei: Bédarida, Stratégie secrète, S. 483-488.

217 So hatte Reynaud am 26. April einen persönlichen, scharf gehaltenen Brief an Chamberlain geschrieben, in dem er jede Evakuierung des französischen Kontingents ablehnte und die Bildung eines einheitlichen Oberkommandos anregte (abgedruckt in: Die Geheimakten des französischen Generalstabes (Weißbuch Nr. 6, hg. vom Auswärtigen Amt), Berlin 1941, Nr. 42, S. 96 f.; dazu: Bédarida, Stratégie secrète, S. 486). Noch bis Anfang Mai versuchte Reynaud, den vollständigen englischen Abzug aus Mittelnorwegen zu verhindern (vgl. sein Telegramm an Chamberlain vom 1.5. 1940; MAE, Papiers 1940, Fonds Reynaud, Dossicr 2. Abgedruckt in: Geheimakten des französischen Generalstabes, Nr. 49, S. 116f., 334-336). Dazu auch: Duroselle, L'Abîme, S. 145.

218 Das Gesprächsprotokoll des britisch-französischen Treffens vom 27. April bei: Ebenda, S. 495516. Aufschluß über die Stimmung Reynauds nach der Rückkehr aus London geben die Memoiren seines Mitarbeiters Paul Baudouin. Demzufolge erschien der Ministerpräsident müde, niedergeschlagen und bitter in seinem Urteil über die englische Regierung, einer Gruppe „alter Männer, die nichts riskieren wollen" (Paul Baudouin, Neuf mois au gouvernement (avril - décembre 1940), Paris 1948, S. 41).

219 Darauf läßt seine Äußerung gegenüber dem englischen Botschafter vom 14. April schließen, wonach ein Vorgehen im Kaukasus nur in Antwort auf sowjetische Angriffshandlungen ins Auge gefaßt werden dürfe. Ansonsten habe man eine Ausweitung des Krieges auf die Sowjetunion möglichst zu vermeiden (Campbell an Halifax, 14.4. 1940; zitiert bei Bartel, Frankreich und die Sowjetunion, S. 331).

In seinen Erinnerungen übergeht Reynaud sein energisches Eintreten für eine Kaukasus-Operation auch noch nach dem Interalliierten Rat vom 28. März 1940. (So hatte er ctwa den französischen Botschafter in London, Corbin, noch am 4. April angewiesen, bei Chamberlain Druck auf die Verabschiedung eines gemeinsamen Aktionsplans auszuüben; vgl. Ebenda, S. 330). Dagegen: Reynaud, Mémoires II, S. $314 \mathrm{f}$. Auch in der vorangegangenen Fassung hatte er sich zu Unrecht davon distanziert, die Bombardements-Pläne nach seinem Regierungsantritt aktiv gefördert zu haben: Ders., Au coeur de la mêlée, $S$. 370 f.

Zur Entwicklung der Kaukasus-Planungen in Frankreich vom Regierungsantritt Reynauds bis zur Aufgabe des Projekts: Bartel, Frankreich und die Sowjetunion, S. 328-332.; Duroselle, L'Abîme, 
Die Abkühlung des britisch-französischen Verhältnisses über der Frage des alliierten Einsatzes in Norwegen fand ihre Entsprechung in wachsenden kabinettsinternen Spannungen auf französischer Seite. Das ohnehin seit dem Machtwechsel vom März bestehende latente Mißtrauen zwischen Reynaud und Daladier ${ }^{220}$ erhielt durch die bald absehbare negative Wendung der Entlastungsaktion in Nordeuropa neue Nahrung. Richtete sich beider Kritik einmütig gegen die englische Vorbereitung und Durchführung der Aktion, kam es bald auch zu gegenseitigen Schuldzuweisungen. Der Kriegsminister, bei den alliierten Gesprächen vom 28. März nicht anwesend und durch die Reynaudsche Politik schneller Verhandlungserfolge sachlich ebenso wie in seiner persönlichen Eitelkeit unangenehm berührt, kritisierte die mangelnde Voraussicht des Gremiums, eine deutsche Aktion sinnvoll abzufangen.221 Reynaud reagierte empfindlich: Ab Mitte April gab er seinem Kriegsminister die Anweisungen zum Vorgehen in Norwegen in erster Linie auf brieflichem Wege. Kühl und distanziert formulierte er seine Unzufriedenheit mit der geleisteten Arbeit; Daladier hingegen schrieb die kritisierten Pannen auf das Konto der Briten.222 Ungeachtet dessen visierte Reynaud spätestens seit Ende April eine Kabinettsumbildung an, die Daladier mit Einverständnis von Senatspräsident Jeanneney seinen Posten entziehen sollte. Nur die Sorge vor der fehlenden Plausibilität des Schritts in den Augen von Parlament und Öffentlichkeit hielt ihn immer wieder davon ab. ${ }^{223}$ Daneben machte er es sich ab Mitte April mehr und mehr zur Regel, den Oberkommandierenden Gamelin als Verantwortlichen für Versäumnisse und Verzögerungen bei der Einschiffung des französischen Expeditionskorps in die Pflicht zu nehmen. Der Ministerpräsident ließ keinen Zweifel daran, daß er den General mit der militärischen Leitung der französischen Kriegsanstrengungen für überfordert hielt und sparte in Kabinettssitzungen nicht mit Vorwürfen. ${ }^{224}$ Daladier stellte sich ostentativ vor seinen Oberbefehlshaber, mit dem ihn eine langjährige Kooperation verband.225 Dreimal versuchte Reynaud, Gamelin mit Zustimmung des Kabinetts abzusetzen; erst am 9. Mai gelang es ihm, die Opposition Daladiers zu überwinden. Im Rahmen einer bewußt herbeigeführ-

S. 146-150. Präzise auch: Bédarida, Stratégie secrète, S. 405-407. Den Meinungswandel Reynauds übersieht: Heimsoeth, Zusammenbruch, S. $284 \mathrm{f}$. und $291 \mathrm{f}$.

220 Oliver Harvey notierte zum Verhältnis Reynaud-Daladier und zur daraus sich ergebenden Problematik einer geradlinigen französischen Politik: „[...] Paul Reynaud has undoubtedly intrigued against Daladier - egged on by his entourage and by his own vanity - whilst Daladier undoubtedly mistrusts Paul Reynaud as a peasant distrusts a bourgeois." (Diaries of Oliver Harvey, S. 342).

221 Bullitt an Roosevelt, 28. 4. 1940, in: For the President. Personal and Secret Correspondance between F.D. Roosevelt and W.C. Bullitt, Boston 1972, S. 411.

222 Vgl. Reynaud an Daladier, 11. 4., 15. 4., 25. 4., 30. 4 . 1940 und die Antworten Daladiers an Reynaud, 13. 4., 15. 4., 17. 4., 21. 4. 1940; MAE, Papiers 1940, Fonds Reynaud, Dossier 2. Eine Sammlung des Briefwechsels befindet sich auch in: SHAT, 5 N 580. Dazu auch das Rechtfertigungsschreiben des Oberbefehlshabers der Flotte: Darlan an Daladier, 12. 4. 1940, in: Hervé CoutauBégarie/Claude Huan (Hg.), Lettres et notes de l'amiral Darlan, Paris 1992, S. 171-173.

223 Vgl. dazu Jeanneney, Journal politique, S. 41-44.

${ }_{224} \mathrm{Zu}$ den Vorwürfen vgl. Jeanneney, Journal politique, S. 39-44. Reynaud bemängelte im einzelnen die fehlende Energie und Weitsicht des Generals, ebenso wie die „bürokratisch“ langsame Ausführung der einmal gefaßten Pläne. Vgl. „Procès-verbal de la séance du cabinet de guerre du 12 avril 1940", in: Reynaud, Mémoires II, S. 504 f.

Alexander, Republic in danger, behandelt den Zeitabschnitt von April/Mai 1940 und die Norwegen-Aktion erstaunlicherweise nicht eingehender; das Verhältnis Gamelin-Reynaud für diese Periode wird nicht näher beleuchtet.

${ }^{225}$ Zur Hochschätzung Gamelins durch Daladier: Alexander, Republic in danger, S. 89. 
ten Regierungskrise konfrontierte er den Oberbefehlshaber mit einer weitgehenden, von langer Hand vorbereiteten Liste von Gravamina.226 Auf den Protest Daladiers hin erklärte Reynaud den Rücktritt des Kabinetts, offenbar in der Hoffnung, als sein eigener Nachfolger und unter Entmachtung der unliebsamen Gegner neu berufen zu werden. Dem oft zitierten Bericht seines Mitarbeiters Dominique Leca zufolge setzte er auf den Rücktritt als letztes und stärkstes Disziplinierungsmittel: „Ma démission, c'est le coup d'aiguillon nécessaire pour qu'ils comprennent qu'il n'y a pas d'autre solution que de me suivre. L'accepter, ils n'oseront pas." 227 Der deutsche Angriff auf Frankreich vom 10. Mai 1940 verhinderte den innenpolitischen Schachzug. Vor der existentiellen Bedrohung wurden nun die kabinettsinternen Konflikte vorläufig ad acta gelegt. Die Zusammensetzung der Regierungsequipe blieb weitgehend erhalten, abgesehen davon, daß jetzt auch die Rechte bereit war, neben den Sozialisten im Kabinett mitzuarbeiten. 228

Nach noch nicht einmal zweimonatiger Tätigkeit im Amt hatte Paul Reynaud auf eine Zwischenbilanz seiner Kriegführung gegen Deutschland zurückzublikken, die im wesentlichen negativ ausfallen mußte. Den zentralen Anspruch auf Erneuerung des französischen militärischen Vorgehens, unter dem er angetreten war, hatte er nicht einlösen können. Auf der Grundlage von Planungen, die eher von Kontinuität als von eindeutigem Bruch mit den Intentionen seines Vorgängers geprägt waren, hatte er bemerkenswerte, doch brüchige Etappenerfolge erzielt. Vorwiegend aufgrund unglücklicher äußerer Umstände in Verbindung mit interalliierten Divergenzen war ihm das Gewonnene weitgehend zwischen den Fingern zerronnen. Innenpolitisch wog überdies schwer, daß sich Reynauds Vertrauenskredit aufgrund voreiliger Erfolgsmeldungen, die er während der Norwegenaktion vor der Abgeordnetenkammer abgegeben hatte, noch einmal vermindert hatte. ${ }^{229}$

War Reynauds Handlungsspielraum bereits seit Antritt der Ministerpräsidentschaft begrenzt gewesen, so konnte nach Beginn des deutschen Frankreichfeldzuges von freier politischer Aktion keine Rede mehr sein. Die militärisch-politischen Ereignisse sind bekannt und sollen im folgenden nurmehr knapp dargestellt werden. ${ }^{230}$ Entgegen dem anfänglichen Optimismus in der politischen und militärischen Führung mußte man auf französischer Seite rasch die ersten Rückschläge

226 Duroselle, L'Abîme, S. 131. Vgl. auch die Schilderung bei Heimsoeth, Zusammenbruch, S. 295 f. Zum Ablauf der Kabinettssitzung vom 9.5.1940 im wesentlichen übereinstimmend: Reynaud, Mémoires II, S. 337; Jeanneney, Journal politique, S. 45 f.; Baudouin, Neuf mois, S. 44-46.

227 Dominique Leca, La rupture de 1940, Paris 1978, S. 124 (Eintrag vom 4. 5. 1940).

228 Reynaud nahm Louis Marin von der "Fédération Républicaine“ sowie Jean Ybarnégaray vom „Parti Social Français" als Staatsminister ohne Ressort auf und entließ dafür fünf Staatssekretäre (Bonnefous, Histoire politique VII, S. 321).

${ }_{229}$ Vgl. JO, Chambre des Députés, Débats parlementaires, Séance du 12 avril 1940, S. 668; dazu auch Rossi-Landi, Drôle de guerre, S. 69.

230 Die neueste Gesamtdarstellung des deutschen Frankreichfeldzuges aus der Feder eines Militärhistorikers: Karl-Heinz Frieser, Blitzkrieg-Legende. Der Westfeldzug 1940 (Operationen des Zweiten Weltkrieges 2), München 1995.

$\mathrm{Zu}$ den politischen Vorgängen ausführlich und anhand der verfügbaren Akten insbesondere des französischen Außenministeriums: Duroselle, L'abîme, S. 164-231; ohne Aktenbenutzung, doch unter Verwertung der vorliegenden Memoirenliteratur: William D. Shirer, Der Zusammenbruch Frankreichs. Aufstieg und Fall der Dritten Republik, München/Zürich 1969; zusammenfassend: Heimsoeth, Zusammenbruch, S. 342-362. 
hinnehmen. Nach nur vier Kampftagen durchstießen die deutschen Truppen die Ardennen und überquerten am 13. Mai die Maas. Am 7. Juni brach die französische Front an der Somme, nachdem die deutsche Führung zwei Tage zuvor den Angriff auf Kernfrankreich eingeleitet hatte. Am 11. Juni bereits hatten sich die deutschen Verbände Paris so weit angenähert, daß die Regierung die Hauptstadt verlassen mußte und sich zunächst in mehreren Schlössern entlang der Loire, dann in Bordeaux niederließ.

Paul Reynaud versuchte, durch zwei weitere Regierungsumbildungen die Effektivität der Kabinettsarbeit zu erhöhen. Letztlich aber waren es eben diese Modifikationen, welche die Zahl jener Kabinettsmitglieder erhöhten, die sich am 16. Juni für das Ausloten der deutschen Waffenstillstandsbedingungen aussprechen sollten. Am 18. Mai zunächst rief er Marschall Pétain, der seit einem Jahr als Botschafter in Madrid akkreditiert war, nach Paris zurück und betraute ihn mit dem Amt des stellvertretenden Ministerpräsidenten. Er selbst übernahm nun von Daladier das Verteidigungsministerium, der dafür ins Außenamt überwechselte. An der Spitze der Armee löste am Tag danach Weygand, bis dahin Oberkommandierender in Syrien, den entlassenen Gamelin ab. Die Folgen dieser personalpolitischen Fehlentscheidungen zeigten sich nur zu bald: Im Kriegsrat vom 25. Mai kam auf Initiative Weygands zum ersten Mal die Möglichkeit eines Waffenstillstands zur Sprache. Damit war ein bislang sorgsam gemiedenes Tabu gebrochen. Während Reynaud weiter zunächst in Großbritannien um Unterstützung ersuchte, formierte sich innerhalb des Kabinetts zunehmend die Gruppe jener, die die Fortführung der Kämpfe für sinnlos erachteten. Der neue Staatssekretär im Außenministerium, Paul Baudouin, gehörte neben Weygand und Pétain zu diesem Kreis, auch der radikalsozialistische Stellvertreter des Ministerpräsidenten, Camille Chautemps, äußerte Bedenken.231

Reynaud, der seit seinem dringenden Hilferuf um Luftunterstützung vom 14. Mai nahezu täglich in Kontakt mit dem neuen englischen Ministerpräsidenten Churchill stand 232 , konnte aus der Zusammenarbeit mit den britischen Alliierten wenig Rückhalt für die Auseinandersetzung mit seinen innenpolitischen Opponenten gewinnen. Zwar hatte Churchill bis zum 16. Mai größere Luftwaffenverbände nach Frankreich verlegt und damit etwa ein Viertel der englischen Jagdverbände auf dem Festland stationiert. Insbesondere die Begleitumstände des Rückzugs und der Evakuierung der britischen Expeditionstruppen bei Dünkirchen bestätigten jedoch die Friedensfraktion innerhalb der französischen Regierung in ihrer Haltung und lösten in der Öffentlichkeit antienglische Ressentiments aus. ${ }^{233}$ Reynaud konnte nur resigniert die Grenzen der englischen Hilfsbereitschaft zur Kenntnis nehmen.234

231 Baudouin, Neuf mois, S. 89-91; Villelume, Journal d'une défaite, S. 393; De Monzie, Ci-devant, S. 238. Dazu Heimsoeth, Zusammenbruch, S. $348 \mathrm{f}$.

232 Vgl. dazu die Sammlung von Telegrammen zwischen Churchill und Reynaud, die Reynauds Kabinettschef im Außenministerium, Dejean, anlegte (MAE, PA-AP 288, Dossier 6). Zur Entwicklung der britisch-französischen Beziehungen: Müller, Ende der Entente Cordiale; Gates, End of the affair, S. $74 \mathrm{ff}$.

${ }^{233}$ Dazu Duroselle, L'abîme, S. 193-200.

${ }^{234}$ In einem Telegramm an Churchill hatte er am 8.6. die Überführung sämtlicher 39 englischen Jägerstaffeln nach Frankreich gefordert und auf die abschlägige Reaktion mit Indignation reagiert; 
Die dringenden Bitten um materielle Unterstützung, die man daneben an den amerikanischen Präsidenten Roosevelt gerichtet hatte, fanden erst am 3. Juni Gehör - zu spät, um noch wirksame Hilfe bewirken zu können. In mehreren persönlichen Adressen an den Präsidenten drängte Reynaud ab dem 6. Juni auf ein militärisches Eingreifen der USA. Doch auch das verzweifelte Pathos, mit dem der Ministerpräsident das Schicksal Frankreichs für den Fall einer amerikanischen Ablehnung umschrieb, blieb ohne Erfolg: „Vous verrez, alors, la France s'enfoncer comme un homme qui se noie et disparaître, après avoir jeté un dernier regard vers la terre de liberté d'où elle attendait le salut."“235 Der Optimismus Churchills konnte nichts daran ändern, daß ein Kriegseintritt der USA vorläufig an der antiinterventionistischen Stimmung in Kongreß und amerikanischer Öffentlichkeit scheiterte. ${ }^{236}$ Am 15. Juni, kurz vor der Niederlage Frankreichs, nahm Roosevelt dem französischen Ministerpräsidenten alle diesbezügliche Hoffnung: „Je sais que vous comprendrez que ces déclarations n'entraînent aucun engagement d'ordre militaire. Seul le Congrès peut prendre de tels engagements." 237

Anfang Juni bereits waren damit die diplomatischen Mittel zur außenpolitischen Abstützung der französischen Kriegführung weitgehend ausgereizt. Reynaud war entgegen dem Druck Daladiers und de Monzies nicht bereit, seine Friedensdemarche bei Mussolini zu erneuern, über die er noch im April versucht hatte, den Duce unter Verweis auf das Band der gemeinsamen „civilisation méditerranéenne" vom Kriegseintritt abzuhalten.238 Ein inoffiziell eingeleiteter Versuch, die Beziehungen zur Sowjetunion wiederaufzunehmen, um dort Materialkäufe zu tätigen, war Ende Mai an Verfahrensfragen gescheitert. ${ }^{239}$ Auch auf militärischem Gebiet wurde die Lage immer hoffnungsloser, seit ein Ende Mai eingeleiteter letzter Versuch Weygands, die Verteidigungslinien zu stabilisieren, fehlgeschlagen war. Um den 7. Juni existierte keine kontinuierliche Frontlinie mehr. ${ }^{240}$

vgl. Reynaud an Churchill, 8.6. und 10.6.1940 (MAE, PA-AP 288, Dossier 6); Churchill an Reynaud, 8.6. 1940 (ebenda). Zuvor schon hatte der englische Botschafter den Ministerpräsidenten dazu ermuntert, doch besser auf Großbritannien zu vertrauen, anstatt ständig neue Appelle zu formulieren, die sich als kontraproduktiv erweisen könnten (Notiz über ein Gespräch CampbellReynaud vom 3.6. 1940; ebenda).

235 Reynaud an Roosevelt, 14.6. 1940 (MAE, PA-AP 288, Dossier 7). In einem Telegramm vom 10.6. hatte Reynaud den französischen Widerstandswillen beschworen: „Nous lutterons en avant de Paris, nous lutterons en arrière de Paris, nous nous enfermerons dans une de nos provinces, et, si nous en sommes chassés, nous irons en Afrique du Nord et, au besoin, dans nos possessions en Amérique." (Reynaud an Roosevelt, 10.6. 1940; ebenda). Ein Abhörprotokoll des Telephongesprächs Reynaud-Roosevelt findet sich in den Beständen des französischen Kriegsarchivs (SHAT, 5 N 580 ).

${ }^{236}$ So die Analyse des französischen Botschafters in Washington nach einem Gespräch mit Präsidentenberater Sumner Welles: St. Quentin an Reynaud, 14.6. 1940 (Ebenda); Churchill hatte die Antwort Roosevelts vom 14.6. als Anzeichen für den unweigerlichen amerikanischen Kriegseintritt interpretiert („Message de M. Churchill pour M. Paul Reynaud“, 14.6. 1940; Ebenda).

${ }^{237}$ Roosevelt an Reynaud, 15. 6. 1940, „reçu à Bordeaux à 19 heures“ (Ebenda).

238 Vgl. das Telegramm Reynauds an Mussolini vom 22. 4. 1940 und die abweisende Antwort des Duce vom folgenden Tag (MAE, Papiers 1940, Fonds Reynaud, Dossier 5; die Schreiben finden sich abgedruckt in: ADAP D IX, Nr. 172 und 173, S. 200 f., Zitat: S. 200). Mussolini hatte Reynauds Telegramm an Hitler übermittelt, der sich über die "weinerliche Anklage“ des Ministerpräsidenten mokierte (Ebenda, Nr. 190 und 192, S. 220 und 223 f., Zitat: S. 224).

Zu Daladiers Drängen auf einen neuerlichen Vorstoß beim Duce anhand von Dokumenten aus dem Nachlaß des Ministers: Heimsoeth, Zusammenbruch, S. $351 \mathrm{f}$.

239 Siehe hierzu die eingehende Darstellung bei Bartel, Frankreich und die Sowjetunion, S. $661 \mathrm{ff}$.

240 Eingehend dazu: Duroselle, L'abîme, S. 193-202. 
Vor diesem beherrschenden Hintergrund konnte die letzte größere kabinettspolitische Maßnahme Reynauds, seine Regierungsumbildung vom 5. Juni, keine positive Wirkung mehr entfalten. Im Gegenteil: anstatt, wie beabsichtigt, die Gruppe der Reynaud-Anhänger zu stärken - Charles de Gaulle wurde als Staatssekretär ins Verteidigungsministerium berufen -, förderte Reynaud auch solche Persönlichkeiten, die sich wie der neue Finanzminister, Yves Bouthillier, Mitte Juni gegen ihren Ministerpräsidenten und für die Einstellung der Kämpfe aussprechen sollten.

In dem Maße, in dem sich die Wahrscheinlichkeit der Niederlage verdichtete, übten Befürworter wie Gegner der Kampfeinstellung zunehmenden Druck auf Reynaud aus: Charles de Gaulle, Innenminister Georges Mandel, Marineminister César Campinchi und Kabinettschef Maurice Dejean zählten eindeutig zu letzteren; Staatssekretär Paul Baudouin, der Verbindungsoffizier zum Generalstab Colonel de Villelume und die Lebensgefährtin Reynauds, Hélène de Portes, bildeten neben Weygand und Pétain den Kern der ersteren Gruppe. Der Ministerpräsident, der in diesen Tagen seinen wiederholt bekundeten Durchhaltewillen ${ }^{241}$ gegenüber der Friedenspartei immer weniger durch hoffnungstärkende Fakten untermauern konnte, gab am Abend des 15. Juni in entscheidender Situation dem Drängen seines Kabinetts nach. An diesem Tag akzeptierten seine Minister mehrheitlich den Kompromißvorschlag Chautemps', wonach bei der deutschen Führung die Bedingungen für einen Waffenstillstand erfragt werden sollten. ${ }^{242}$ Reynaud versuchte, sein Gewicht durch einen letzten Schachzug zu stärken, der in seiner diplomatischen Subtilität das Ausmaß des bereits erreichten Dilemmas verdeutlicht: Er ließ an die englische Regierung die Anfrage richten, unter welchen Bedingungen sie Frankreich aus der Abmachung vom 28. März entlassen und einen Waffenstillstand akzeptieren würde. Im Falle der Ablehnung, so seine rückblickende Darstellung, hätte er gestärkt vor den Ministerrat treten können; wäre er dennoch gestürzt worden, hätte er sich zumindest darauf berufen können, das Äußerste zur Abwendung der Kampfeinstellung versucht zu haben. ${ }^{243}$ Die endgültige britische Antwort, der Vorschlag auf weitgehende Union der beiden Staaten, stieß im Ministerrat auf einhellige Ablehnung.244 Paul Reynaud trat am 16. Juni 1940 zurück, nachdem er laut eigener Aussage den Eindruck gewonnen hatte, daß die Mehrheit der Minister einem Waffenstillstand zuneigte. ${ }^{245}$

In einer Darstellung, die wie der obige Abschnitt das Augenmerk auf die größeren Entscheidungszusammenhänge richtet, drohen die politisch Handelnden an

${ }^{241}$ Vgl. etwa die Entschlossenheitsbekundungen Reynauds während der Sitzung des Kriegsrats vom 5. Juni (Baudouin, Neuf mois, S. 123).

242 Heimsoeth, Zusammenbruch, S. 356.

${ }^{243} \mathrm{Vgl}$. zu den Überlegungen Reynauds: Reynaud, La France II, S. 341.

244 Duroselle, L’abîme, S. 227-231; zur Geschichte des Vereinigungsplans, der durch de Gaulle telephonisch aus London übermittelt wurde auch: Lacouture, De Gaulle I, S. 339-344. Eine Mitschrift des Gesprächs mit de Gaulle von der Hand Reynauds findet sich in seinem Nachlaß (AN, 74 AP 22).

245 Reynaud, La France II, S. 356 f. Aus einer handschriftlichen Notiz Reynauds, die unter seinen nachgelassenen Papieren zu finden ist, geht hervor, daß er das Kräfteverhältnis zwischen Befürwortern und Gegnern des „armistice“" mit 13 zu 11 zugunsten ersterer einschätzte (AN, 74 AP 22). Die Diskussion darüber, ob Reynaud damit die Meinungslage richtig interpretierte: Gates, End of the Affair, S. $428 \mathrm{f}$. 
Kontur zu verlieren, selbst wenn sie in den historischen Abläufen eine so zentrale Stellung einnahmen wie Paul Reynaud. Im vorliegenden Fall ergibt sich dieser Befund allerdings in hohem Maße aus dem historischen Phänomen selbst. Eine ganze Reihe überpersönlicher Faktoren konnte im Sommer 1940 die Handlungsspielräume eines französischen Ministerpräsidenten beschränken, unabhängig vom Format und politischen Potential des Amtsinhabers. Die neuere Forschung hat in ihren Deutungen des militärisch-politischen Debakels von 1940 solche Einflußgrößen unterschiedlichen Abstraktionsgrades herausgearbeitet, ohne freilich in deren Gewichtung zu einem schlüssigen Konsens gelangt zu sein. Einig ist man sich immerhin über die schwerwiegende Rolle strategischer Fehleinschätzungen und konkreter Führungsschwächen in der militärischen Elite Frankreichs; die unter Vichy verbreitete Anschauung von der materiellen Unterlegenheit gegenüber dem deutschen Gegner wurde hingegen weitgehend als Mythos entlarvt. Daneben hat die seriöse Forschung längerfristig wirksame sozialpsychologische oder sozioökonomische Faktoren, die politische Spaltung des Landes seit der Volksfront, Schwächen des politischen Systems und den demographischen oder industriellen Rückstand Frankreichs gegenüber einem überlegenen „bloc germanique“ als Erklärungshilfen herangezogen. Dies geschah allerdings angesichts der Komplexität der Materie und der Vorbelastung der Diskussion durch die Dekadenzthesen Vichys eher in vorsichtig tastender Weise. ${ }^{246}$

Dennoch soll im folgenden nochmals auch die Rolle eines einzelnen, die Rolle Paul Reynauds in Augenschein genommen werden. Es wird dabei darum gehen, den Schritt von den großen Deutungsmustern zu den konkreten Möglichkeiten und Grenzen seines politischen Handelns zu tun. Stärker als bisher soll auch nach der Fortdauer persönlicher Prägungen, politischer Vorstellungen oder des daraus erwachsenen politischen Stils gefragt werden. Der Blick auf Kontinuitäten solcher Art wurde geraume Zeit durch jene Brüche abgelenkt, aufgrund derer seine erfolgreiche Karriere als „dur“ im Kabinett Daladier in so erklärungsbedürftiger Weise mit dem schwankenden Erscheinungsbild kontrastierte, das er als Ministerpräsident in mancher Hinsicht bot. Bis in neuere Darstellungen hinein lassen sich daher Deutungsansätze verfolgen, die starkes Gewicht auf den übermächtigen Einfluß seiner Umgebung oder auf die fehlende psychologische Eignung für das Ministerpräsidentenamt legen und ganz offensichtlich ergänzungsbedürftig sind. 247

246 Vgl. dazu stellvertretend und als neueste Bestandsaufnahme von Forschungstendenzen die Beiträge in: Joel Blatt (Hg.), The French Defeat of 1940. Reassessments, Providence/Oxford 1998. Charakteristisch ist der vorsichtige Versuch eines Resümees unter dem Titel „A défaut de conclusion" bei: Crémieux-Brilhac, Les Français de l'an 40, Band II, S. 709-715, Zitat: S. 710. Zum Anteil der Militärdoktrin an der Niederlage bislang wohl die beste Arbeit: Ladislas Mysyrowicz, Autopsic d'une défaite. Origines de l'effondrement militaire français de 1940, Paris 1973.

247 Vgl. etwa das entsprechende Erklärungsmuster u.a. bei Jean-Pierre Azéma, 1940. L'année terrible, Paris 1990, S. 144; Camille Chautemps, Cahiers secrets de l'armistice (1939-1940), Paris 1963, S. 175 f.; Alfred Fabre-Luce, Journal de la France, mars 1939-juillet 1940, Paris 1940, S. 362. Verpflichtet ist die in den folgenden Abschnitten vorgetragene Deutung dagegen insbesondere der minutiösen und scharfsinnigen Rekonstruktion der Ereignisse bei Duroselle, L'abîme, und Gates, End of the affair. Differenziert in der Deutung der Person Reynauds auch: Emmanuel Berl, La fin de la IIIe République. 10 juillet 1940, Paris 1968, S. 67-69.

Vgl. zur frühen Auseinandersetzung um Reynauds Ministerpräsidentenzeit bereits unter dem $\mathrm{V}_{\mathbf{1}}$ chy-Regime und in den ersten Nachkriegsjahren Kapitel XI.1. dieser Arbeit. 
$\mathrm{Zu}$ allem Überfluß trug seine eigene rückblickende Darstellung eher dazu bei, weitere Interpretationsprobleme zu erzeugen, als Klarheit zu schaffen. Seit seinen ersten Äußerungen im Prozeß gegen Philippe Pétain im Jahre 1945 nahm er über Jahrzehnte hinweg schier unermüdlich immer neue publizistische Anläufe, um buchstäblich noch den kleinsten Anschein eines etwaigen historischen Versagens in den Krisenmonaten Mai/Juni 1940 zu entkräften. Es bleibt zu bezweifeln, daß er mit dem komplexen Erklärungsgebäude, das daraus erwuchs, sein Ziel erreichte. Insbesondere zeigt sich bei näherer Betrachtung, daß das entworfene Selbstporträt des "Jusqu'au-boutiste“, des entschlossenen Durchhaltestrategen, der erst durch das schwächliche Nachgeben seiner Minister zum Einlenken gezwungen worden sei, einer kritischen Konfrontation mit dem historischen Befund nicht standhalten kann. ${ }^{248}$ Ungeachtet dessen blieb Paul Reynaud in der retrospektiven Aufarbeitung seiner kurzen Ministerpräsidentenzeit bis zu seinem Tod geistiger Gefangener einer politischen Selbstinterpretation, deren Umsetzung ihm im Frühjahr 1940 nicht gelungen war. Dies festzustellen heißt keineswegs, ihn umgekehrt in die Nähe derer zu rücken, die von vorneherein den Kampf gegen das nationalsozialistische Deutschland ablehnten; es bedeutet gleichwohl, ein differenziertes und durchaus ambivalentes Bild seines Handelns zuzulassen.

Ein ausgewählter, zentraler Aspekt - Reynauds Haltung in der Frage des ,armistice“, also des Abschlusses eines Waffenstillstands mit Deutschland - wird im folgenden Gelegenheit bieten, ein solches Bild zu entfalten. Am 25. Mai 1940 zum ersten Mal als Möglichkeit im Ministerrat angedeutet, am 12. Juni erstmals diskutiert, hat die Waffenstillstandsfrage seither die Gemüter von Zeitgenossen und Historikern wie wenige andere Ereignisse der neueren französischen Geschichte bewegt. Nötiger und sinnvoller Schritt, Wahl des kleineren Übels oder Akt des Verrats an der nationalen Sache - so lauteten die Deutungsalternativen, die in unterschiedlichem Mischungsverhältnis bis heute vorzufinden sind. Vor allem die Tatsache, daß sich ein vierjähriges autoritäres und verbrecherisches $Z$ wangsregime und eine Phase beschämender Kollaboration mit dem Sieger anschlossen, machte den Vorgang seit 1944 zu einem „heißen Eisen“ der nationalen Erinnerungskultur und der Historiographie. ${ }^{249}$ Es kann in den folgenden Abschnitten nicht darum gehen, den bereits vorliegenden Tag-für-Tag-Analysen zur Vorgeschichte des

248 Gemeint ist der Tenor der Memoirenwerke, die Reynaud seit 1947 vorlegte: Reynaud, La France; ders., Au coeur de la mêlée; ders., Mémoires.

${ }^{249}$ Azéma, De Munich à la Libération, S. 71. Vgl. zum Waffenstillstand von 1940 neben den bereits genannten Überblicksarbeiten von Duroselle, Gates und Azéma speziell: Albert Merglen, Quelques réflexions historiques sur l'armistice franco-germano-italien de juin 1940, in: Guerres mondiales et conflits contemporains 45 (1995), S. 79-93; Philippe Simonnot, Le secret de l'armistice 1940, Paris 1990; Michael Salewski, Knotenpunkt der Weltgeschichte? Die Raison des deutschfranzösischen Waffenstillstands vom 22. Juni 1940, in: Claude Carlier u. a. (Hg.), La France et l'Allemagne en guerre, Paris 1990, S. 115-129; Hermann Böhme, Der deutsch-französische Waffenstillstand im Zweiten Weltkrieg, Band 1: Entstehung und Grundlagen des Waffenstillstandes von 1940 (Quellen und Darstellungen zur Zeitgeschichte 12), Stuttgart 1966; André Beaufre, Le drame de 1940, Paris 1965; Klaus-Jürgen Müller, Zum deutsch-französischen Waffenstillstand 1940, in: Wehrwissenschaftliche Rundschau 11 (1961), S. 356-359; André Truchet, L'Armistice de 1940 et l'Afrique du Nord, Paris 1955; Louis Marin, Gouvernement et commandement. Conflits, différends, immixtions qui ont pesé sur l'armistice de juin 1940, in: Revue d'histoire de la deuxième guerre mondiale 2/8 (1952), S. 1-28 sowie 3/9 (1953), S. 1-14; Albert Kammerer, La vérité sur l'armistice. Ephéméride de ce qui s'est réellement passé au moment du désastre, Paris 1944. 
Waffenstillstands vom Juni 1940 eine weitere hinzuzufügen. Die historischen Abläufe werden allerdings in dem Maße herangezogen werden müssen, in dem aus der Konfrontation mit der Reynaudschen Selbstdarstellung weitere Elemente zur Einschätzung seiner politischen Person und - indirekt - zum Verständnis seiner persönlichen Situation in den ersten Nachkriegsjahren erwachsen.

Die Initiative des stellvertretenden Ministerpräsidenten Chautemps vom 15. Juni 1940, mit englischer Zustimmung „unverbindlich“ die deutschen Waffenstillstandsbedingungen zu erfragen, bildete einen Angelpunkt sowohl der historischen Abläufe wie auch der nachfolgenden Deutungsstrategie Paul Reynauds. Sie setzte als Katalysator jenen diplomatischen und kabinettspolitischen Prozeß in Gang, der schließlich zum Rücktritt des Regierungschefs und zum Waffenstillstandsersuchen Pétains am 17. Juni 1940 führte. Camille Chautemps präsentierte seinen Vorschlag in der entscheidenden Kabinettssitzung als Kompromißlösung, um die angesichts der verzweifelten Kriegslage gespaltene Regierungsmannschaft wieder auf entschlossenere Fortführung des Kampfes zu einigen. Aufgrund der vermutlich unannehmbaren deutschen Friedensbedingungen, so seine Argumentation, werde es gelingen, über dieses procedere den Widerstandswillen der Nation zu stärken und die Verlagerung der Regierung nach Nordafrika plausibel zu machen, ohne Desertionsvorwürfe fürchten zu müssen. ${ }^{250}$ Die Verführungskraft, die der Vorschlag auf die Minister Reynauds ausübte, lag in seiner Ambivalenz: Er erlaubte es dem Gremium, die offene Konfrontation der mittlerweile entstandenen Lager von Befürwortern und Gegnern der Kampfeinstellung zu umgehen und einer klaren Entscheidung weiterhin auszuweichen. Im Ergebnis sank die bisher wirksame Hemmschwelle gegenüber einer Verhandlungslösung, die Meinungsfronten verwischten sich und die Fraktion der „Falken“ im Kabinett erlebte einen beschleunigten Erosionsprozeß. Auch jene Minister, so die rückblickende Deutung Léon Blums, die zuvor eher einer Position der Härte zugeneigt hatten, ließen sich von der Argumentation Chautemps' beeindrucken. ${ }^{251}$ Die naheliegende Überlegung, daß das Bekanntwerden einer derartigen Anfrage fatale Wirkung auf die Kampfmoral in der Armee haben oder daß man sich auf deutscher Seite wohl kaum auf die anvisierte Umkehr der üblichen Reihenfolge von Waffenstillstandsvereinbarung und Bekanntgabe der Bedingungen einlassen würde, scheint, sofern sie angestellt wurde, im Kabinettsrat keine ausschlaggebende Rolle gespielt zu haben. 252

Der Memoirenschreiber Reynaud verortete in der Initiative Chautemps' die Schlüsselstelle einer letztlich erfolgreichen „Intrige“ gegen seine Politik, den „Abfall" eines Mitarbeiters, dem er Vertrauen geschenkt hatte und der im gezielten Zusammenspiel mit Pétain den Waffenstillstand herbeiführte, um die Republik zu stürzen. ${ }^{253}$ Sieht man einmal ab davon, daß die von Reynaud angeführten Äuße-

250 Vgl. die Darstellung bei Reynaud, La France II, S. 340 f.; ders., Au coeur de la mêlée, S. 803 f.; Chautemps, Cahiers secrets, S. 155.

251 Ich schließe mich in den folgenden Abschnitten zur Einschätzug der „proposition Chautemps“ der Argumentation bei Gates, End of the affair, S. 214-218, bes. S. 215 an. Zur Ansicht Blums vgl. seine Aussage vor der parlamentarischen Untersuchungskommission nach Kriegsende: Les événements survenus en France de 1933 à 1945, Annexes (dépositions), Band I, S. 261 (30. 7. 1947).

252 Gates, End of the affair, S. $215 \mathrm{f}$.

${ }^{253}$ Reynaud, Au coeur de la mêlée, S. 809-813. Vgl. auch seine Stellungnahme vor der Kommission 
rungen Chautemps' keineswegs eine Verschwörungstheorie untermauern können, drängen sich darüber hinaus Zweifel auf, ob der Regierungschef den Vermittlungsvorschlag seines Ministers wirklich bereits von Anfang an so grundsätzlich ablehnte, wie er es im nachhinein suggerierte. Vor allem die inhaltliche Ausgestaltung seiner Demarche bei den britischen Alliierten läßt aufhorchen. Hatte er zunächst noch mit dem Gedanken an Rücktritt gespielt, als sich im Kabinett ein Stimmungswandel zugunsten Chautemps' abgezeichnet hatte, entschloß er sich nach kurzer Überlegung dann doch zu der Mission, weil er nach eigenem Bekunden hoffte, im Anschluß an die erwartete britische Ablehnung gestärkt vor seinen Ministerrat zurückkehren $\mathrm{zu}$ können. ${ }^{254} \mathrm{Zu}$ dieser nachträglich vorgelegten Selbstinterpretation stand dann aber der logische Gehalt seiner Äußerungen gegenüber dem britischen Botschafter Campbell und dem Verbindungsoffizier zu Churchill, General Spears, in eigenartigem Gegensatz. Ihnen erklärte der Ministerpräsident am Abend des 15. Juni, daß die britische Regierung im Falle ihrer Zustimmung zur vorgeschlagenen Erkundigungsaktion davon ausgehen könne, daß die Auslieferung der französischen Flotte an Deutschland nicht in Frage käme; bei Ablehnung des Vorschlags habe er hingegen keine andere Wahl, als zurückzutreten. Dann aber könne er nicht garantieren, daß ein eventueller Nachfolger nicht doch zur befürchteten Überstellung der Marineeinheiten bereit sei.255

Der englischen Seite ließ Reynaud damit keinerlei Ansatzpunkte, um das Ersuchen seines Kabinetts, zu dessen Fürsprecher er sich gemacht hatte, abzulehnen. Im Gegenteil: Mit dem Verweis auf das Schicksal der Flotte hatte er britische Lebens-, ja Überlebensinteressen ins Spiel gebracht und zu einem schlagenden Argument umgemünzt. Denn natürlich war ihm genau bekannt, daß man in Großbritannien kaum eine strategische Wendung der Kriegslage mehr fürchtete als die potentielle Vereinigung der deutschen, italienischen und französischen Marinestreitkräfte, wäre doch damit die englische Überlegenheit zur See definitiv beendet und das wertvollste Faustpfand für die Abwehr eines deutschen Invasionsversuchs dramatisch entwertet worden; nicht umsonst hatten die britischen Unterhändler die Flottenfrage seit dem Treffen von Briare am 11. Juni immer wieder angesprochen. ${ }^{256}$ Wie also hätte Reynaud mit nur einigermaßen vertretbarer Wahrscheinlichkeit von der englischen Zurückweisung seiner Anfrage ausgehen können, um darauf, wie er im Rückblick behauptete, eine letzte „Chance für Frankreich“ zur Abwehr der waffenstillstandsfreundlichen Tendenzen in seinem Kabinett zu gründen?257 Und wie kaum anders zu erwarten, reagierte die britische Führung mit der bedingten Annahme, falls die französische Flotte dem deutschen Zugriff entzogen bleibe, bevor sie ihre Zusage in einem überraschenden Coup noch am gleichen Tag durch das Angebot einer britisch-französischen Staatenunion ersetzte.

„Serre“: Les événements survenus en France de 1933 à 1945, Annexes (dépositions), Band VIII, S. $2416 \mathrm{f} .(12.12 .1950)$.

254 Reynaud, Au coeur de la mêlée, S. 807; ders., La France II, S. 341.

$255 \mathrm{Vgl}$. Edward Spears, Assignment to Catastrophe. Band II: The Fall of France, June 1940, Melbourne u.a. 1954, S. 265-270.

256 Gates, End of the affair, S. 217 f., 259 f.; Shirer, Zusammenbruch Frankreichs, S. 859-862.

257 Vgl. Reynaud, La France II, S. 341; ders., Au coeur de la mêlée, S. 807. 
Tatsächlich spricht einiges dafür, daß Reynaud die Idee Chautemps' unterstützte und deshalb die englische Seite bereitwillig darauf vorbereitete, in „ehrenhafter Weise einen Separatfrieden abzuschließen, wenn man dazu gezwungen sei“. Analysiert man seine Erklärungen gegenüber Herriot und Jeanneney, dann hielt er die Anfrage beim deutschen Gegner aus eben jenen "taktischen“ Gründen für nötig, die auch Chautemps ins Feld geführt hatte; die Demarche selbst wollte er jedoch einem Nachfolger überlassen.258 Wohlgemerkt: Paul Reynaud machte sich damit formal lediglich zum Mittler dafür, die englische Haltung zu einem Erkundigungsvorstoß zu sondieren und positiv zu beeinflussen. Dem offiziellen Abschluß einer Waffenstillstandsvereinbarung durch die französische Regierung stimmte er weiter mit keinem Wort zu, und er tat dies auch bis zum Ende seiner Amtszeit nicht. Gleichwohl erweckt sein diplomatisches Vorgehen vor allem anderen den Eindruck der Ambivalenz. Es ist nach dem bisher Gezeigten kaum von der Hand zu weisen, daß er darauf setzte, die französische Politik aus ihrer am 28. März 1940 gegenüber Großbritannien eingegangenen Selbstverpflichtung gleitend und ohne Gesichtsverlust herauszulösen. Das anvisierte Verfahren hätte dabei den Weg bahnen können: Es machte die Entscheidung über den Fortbestand der französisch-englischen Vereinbarung akut und legte sie zugleich in die Hände der britischen Alliierten, ohne daß Reynaud explizit die verpönte Bitte um Suspendierung des Separatfriedensverbots formulieren mußte. Zugleich hätte er sich auch nach der erhofften englischen Zustimmung nicht durch das Gespräch mit dem Feind kompromittiert, was einer möglichen anschließenden Rückkehr ins Amt sicherlich förderlich gewesen wäre. Zu fragen bleibt, ob Reynaud die Katalysatorenwirkung der projektierten Kompromißlösung im Hinblick auf die Entscheidungsbildung im Ministerrat erkannte: Folgt man seiner eigenen Darstellung, war dies durchaus der Fall.259 Dann aber bleibt vor dem Hintergrund des bisher Gesagten nurmehr eine weitere Folgerung: $\mathrm{Da}$ er die Anfrageaktion beim deutschen Sieger als richtig befürwortete, war er spätestens Mitte Juni bereit, nicht nur die Lockerung der britisch-französischen Allianz, sondern darüber hinaus auch eine mögliche rasche Ablösung seiner Durchhaltepolitik zumindest für begrenzte Zeit billigend in Kauf zu nehmen.

Die Umsetzung der "proposition Chautemps“ bildet ein zwar schlagendes, doch keineswegs das einzige Beispiel für die ambivalente, oft improvisierte und nicht widerspruchsfreie Strategie, die der Ministerpräsident angesichts der sich abzeichnenden Niederlage Frankreichs einschlug und die zur glättenden Selbststilisierung, die er rückblickend vortrug, in deutlichem Gegensatz stand.

Zweifellos war Reynaud bei Beginn des deutschen Angriffs ein überzeugter Anhänger des Kampfes mit allen verfügbaren Mitteln und auf unbegrenzte Zeit. Es fällt auch nicht schwer, Beispiele für Äußerungen und Taten auszumachen, in denen er immer wieder und buchstäblich bis zum letzten Tag seiner Amtszeit Ent-

258 „Reynaud rappelle que, cédant au courant, il avait engagé conversation avec Churchill sur les moyens d'envisager honorablement une paix séparée, au cas où l'on y serait acculé. [...] Il ne met d'ailleurs pas en doute que, lorsque l'Allemagne aurait fait connaître ses conditions, il s'ensuivrait contre elle une telle réprobation dans le pays que la volonté de résistance s'en trouverait rétablie chez les hésitants. Il lui paraît "tactique“ de subir cette interrogation, si le Conseil en est d'avis. Mais il répète avec force qu'il s'interdit cela quant à lui." (Jeanneney, Journal politique, S. 74 (16. 6. 1940)). ${ }^{259}$ Vgl. Reynaud, Au coeur de la mêlée, S. 804, 806. 
schlossenheit und Durchhaltewillen signalisierte. $\mathrm{Da}$ er die demoralisierenden Wirkungen der "Drôle de guerre“ früh erkannt hatte, fuhr er mit Blick auf die französische Öffentlichkeit auch nach dem 10. Mai fort, per Rundfunk pathetisch gehaltene Appelle zu Einigkeit und Opferbereitschaft zu formulieren. Im Ministerrat und gegenüber der militärischen Führung hielt er am offiziellen Durchhaltekurs fest, auch als Weygands Plan zur Rettung der durch den deutschen Vorstoß eingeschlossenen Nordarmeen um den 24./25. Mai mißlungen und der Oberbefehlshaber daraufhin zur Überzeugung von der unaufhaltsamen Niederlage gekommen war. Die Argumente, die Reynaud mehrfach gegen den immer offener für die Kampfeinstellung votierenden Weygand vortrug, waren in der Tat naheliegend, auch wenn sie ihre Wirkung auf diesen ebenso wie auf den sekundierenden Pétain verfehlten: daß die einzige Rettung auf lange Sicht in der Zusammenarbeit mit den angloamerikanischen Mächten liege; daß das französische Kolonialreich und seine Flotte nach wie vor intakt seien und als Basis für die Fortsetzung des Kampfes dienen könnten; daß ein Bruch der Vereinbarung mit Großbritannien gegen die nationale Ehre verstoße. ${ }^{260}$ Durchhalten als patriotische Pflicht war Reynaud ein selbstverständliches Anliegen, und auch was er nicht aussprach, blieb als Motiv für sein obstinates Festhalten an der offiziellen Position seiner Regierung von Gewicht: seine Angst vor einem Bürgerkrieg, sobald es zum Friedensschluß käme ${ }^{261}$, und schließlich wohl die Sorge um die persönliche Reputation, hatte er sich doch seit Jahren bereits öffentlichkeitswirksam auf einen Kurs der Härte festgelegt, von dem abzuweichen in jedem Fall den Verlust an Prestige und Einfluß nach sich gezogen hätte.

Die Kapitulation des belgischen Königs in der Nacht vom 27. Mai veranlaßte Reynaud denn auch zu einer äußerst heftigen Stellungnahme gegen Leopold III., in der er wenig verhüllt den Verrat des Monarchen an der gemeinsamen Sache konstatierte und brandmarkte - wohl nicht zuletzt, um entsprechende Tendenzen in seiner Umgebung abzuschrecken. ${ }^{262}$ Nach eigenem Bekunden war dieses Vorgehen Teil einer wohldurchdachten Taktik: Reynaud setzte demzufolge gezielt darauf, jede Diskussion über ein französisches Waffenstillstandsersuchen abzuwehren, gleichzeitig den künftigen Widerstand von Nordafrika aus vorzubereiten und parallel dazu das Kabinett bei Gelegenheit so umzugestalten, daß der Einfluß Weygands und Pétains eingedämmt werden könnte. 263 So schlüssig das Konzept im nachhinein erscheint, so wenig hat doch Reynaud auch nur ein einziges der gesteckten Ziele erreicht. Mehr noch: Bereits zeitgenössische Beobachter taten sich wenige Wochen nach Beginn der Kampfhandlungen schwer damit, die reklamierte Zielstrebigkeit als durchgehende Haltung Reynauds zu identifizieren. In der Pariser Öffentlichkeit konnte das kämpferische Auftreten des Ministerpräsidenten bereits gegen Ende Mai nicht mehr überzeugen, und es ging die Rede von der eigentlichen „Fragilität“ des Regierungschefs hinter der vorgeblichen „fermeté“. Dem

260 Reynaud, Au coeur de la mêlée, S. 567 f.

261 Villelume, Journal d'une défaite, S. 425.

262 Ausführlich dazu und zu den Nachkriegskontroversen um das Verhalten von Leopold III., in denen auch Reynaud aufgrund seiner heftigen Angriffe unter Beschuß geriet: Reynaud, Au coeur de la mêlée, S. 628-684; Gates, End of the affair, S. $134 \mathrm{f} ., 157$.

${ }^{263}$ Reynaud, Au coeur de la mêlée, S. 570, 575; Gates, End of the affair, S. $135 \mathrm{ff} ., 157 \mathrm{ff}$. 
britischen Botschafter Campbell schienen die Erklärungen Reynauds zum gleichen Zeitpunkt „eher vom Kopf als vom Herzen“ zu kommen, weswegen er unsicher blieb, ob dieser in seinen Entschlossenheitsbekundungen „völlig aufrichtig" sei oder nicht doch irgendwann einem neuen, zum Separatfrieden drängenden Kabinett Platz machen würde. ${ }^{264}$

Wie läßt sich nun dieses widersprüchliche Erscheinungsbild plausibel auflösen und wo lagen seine Wurzeln? Der rasche Zusammenbruch der französischen Militärmacht hatte auch Reynaud völlig überraschend getroffen. Nicht daß er sich Illusionen gemacht hätte: Als Finanzplaner und Miliärreformer wußte er mehr als viele andere Politikerkollegen um potentielle Schwachstellen in der Kriegsvorbereitung seines Landes, und aus den Tatsachen, die er kannte, leitete er die strukturelle Unterlegenheit Frankreichs ab. Sorge bereitete ihm vor allem die demographische Situation und die Rüstungsproduktion, von der er annehmen mußte, daß sie erst bis Herbst 1940 das notwendige Minimum an Waffen liefern würde. ${ }^{265} \mathrm{Da}$ neben kann davon ausgegangen werden, daß sein Vertrauen in die Führungsstärke und die strategischen Konzepte der Militärs seit den Kontakten mit de Gaulle geschwunden war. Dem Zweckoptimismus Gamelins brachte er einiges Mißtrauen entgegen, seitdem er im Herbst 1939 die Erfahrung hatte machen müssen, daß dieser auf seine drängenden Erkundigungen nach dem Vorbereitungsstand der Armee, dem Schutz der französischen Produktionsstätten oder den Lehren, die man aus dem deutschen Vorgehen in Polen zog, nur zu unbefriedigenden Auskünften in der Lage war. ${ }^{266}$ Im Oktober 1939 ging Reynaud davon aus, daß die deutsche Seite die Situation nutzen und bald zur Offensive übergehen würde. Unabhängig davon bereitete er Frankreich als Finanzminister entschlossen auf den Krieg vor auf einen längerdauernden Krieg freilich, der genügend Atem lassen würde, die bestehenden Defizite aufzuholen. Der schnelle Durchbruch der deutschen Panzerkolonnen, wie er sich im Mai 1940 einstellte, überstieg bis dahin schlichtweg auch sein Vorstellungsvermögen. Um so deutlicher scheint er relativ bald nach Beginn der Kampfhandlungen zur Einsicht in die Niederlage gekommen zu sein. Ein knappes Jahr vor seinem Tod und mittlerweile fern den Rechtfertigungskämpfen der ersten Nachkriegsjahre räumte Reynaud ein, daß er bereits um den 18. Mai 1940 in erster Linie nurmehr die „Ehre der Armee“ habe retten wollen. Seine einzige realistische Möglichkeit habe im Hinarbeiten auf eine „ehrenvolle Niederlage“ bestanden. ${ }^{267}$ Diese Aussage korrespondiert mit der Einschätzung des amerikanischen Botschafters Bullitt, der in seinen Aufzeichnungen berichtet, Reynaud habe um diese Zeit bereits mit der Möglichkeit einer „absoluten Niederlage Frankreichs und Englands" gerechnet. ${ }^{268}$

Die Bewältigung des Dilemmas, das sich daraus ergab, stand als Leitmotiv über den folgenden politischen Bemühungen des französischen Ministerpräsidenten

${ }_{264}$ Dic Gerüchte finden sich bei: Jeanneney, Journal politique, S. 59 (30. 5. 1940); die Aussagen Campbells sind zitiert nach Gates, End of the affair, S. 156, der dabei unveröffentlichtes britisches Material wiedergibt.

265 Villelume, Journal d'unc défaite, S. 62 (Eintrag v. 10. 10. 1939), 177 (31. 1. 1940).

266 Ebenda, S. 61.

267 Brief Reynauds an William L. Shirer, 29. 8. 1965; zitiert nach Shirer, Zusammenbruch Frankreichs, S. 734.

268 Telegramm Bullitt, 18. 5. 1940 (FRUS 1940/1, S. 229). 
bis zu seinem Rücktritt am 16. Juni. Eine „ehrenhafte“ Lösung zu finden im politischen Dreieck zwischen Kabinett, militärischer Führung und britischem Allianzpartner, ohne von der englisch-französischen Separatfriedensvereinbarung offen abzugehen: Das hieß für Reynaud, einen gewagten Balanceakt zu vollführen zwischen betonter Härte intern und dem parallelen Bemühen, den englischen Premierminister in verklausulierter, doch zunehmend deutlicher Form auf den französischen Zusammenbruch vorzubereiten. Solange die englische Seite nicht einlenkte, blieb die Fortsetzung des Kampfes Reynauds erste Option - ob aus voller innerer Überzeugung, darf hingegen bezweifelt werden. Die Möglichkeiten für einen Rückzug der Regierung in die Bretagne oder nach Nordafrika ließ er erkunden, ohne daß diese Pläne bis zum Zusammenbruch wirklich realisierbare Formen angenommen hätten.

Der politisch-militärische Diskurs zwischen den beiden Staatsführungen hat Reynaud nicht die erhofften neuen Handlungsmöglichkeiten eröffnen können; eher trug er neben der sich ständig verschärfenden Kriegslage und den wachsenden Widerständen im eigenen Lager dazu bei, seine Spielräume weiter zu verengen. Churchill war seit etwa Mitte Mai für die Möglichkeit einer französischen Niederlage sensibilisiert und erkannte Reynauds Anliegen natürlich, spielte aber ebenfalls auf Zeit und reagierte elastisch: Aus der am 28. März eingegangenen Verpflichtung eindeutig entlassen hat er die französische Führung bis zuletzt nicht.269 Statt dessen setzte er auf ein kombiniertes Vorgehen, um den Verbündeten zur Fortsetzung des Kampfes zu bewegen. Das wichtigste Faustpfand war dabei zunächst die englische Militärhilfe insbesondere in Form von Luftunterstützung, die er auf nahezu tägliche Bitten Reynauds hin und gegen den Rat der eigenen Stabschefs zu forcieren suchte. Als am 8. Juni auch für ihn der Punkt erreicht war, an dem sich der Einsatz weiterer geforderter Staffeln um der Sicherheit Großbritanniens und der Fortsetzung des Krieges willen verbot, schwächte dies zwangsläufig die Position Reynauds gegenüber dessen nunmehr erklärten Widersachern Pétain und Weygand. Churchills psychologisch geschicktes Taktieren, seine fortwährenden Versicherungen, Großbritannien werde den Kampf in jedem Falle fortsetzen, haben Reynaud persönlich zweifellos auch danach immer wieder darin bestärkt, an seiner einmal eingeschlagenen Linie festzuhalten. Als aber der englische Premier in der zweiten Juniwoche dazu überging, seine Vorstellungen von Straßenkämpfen in Paris, vom Einsatz der Guerillataktik in der Provinz und von der Hoffnung auf künftig gesteigerte Waffenlieferungen zu entwickeln, stieß er damit auch bei Reynaud auf nurmehr wenig positive Resonanz, ganz zu schweigen von dessen Antagonisten im sich entfaltenden Schlußteil des Dramas. ${ }^{270}$

Der Ministerpräsident manövrierte sich mit seinem einsamen Agieren zwischen den Parteien in die Rolle eines diplomatischen Vermittlers, dessen Vertrauenskredit zunehmend schwand. Angesichts der auseinanderdriftenden Positionen von britischem Kabinett und Waffenstillstandsanhängern in der französischen Führung verlor seine Politik in der Wahrnehmung beider Seiten an Kontur und Über-

269 Duroselle, L'abîme, S. 217 f.; Gates, End of the affair, S. $124 \mathrm{ff}$.

270 Vgl. dazu den Verlauf des Treffens von Briare am 11. Juni 1940: Duroselle, L'abîme, S. 207-212; Gates, End of the affair, S. 172-175. 
zeugungskraft. Als williger Übermittler von Vorstößen der Friedensfraktion und eigenen Kompromißideen erzeugte er in London Bedenken ob seiner Verläßlichkeit, auch wenn er formal unbeirrt zu bleiben schien; als Durchhaltestratege, der sich nicht scheute, eigenmächtig Entschlossenheitserklärungen für sein Kabinett abzugeben oder den Gesprächszugang seiner Minister zu Churchill zu begrenzen, erregte er das Mißtrauen der Schwankenden im eigenen Kabinett und vermehrte das Lager seiner internen Opponenten. ${ }^{271}$

Ein Beispiel für die verzweifelte Suche nach einem akzeptablen Ausweg aus der politisch-militärischen Zwangslage stellten bereits Reynauds Gespräche in London vom 26. Mai dar. Ohne offen die mögliche Einstellung der Kämpfe durch Frankreich anzusprechen, gab er hier eine dramatische Schilderung der militärischen Situation, überzeichnete die Einigkeit seines Kabinetts mit Weygand bezüglich eines baldigen Endes der französischen Widerstandskraft und gab sich wenig zuversichtlich im Hinblick auf amerikanische Hilfsleistungen. Darüber hinaus war er offensichtlich bestrebt, eine gemeinsame britisch-französische Intervention bei Mussolini anzuregen mit dem Ziel, diesen gegen territoriale Zugeständnisse als Mittler für eine Friedensregelung mit Deutschland zu aktivieren. Erst als das britische Kriegskabinett das Vorhaben nach einigem Zögern ablehnte, nahm auch Reynaud Abstand davon. Die Abfassung einer abgeschwächten Note, die dem italienischen Botschafter auf Initiative Daladiers, de Monzies und Baudouins dennoch übergeben wurde, konnte oder wollte Reynaud dagegen nicht verhindern. Spätestens nach dieser Aussprache vom 26. Mai war Churchill klar, daß nicht nur mit einer französischen Niederlage, sondern darüber hinaus auch mit dem Ausscheiden der Alliierten aus der gemeinsamen Front gerechnet werden mußte. ${ }^{272}$ Am 13. Juni erneuerte Reynaud dann in der bis dahin wohl direktesten Weise seine Vorstöße: Während eines Treffens mit dem englischen Premierminister in der Präfektur von Tours sondierte er in hypothetisch gehaltenen, doch von Churchill durchaus eindeutig verstandenen Ausführungen die englische Haltung im Hinblick auf den Abschluß eines Separatfriedens durch Frankreich, ohne freilich eine andere als aufschiebende Antwort zu erhalten. ${ }^{273}$

$\mathrm{Zu}$ wirklich klaren, wenngleich schmerzhaften und risikobehafteten Entscheidungen konnte Reynaud sich weder in der einen noch der anderen Richtung durchringen. Vor der Entlassung des Wortführers der Waffenstillstandsbefürworter, Weygand, schreckte er zurück, da er den Bruch scheute, die Opposition der Widerspenstigen fürchtete und offenbar lange auf deren Einbindung hoffte. Ganz grundlos scheint allerdings seine Sorge vor möglichen bewaffneten Widersetzlichkeiten der Militärs im Anschlư an eine derartige Entscheidung nicht gewesen zu

271 Zum Ablauf des französisch-britischen Treffen von Tours am 13. Juni und zum Lavieren Reynauds: Gates, End of the affair, S. 187-205.

272 Insgesamt zu dieser Episode und ihrer Deutung: Duroselle, L'abîme, S. 188-193; pointierter und weitergehend im Hinblick auf Reynauds Vorschläge u.a. anhand unveröffentlichter englischer Aufzeichnungen: Gates, End of the affair, S. 143-154. Vgl. auch die Aussage von Reynauds Mitarbeiter de Villelume: Les événements survenus en France de 1933 à 1945, Annexes (dépositions), Band IX, S. 2785.

${ }^{273}$ Reynaud, Au coeur de la mêlée, S. 771; zu seiner Deutung des eigenen Verhaltens als bloßc Darlegung der Ansichten seiner Widersacher: ebenda, S. 774-776; zum Verständnis der englischen Gesprächspartner: Spears, Assignment to Catastrophe II, S. 207-209; Winston S. Churchill, The Second World War. Band II: Their Finest Hour, Boston 1949, S. 178-182. 
sein. ${ }^{274}$ Seine Umbildungen in Kabinett und Beraterkreis vom 18. Mai und 5. Juni blieben ambivalent und stellten keineswegs eine homogene Regierungsmannschaft von "durs" her. Abgesehen etwa von den bereits erwähnten personellen Mißgriffen in bezug auf Bouthillier oder Baudouin erstaunt besonders die Entlassung des englandfreundlichen und italophoben Generalsekretärs des Quai d'Orsay, Alexis Léger, der offenbar der Anbahnung einer Italieninitiative weichen mußte. Mit Oberst Paul de Villelume berief Reynaud am 19. Mai einen Offizier zum Leiter seines „Cabinet de Défense nationale“, den er im Oktober 1939 als Anhänger eines Verständigungsfriedens mit Deutschland kennengelernt hatte und seither regelmäßig in militärisch-politischen Fachfragen zu Rate zog. Gegner des französischen Kriegseintritts wie des Kampfes um jeden Preis und bekanntermaBen der „Friedenspartei“ nahestehend, konkurrierte Villelume mit dem „Falken“ de Gaulle seit Kriegsbeginn um Einfluß auf den gemeinsamen Mentor. Dieser faßte Villelume im März 1940 als Kabinettschef für Auswärtige Angelegenheiten ins Auge und gewährte ihm schon vor der Berufung im Mai privilegierten Zugang zum innersten Kreis. 275 Das konfliktträchtige Nebeneinander der beiden militärischen Exponenten gegensätzlicher Strömungen und auch die Tatsache, daß es offensichtlich bewußt herbeigeführt wurde, wirft deshalb ein weiteres bezeichnendes Licht auf den politischen Krisenbewältigungsstil des Ministerpräsidenten.

Was ihm einerseits als persönliche Technik der Entscheidungsbildung diente, um in der Rolle des Schiedsrichters über den widerstreitenden Meinungen zum Urteil zu gelangen, konnte im weiteren politischen Sinne dazu verhelfen, die Anhänger beider Lager zufriedenzustellen und personelle Ressourcen für alle „Eventualitäten" bei der Hand zu haben. ${ }^{276}$ Noch im Juni 1940 stellte Reynaud seine Regierungsmannschaft „dosiert" zusammen und nahm dabei die Anwesenheit potentieller Widersacher in der Waffenstillstandsfrage billigend in Kauf. Auch nach der Entlassung der profiliertesten Verhandlungsbefürworter, Arbeitsminister Anatole de Monzie und Finanzminister Lucien Lamoureux, beließ er den stellvertretenden Ministerpräsidenten Chautemps im Amt, obwohl dieser bekanntermaßen einer der wichtigsten Anhänger des Münchener Abkommens und der damit verbundenen Deutschlandpolitik gewesen war. ${ }^{277}$ Es mochte ein Akt politischer Klugheit gewesen sein, so zu handeln; in dem Moment, da der politische Pol, auf den das System zugeordnet war, an Bindekraft und Autorität verlor, konnten starke zentrifugale Tendenzen nicht ausbleiben.

Festzuhalten bleibt allerdings, daß dem ambivalenten Erscheinungsbild, das Reynaud in seiner Doppelrolle des Durchhaltestrategen und des Friedenserkun-

274 Die Absicht zur Absetzung Weygands erwähnt Reynaud nur knapp in seinen Memoiren, geht dann aber nicht mehr näher darauf ein: Reynaud, Au coeur de la mêlée, S. 802, 849; ders., La France II, S. 177 f.; zu seiner Andeutung eines möglichen Komplotts Weygands: ebenda, S. 443446. Zur Bewertung: Gates, End of the affair, S. 416-418. Die Furcht Reynauds, gegen Weygand und Pétain regieren zu müssen, findet sich thematisiert bei Spears, Assignment to Catastrophe II, S. 259.

275 Zur Person Légers: Duroselle, L'abîme, S. 69-73; zum Verhältnis Villelume-Reynaud: Villelume, Journal d'une défaite, S. 49-52 (2. 10. 1939), 176-178 (31.1. 1940), 245-249 (23./24. 3. 1940), 340342 (19. 5. 1940) und passim.

${ }_{276}$ Die letztgenannte Interpretation deutet bereits ganz knapp an: René Rémond, Préface, in: Villelume, Journal d'une défaite, S. XIf. (Zitat: S. XII).

${ }_{277}$ Zum Revirement vom 5. Juni 1940: Gates, End of the affair, S. $165 \mathrm{f}$. 
ders bald in den Augen von Mitarbeitern, englischen Verhandlungspartnern und Öffentlichkeit bot, weniger ein Übermaß an politischer Beeinflußbarkeit oder psychischer Schwäche zugrundelag als seine letztlich realistische Einschätzung der militärischen Lage seit Mitte Mai bzw. seine pessimistische Deutung der Kräfteverhältnisse zwischen Frankreich und Deutschland. In Form einer ähnlich gelagerten Doppelstrategie von Verhandlungsbereitschaft und Aufrüstungswillen hat Reynaud unter anderen Bedingungen schon vor Mai/Juni 1940 gangbare Alternativen zum Krieg gesucht; entsprechend orientierte Fachleute wie Villelume hat er nicht zufällig in seinen Beraterkreis integriert. Auch die persönliche Disposition dazu, die "wahrscheinlichen ökonomischen und sozialen Verheerungen " wie auch die „Verluste an Leben und Besitz“ als Folgen des Kriegs „im Interesse des französischen Volkes" zu begrenzen, brachte er bereits in sein Ministerpräsidentenamt mit. ${ }^{278}$ Es war somit eher die seit längerem angelegte, rational begründete Ambivalenz in seinem deutschlandpolitischen Denken und in seiner Kriegspolitik überhaupt, die ihn dazu bewog, widerstreitende Tendenzen in seiner nächsten Umgebung zu dulden und zu fördern - nicht umgekehrt.279

Einer Politik der „lutte à outrance" 280 , wie Reynaud sie im nachhinein für sich reklamierte, entsprach das gleichwohl nicht. Statt in der kraftvollen Leitung der Kriegführung suchte der Ministerpräsident die Wege aus dem Debakel immer wieder im politisch-diplomatischen Bereich - und dies so ausdauernd, daß Senatspräsident Jeanneney ihn schließlich ermahnen mußte, als Kriegsminister den militärischen Aspekt der Situation nicht aus den Augen zu verlieren. ${ }^{281}$ Selbst den möglichen letzten und konsequentesten Akt nationalen Widerstands - den Transfer der Regierung nach Nordafrika - behandelte Reynaud bis zuletzt als eine in erster Linie allgemein politische Option. Er hat sie zweifellos seit dem deutschen Durchbruch bei Sedan am 16. Mai als Alternative ins Auge gefaßt und kontinuierlich bis zu seinem Rücktritt gegenüber allen Widersachern verteidigt. Sie blieb jedoch unter seiner Ägide vor allem Gegenstand theoretischer kabinettsinterner Erörterungen und interalliierter Verhandlungen: Erst am 5. Juni hat er seinen Unterstaatssekretär de Gaulle damit beauftragt, entsprechende Truppentransporte logistisch vorzubereiten. Zu keinem Zeitpunkt aber befaßte er sein Kabinett mit konkreten Planungen oder energischen Bestandsaufnahmen im Hinblick auf die Fortsetzung des Krieges von Frankreichs kolonialen Besitzungen aus. ${ }^{282}$

Reynaud handelte auch unter den Bedingungen des Krieges in mehrfacher Hinsicht als Politiker - und als Zivilist: Im Sinne einer professionellen Prägung zu-

278 Vgl. seine Äußerung gegenüber dem Abgesandten Roosevelts, Sumner Welles, im Frühjahr 1940: „[...] He [d.h. Reynaud, A.d.V.] said that if a practical scheme could be devised, upon the basis of an international air force as a police power, and the abolition of all categories of offensive armament, he would support such a negotiation, believing it to be infinitely more in the interests of the French people than the continuation of the present war, with the probable economic and social havoc and ruin which would result, quite apart from the inevitable losses in life and property. [...]" (Sumner Welles an Roosevelt, 9. 3. 1940; FRUS 1940, Band I, S. 71). Siehe hierzu auch Kapitel X.2.b) dieser Arbeit.

279 Vgl. diesen letzten Gedanken auch bei Berl, Fin de la III ${ }^{e}$ République, S. 68.

280 Reynaud, Au coeur de la mêlée, S. 818.

281 Jeanneney, Journal politique, S. 59 (30. 5. 1940).

282 Schunck, Charles de Gaulle, S. 142f., 150; Gates, End of the affair, S. 130, 165, 184, 212, 237, $303-$ 306. 
nächst, die ihm bei allem kämpferisch-entschlossenen Auftreten das Streben nach Kompromissen, das Austarieren politischer Gewichte und die Sorge um den schnellen, sichtbaren Erfolg zur zweiten Natur hatte werden lassen. Dem nüchternen Dialektiker, der er war, fehlte darüber hinaus in der entscheidenden Periode seines politischen Lebens nicht die Kraft zur Einsamkeit, wohl aber die Fähigkeit, sich über unmittelbare Widerstände mit Blick auf eine notwendigerweise einseitige „Rettervision“ hinwegzusetzen. Sein Mitarbeiter de Gaulle spürte das und reagierte auf die Haltung des Ministerpräsidenten am Abend des 13. Juni mit einem Rücktrittsgesuch, das er erst auf Intervention Mandels zurückzog. ${ }^{283}$ Zweifellos wäre Reynaud gerne eine politisch-militärische Führerfigur vom Range Clemenceaus geworden: Daß er Georges Mandel, ehemals Mitarbeiter des „Tigers“, zum Innenminister berief und Pétain am 18. Mai öffentlich als den „Sieger von Verdun" an seine Seite holte, hatte symbolischen Wert. ${ }^{284}$ Anders aber als seinem Staatssekretär de Gaulle war Reynaud ein bis ins Mythische verklärter, außerhalb politischer Kategorien angesiedelter Nationsbegriff als tragende Grundlage seines Handelns fremd. Reynauds Patriotismus blieb rational eingehegt und definierte sich in hohem Maße aus der Rückbindung an die bestehende republikanische Ordnung. Wie de Gaulle schöpfte er seine zumindest anfängliche Handlungszuversicht aus dem Vertrauen in die so oft bestätigte eigene Analyse- und Durchsetzungsfähigkeit. Mehr als de Gaulle glaubte Reynaud hingegen an die Kraft des etablierten politischen Diskurses, widerstreitende Interessen zusammenzubinden, wenn die Verantwortlichen nur klug genug agierten. Bis in die letzten Stunden seiner Amtszeit bewegte sich Reynaud deshalb auf der Suche nach einem tragbaren Konsens in den Grenzen republikanischer Legitimität und kabinettspolitischer Usancen. Die Usurpation der Macht oder auch nur die Aufkündigung der Loyalitäten, über die er sich an die Exponenten des demokratisch legitimierten Staates gebunden glaubte, lag für ihn außerhalb des Denkbaren.

Ein im Desaster politisch Handelnder aus Prägung und aus republikanischer Überzeugung einerseits, war Reynaud doch drittens auch ein Getriebener, der sich im Verlauf des Debakels unfreiwillig in zunehmendem Maße aus der Gesamtleitung der Kriegführung in die Sphäre des Politischen abgedrängt sah. Spätestens seit der grundlegenden operativen Entscheidung Weygands vom 25. Mai, eine letzte Verteidigungsposition an der Linie Somme-Aisne-Montmédy zu errichten, ohne gleichzeitig eine Rückfallposition in Nordafrika vorzubereiten, waren entscheidende Weichen gestellt; danach verringerte sich der Spielraum des Ministerpräsidenten kontinuierlich. Die Obstruktions- und Insubordinationshaltung Weygands rückte eine eventuelle Evakuation aus dem Bereich des Möglichen, und dies deutlich bevor sich der Oberbefehlshaber am 15. Juni weigerte, über eine

283 Lacouture, Charles de Gaulle I, S. 337f.; Schunck, Charles de Gaulle, S. 149 f.; zum Text des Gesuchs: de Gaulle, Lettres, notes et carnets, juin 1940 - juillet 1941, S. 477 f.

${ }_{284}$ Vgl. auch den Eindruck des Diplomaten Jean Chauvel: Ders., Commentaires. Band I: De Vienne à Alger (1938-1944), Paris 1971, S. 82. Allgemeiner zur Vorbildwirkung der politisch-militärischen Führung des Ersten Weltkriegs im Jahr 1940: Duroselle, L'abîme, S. 52 f.; Pierre Servent, Le mythe Pétain. Verdun ou les tranchées de la mémoire, Paris 1992, S. $236 \mathrm{f}$. 
militärische Kapitulation nach holländischem Vorbild den nötigen zeitlichen Aufschub für die Aktion zu beschaffen. 285

Paul Reynaud trat am 16. Juni 1940 zurück, weil seine seelische Widerstandskraft erschöpft war und weil die allzu subtile Taktik, die er gewählt hatte, keinen politischen Ausweg aus der sich abzeichnenden militärischen Katastrophe und den aufbrechenden Spannungen im Ministerrat hatte eröffnen können. Es fällt schwer, sich dem Eindruck zu entziehen, daß Reynaud im Juni 1940 ein bestimmtes, „ideales“ Ablaufszenario des zu erwartenden Desasters vor Augen hatte: die Vision nämlich, ein in patriotischer Anstrengung geeintes Frankreich werde unter der Führung eines überparteilich entschlossenen Kabinetts so lange wie möglich an der Seite Großbritanniens kämpfen, um dann in aussichtsloser Lage und nach "erfüllter Pflicht“ in ehrenvoller Weise aus dem Kampf ausscheiden zu können. Mitte Juni stand Reynaud vor den Trümmern dieser Wunschvorstellung, weil er allzu lange versucht hatte, Unvereinbares zusammenzubinden. So hatte er es letztlich weder fertiggebracht, seine Minister und Militärs auf die Fortsetzung des Kampfes einzuschwören, noch war es ihm alternativ dazu gelungen, mit den Briten im Hinblick auf eine eventuelle Kampfeinstellung Frankreichs ins reine zu kommen. Über seine ambivalent gehaltene Intervention zugunsten der „proposition Chautemps" hat er ein letztes Mal versucht, die Interessen seines Kabinetts und der britischen Allianzpartner anzugleichen, ohne selbst offen Stellung zu beziehen. Die endgültige englische Reaktion, der Vorschlag einer Staatenunion, verschaffte ihm noch einmal für einen Moment die Chance, das Dilemma, das ihn umtrieb, auf erlösende Art aufgehoben statt entschieden zu sehen. Nach der empörten Ablehnung durch die Mehrheit seiner Minister am Nachmittag des 16. Juni stellte sich die Frage einer Demarche beim deutschen Gegner jedoch erneut und brachte ihn in eine unhaltbare Situation.

Als Resultat seiner Strategie, die eine klare Entscheidung scheute, war zuletzt das Gewicht der Tatsachen ausschlaggebend geworden: In diesem umfassenden Scheitern lag die eigentliche Ursache seines Rücktritts. Es ist deshalb wenig hilfreich, einmal mehr nur der Frage nachzugehen, ob er die Mehrheitsverhältnisse unter seinen Ministern für und gegen die Einstellung der Kampfhandlungen richtig kalkuliert oder etwa einen voreiligen Entschluß gefaßt hat. Auch scheint es erst in zweiter Linie von Bedeutung, ob er in den Gesprächen, die er in verfassungskonformer Weise kurz vor seinem Rücktritt mit Lebrun, Jeanneney und Herriot führte, größeren oder kleineren Entscheidungsspielraum hatte, um eventuell als Chef eines Kabinetts von Waffenstillstandsgegnern weiterzuarbeiten. 286 Paul Rey-

${ }^{285}$ So die These bei: Philip C.F. Bankwitz, Maxime Weygand and the Fall of France: A Study in CivilMilitary Relations, in: The Journal of Modern History 31 (1959), S. 225-242, hier: S. 230-232.

Die Frage, ob eine Fortsetzung der Kämpfe von Nordafrika aus möglich und wünschenswert gewesen wäre, hat bis heute äußerst kontroverse Einschätzungen hervorgerufen. Ihre Erörterung übersteigt indes den Rahmen dieser Arbeit bei weitem. Vgl. dazu die Literaturangaben bei Bankwitz, Fall of France, S. 230; als Beispiele für die Argumentation von Befürwortern und Gegnern seien genannt: Truchet, L'armistice de 1940 et l'Afrique du Nord; Hervé Coutau-Bégarie/Claude Huan, Darlan, Paris 1989, S. 250-263.

286 Diese Fragen haben in Frankreich bis in die sechziger Jahre hinein hitzige Debatten über die Verantwortung des Kabinetts Reynaud für die Machtübernahme Pétains ausgelöst, die vor allem in den Erinnerungsschriften von Beteiligten und im Verlauf der ersten Nachkriegsprozesse ausgetragen wurden. Vgl. vor allem: Louis Marin, Contribution à l'étude des prodromes de l'armistice, in: 
naud wollte zurücktreten, weil er es als „taktisch“ klug erachtete, die deutschen Waffenstillstandsbedingungen $\mathrm{zu}$ erkunden, dadurch einen belastenden politischen „Abszeß“ unschädlich zu machen, den Widerstandswillen der Nation zu stärken und eventuell auf den Wogen der Empörung an die Macht zurückzukehren. ${ }^{287} \mathrm{Da}$ er die Ausführung der Anfrageaktion ablehnte, Lebrun jedoch in seiner Interpretation der Mehrheitsmeinung im Kabinett auf ihr beharrte, konnte nach Lage der Dinge nur Pétain als neuer Ministerpräsident in Frage kommen.

Wichtig für die Beurteilung der Politik Reynauds erscheint die Überlegung, ob seine Krisenbewältigungstaktik als Ganze und schon im Ansatz als verfehlt anzusehen war. Der historische Befund gebietet es, hierbei zwischen dem politischen Umgang mit der drohenden Niederlage und der Tatsache des nachfolgenden Regimewechsels deutlich zu trennen. In beiderlei Hinsicht wird der Befund zwiespältig ausfallen müssen.

Reynauds Spiel mit mehreren politischen Bällen, das er nach einer Phase kurzlebiger Erfolge im Mai 1940 aufnahm, verfügte aus einer Reihe von äußeren Gründen über geringen Entfaltungsraum. Die wichtigsten sind im Verlauf dieser Darstellung bereits angeführt worden: die Tatsache, daß die Kriegslage schnell aussichtslos wurde, an erster Stelle; der Umstand, daß Reynaud nicht über genügend Rückhalt in der politischen Landschaft Frankreichs verfügte, um die Kräfte hinter sich zu einen; schließlich das Aufflackern eines veritablen innenpolitischen Machtkampfes mit Maxime Weygand, dessen Schärfe sich nicht aus militärstrategischen Dissonanzen allein, sondern nur unter Berücksichtigung der jahrzehntealten Vorbehalte des Generals gegenüber republikanischen Institutionen und Politikern erklären läßt. Daneben aber hatte Reynaud selbst großen Anteil daran, daß er sich Mitte Juni in jener Sackgasse wiederfand, deren Konsequenz sein Rücktritt war: weil er den entscheidenden, wenn auch riskanten Befreiungsschlag - die Entlassung Weygands - nicht gewagt, die wachsende Eigendynamik seiner doppelbödigen Strategie unterschätzt und so letztlich seine politische wie moralische Autoritätsposition zerstört hatte. Das politische Spiel im richtigen Moment zu beenden und ohne Vorbehalte eine einzige Option zu ergreifen hat Paul Reynaud bis zum Schluß versäumt: Noch im Rücktritt, der eigentlich keiner sein wollte, manifestierte sich die gefährliche Ambivalenz seiner Politik.

Das Ende der Republik in Frankreich ergab sich nicht notwendigerweise aus der Niederlage und dem umstrittenen Abschluß des „armistice“, für den Reynauds Rücktritt den Weg bereitet hat. Beides trug dazu bei, das lange aufgestaute, verbreitete Ungenügen an der Funktion der republikanischen Institutionen zu ak-

Revue d'Histoire de la Deuxième Guerre Mondiale 1 (1951), S. 1-26; eine dichte Zusammenstellung der Zahlenexempel, die vor allem die beteiligten Minister in der Rückschau vorlegten, bietet einmal mehr Gates, End of the Affair, S. 424-427.

$\mathrm{Zu}$ den Entscheidungsspielräumen des Ministerpräsidenten in kontroverser Einschätzung: Bankwitz, Fall of France; dagegen: Chautemps, Cahiers secrets, S. 175 f.; Georges Bonnet, Quai d'Orsay, Isle of Man 1965, S. 290. Vgl. auch die abwägende Wertung von Jean-Noël Jeanneney in: Jeanneney, Journal politique, S. 414-417, Anm. 130; Gates, End of the Affair, S. 241-243, 520f.

287 Vgl. seine bereits erwähnte Äußerung gegenüber Jeanneney und Herriot am 16. Juni 1940, gegen 21 Uhr (Jeanneney, Journal politique, S. 74). Kritiker wie Anhänger Reynauds gehen davon aus, daß er zumindest eine Zeitlang mit der erneuten Berufung rechnete: vgl. Charles Pomaret, Le dernier témoin. Fin d'une guerre, fin d'une république. Juin et juillet 1940, Paris 1968, S. 95; Leca, Rupture de 1940, S. 233 f. 
tualisieren, die politischen „Verantwortlichen“ für das Desaster zu diskreditieren und das Verlangen nach überparteilicher Führung durch den Weltkriegsmarschall beim politischen Personal der Republik überstark werden zu lassen. Ausschlaggebend für die autoritär geprägte Verfassungsreform vom 10. Juli wurde aber daneben das entschlossene und geschickte Manövrieren einer Gruppe von republikfeindlichen Politikern um Laval und Alibert. ${ }^{288}$ Dennoch kann es nicht anders als eine traurige Ironie der Geschichte bezeichnet werden, daß ausgerechnet einer der entschiedensten republikanischen Reformer der Dritten Republik jener personellen Konstellation den Weg an die Macht freigab, die das ganze Gebäude zum Einsturz brachte.

\section{c) Vom Subjekt zum Objekt der Politik: Abschied von der Macht, Inhaftierung und Deportation}

Nach der Rücktrittsentscheidung, die Reynaud ohne Beratung mit seinem Kabinett am Abend des 16. Juni fällte, hat er offenkundig versucht, auf der politischen Bühne präsent zu bleiben. Er hielt sich zwar diskret den Abgeordnetenzirkeln um Herriot und Jeanneney fern, die er zuvor regelmäßig frequentiert hatte, verließ aber Bordeaux zunächst nicht. Jene, die ihn in diesen Tagen bis zu seiner Abreise am 26. Juni 1940 aus nächster Nähe erlebten, registrierten in seinem Verhalten Niedergeschlagenheit und Melancholie, gemischt mit einem Gefühl der Erleichterung über die abgeworfene Last. Selbst gegenüber engen Mitarbeitern schwieg er sich aber aus über seine nächsten Absichten, wartete ab, wie sein Nachfolger vorgehen würde. Spears und Botschafter Campbell, die ihn am Abend des 16. Juni zu einem Gespräch aufsuchten, gewannen den Eindruck eines Mannes, der bestrebt war, gegenüber den Alliierten weiter Haltung zu bewahren, und der davon ausging, schon bald ins Amt zurückzukehren. Reynaud schien davon so überzeugt, daß er Spears noch am 16. Juni um die Bestätigung eines Treffens mit Churchill am nächsten Tag in Concarneau bat. In der Wahrnehmung der Briten entsprangen die Einlassungen ihres Gesprächspartners allerdings eher einem Prozeß erfolgreicher Autosuggestion als realistischer Einschätzung der Gegebenheiten.289

Eine knappe Woche lang hat sich Paul Reynaud widerstreitenden Hoffnungen hingegeben, deren Gehalt allenfalls vermutet werden kann. Fest steht, daß er keineswegs den Bruch mit seinem Nachfolger suchte, dessen Haltung er in den letzten Wochen so vehement verurteilt hatte. Seit dem 18. Juni spielte er mit dem Gedanken, den Posten des Botschafters in den USA anzunehmen, da ihm Pétain ein entsprechendes Angebot gemacht hatte. Nach einigem Zögern sagte er am 21. Juni zu. Kurze Zeit später zerschlug sich das Projekt, ohne daß klar erkennbar wäre, von welcher Seite die Absage zuerst kam. ${ }^{290}$ Daneben hat Reynaud wohl ebenfalls

${ }^{288}$ Mayeur, Troisième République, S. 393; Jean Sagnes, Le refus républicain: Les quatre-vingts parlementaires qui dirent "non“ à Vichy le 10 juillet 1940, in: Revue d'histoire moderne et contemporaine 38 (1991), S. 555-589.

${ }^{289}$ Jeanneney, Journal politique, S. 78 (19.6. 1940); Spears, Assignment to Catastrophe II, S. 297 f., 304-311; Reynaud, La France II, S. 366. Zu den Tagen nach Reynauds Rücktritt auch: Leca, Rupture de 1940, S. 234-260.

290 Unklar bleibt, ob Reynaud das Amt nach einiger Überlegung aus freien Stücken ablehnte, weil ihm, wie er behauptet, die Vertretung Pétains aus „moralischen Gründen“ nicht möglich war, oder 
erst unmittelbar vor seiner Abreise aus Bordeaux den Gedanken aufgegeben, im Gefolge unannehmbarer deutscher Waffenstillstandsbedingungen wieder an die Macht zu kommen: zu einem Zeitpunkt also, da feststand, daß die deutsch-französischen Verhandlungen „erfolgreich" verlaufen und die deutschen Konditionen "milde“ genug waren, um akzeptabel zu sein. Die Alternative eines Widerstandskabinetts zur Fortsetzung der Kämpfe war damit durch die Ereignisse überholt worden, der Wille zur Revision der nunmehr geschaffenen Tatsachen in der politischen Klasse angesichts der fast allgemeinen Erleichterung über das Ende der Kämpfe nicht mehr vorhanden. Bis dahin mochte es für ihn folglich Grund genug gegeben haben, Vorsicht walten zu lassen in der Bewertung des Nachfolgers: Sei es, daß er auf dessen Unterstützung rechnete für den Fall der Wiederberufung, die ihm Lebrun noch am 20. Juni in Aussicht stellte; sei es, daß er seine Chancen wahren wollte, in Washington auf den Kriegseintritt der USA hinzuwirken.291 Auch im engsten Freundeskreis scheint er sich in den Tagen nach dem Rücktritt über Pétains Waffenstillstandspolitik nicht kritisch geäußert zu haben; den Waffenstillstandsvertrag vom 22. Juni hat er ebensowenig wie irgendein anderer französischer Politiker öffentlich verurteilt.

Die politische Offenheit jener wenigen Tage zwischen Krieg und Frieden ließ mancherlei Illusionen über Kontinuitäten in der französischen Innen- und Außenpolitik zu, die aus der Rückschau unverständlich oder naiv erscheinen mögen. Die Legitimität der neuen Regierung war jedoch unbezweifelbar, und gerade die Person des Marschalls an ihrer Spitze schien dafür zu bürgen, daß die Macht auch in Zukunft nach rechtsstaatlichen Kriterien ausgeübt werden würde. Paradoxerweise waren es gerade die Begleitumstände eines unheilschwangeren Vorgangs der zeitweiligen Verhaftung Georges Mandels am 17. Juni -, die Reynaud beruhigten: Solange Pétain noch imstande war, Irrtümer einzusehen und in Form eines Entschuldigungsbriefes sein Bedauern auszusprechen, hielt sich offensichtlich der Einfluß radikaler Elemente in seinem Umkreis in Grenzen.292

Demonstratives und kaum mehr verständliches Vertrauen in die Kontinuität der Regierungspolitik bekundete Reynaud auch auf außenpolitischem Feld. Nachdem Churchill in einer Rundfunkansprache vom 22. Juni den Abschluß des Waffenstillstands harsch kritisiert hatte, übersandte ihm Reynaud zwei Tage später eine persönlich gehaltene Nachricht. Darin appellierte er an den Premierminister, sich auch vom geschlagenen Frankreich nicht abzuwenden, und versuchte, englische Befürchtungen in bezug auf die Auslieferung der französischen Flotte $\mathrm{zu}$ zerstreuen. Eine große Portion an politischem Wunschdenken scheint dabei mitgespielt zu haben, genährt auch durch das schlechte Gewissen des abgetrete-

ob Pétain von dem Angebot Abstand nahm, da er die deutsch-französischen Verhandlungen nicht belasten wollte. Vgl. die widersprüchliche Darstellung der Abläufe bei Reynaud, La France II, S. 390-396; ders., Au cocur de la mêlée, S. 883-885, 890 (Zitat); ders., Mémoires II, S. 450 bzw. Paul Baudouin, Neuf mois, S. 193-196.; Pomaret, Dernier témoin, S. 95 f. Die Aufzeichnungen Jeanneneys widersprechen der Behauptung Reynauds, er hätte bis zum 23. Juni abgelehnt, Klarheit bringen aber auch sie nicht: Jeanneney, Journal politique, S. 84 (23.6. 1940). Zur Bewertung im Überblick: Gates, End of the Affair, S. $430 \mathrm{f}$.

${ }^{291}$ Reynaud, Au coeur de la mêlée, S. 884 f.; Leca, Rupture de 1940, S. 243 f.; 256 f.; Aussage Lebruns in: Les événements survenus en France de 1933 à 1945, Annexes (dépositions), Band IV, S. $1017 \mathrm{f}$. 292 Vgl. Pomaret, Dernier témoin, S. 95; de Gaulle, Mémoires de guerre I, S. 73; Leca, Rupture de 1940, S. 244. 
nen Regierungschefs gegenüber seinem Verhandlungspartner der vergangenen Wochen. ${ }^{293}$ Noch glaubte Reynaud offenbar an die Möglichkeit, Brücken zu schlagen über das Faktum des Waffenstillstands hinweg und auch über die Brüche, die sich ankündigten. De Gaulles Schritt in die Dissidenz hat er gefördert und mit einer Summe von 100000 Francs aus einem Geheimfonds unterstützt; den Rundfunkappell des Generals vom 18. Juni, den er selbst nicht hörte, hielt er aber für verfrüht und ging dazu auf Distanz. ${ }^{294}$ Die Spaltung Frankreichs in zwei sich bekämpfende Bürgerkriegsparteien in seiner Person aufzuheben - das scheint für wenige Tage tatsächlich die Hoffnung Paul Reynauds gewesen zu sein.

Daß sie sich zerschlug, hat den abgetretenen Ministerpräsidenten gleichwohl nicht dazu bewegen können, wie de Gaulle den Weg ins Londoner Exil zu gehen. Nach der beschriebenen Phase des Abwartens war dafür zunächst der weitere, dramatische Verlauf der Ereignisse ausschlaggebend. Bei einem Autounfall, den Reynaud am Steuer seines Wagens nach der Abreise aus Bordeaux erlitt, kam am 28. Juni 1940 seine Begleiterin Hélène de Portes ums Leben. Paul Reynaud, der mit ihr zu Freunden nach Südfrankreich unterwegs gewesen war, wurde dabei selbst nur leicht verletzt, blieb aber einige Tage ans Bett gebunden. ${ }^{295}$ In dieser Zeit hatte er zur Kenntnis zu nehmen, daß zwei seiner Mitarbeiter, Dominique Leca und Gilbert Devaux, die in Vorwegnahme seiner Entscheidung für das Botschafteramt bereits abgereist waren, in Madrid verhaftet worden waren. In ihrem Gepäck hatte man Dokumente, Goldbarren, Schmuckstücke und Banknoten im Wert von mehreren Millionen Francs entdeckt. Gegen Reynaud und die beiden Verhafteten war daraufhin vor dem zuständigen Militärgericht von ClermontFerrand Anklage wegen "unerlaubten Kapitalexports“ erhoben worden; der Vorwurf der persönlichen Bereicherung stand im Raum. In einer Reihe von Briefen an Pétain setzte sich Reynaud daraufhin zur Wehr und kam gegen den Rat seiner Ärzte und gegen den Wunsch des Marschalls am 8. Juli nach Vichy, wohin die beiden Kammern des Parlaments mittlerweile umgezogen waren. ${ }^{296}$ Es scheint ihm in den wenigen Tagen, die er dort verbrachte, in erster Linie um die Verteidigung gegen die erhobenen Vorwürfe gegangen zu sein. An den Debatten um die Reform der Verfassungsgesetze von 1875 hat der erfahrene, in der Vergangenheit so kämpferische Parlamentsredner und engagierte Verteidiger der Republik sich nicht beteiligt. Zugestimmt hat er allerdings am 9. Juli der Einleitung des konstitutionell vorgeschriebenen Verfahrens zur Verfassungsrevision. Bei nur drei Gegenstim-

293 FRUS 1940/1, S. 266f.; der französische Text findet sich abgedruckt in: Reynaud, Au coeur de la mêlée, S. 888; auf der Basis unveröffentlichter englischer Akten: Gates, End of the Affair, S. $298 \mathrm{f}$.

${ }^{294} \mathrm{Zu}$ den Umständen der Abreise: Lacouture, Charles de Gaulle I, S. 349-359. Zur Haltung Reynauds: Leca, Rupture de 1940, S. 242 f., 258; Baudouin, Neuf mois, S. 207; Pomaret, Dernier témoin, S. 97 f.; Reynaud, Au coeur de la mêlée, S. 888, Anm. 1.

${ }_{295}$ Das Gendarmerieprotokoll über den Unfallhergang befindet sich im Nachlaß Reynauds (AN, 74 AP 24). Dazu auch: Joseph Laniel, Jours de gloire et jours cruels 1908-1958, Paris 1971, S. 117.

296 Bricfe Reynauds an Pétain vom 11.7., 9. 8. und 23. 8. 1940 (AN, 74 AP 24). Umfangreiches Material zur "Affaire Leca-Devaux“ findet sich daneben in den Prozeßakten von Riom: vgl. u.a. Reynaud an Baudouin, 26. 6. 1940; Eidesstattliche Aussage von Paul Baudouin, 12. 12. 1941, über die Vorgänge vom 17.6. bis 3. 7. 1940; Aussagen Reynauds vor dem Militärrichter am 19. und 20.8. 1940 (AN, 2 W 72). 
men aus Kammer und Senat wurde die Prozedur nahezu einhellig eröffnet. ${ }^{297}$ Am 10. Juli reiste Reynaud dann jedoch ab, ohne an den beiden Sitzungen der Nationalversammlung teilgenommen zu haben, in denen die Preisgabe der Dritten Republik durch ihre Volksvertreter fast widerstandslos besiegelt wurde. Im Vorfeld der entscheidenden Abstimmung, die die Aufhebung der parlamentarischen Republik mit großer Mehrheit sanktionierte, soll er seinen ehemaligen Ministern davon abgeraten haben, mit „Ja“ zu stimmen; zur Empfehlung, gegen eine Verfassungsreform zu votieren, konnte er sich aber offensichtlich nicht durchringen. Die eigenen Stimmzettel übergab er an seinen Abgeordnetenkollegen Joseph Laniel mit der Maßgabe, er sei „im Prinzip“ gegen die Verabschiedung des Regierungsantrags. In der offiziellen Auswertung des Abstimmungsergebnisses vom 10. Juli taucht Reynaud hingegen als „entschuldigt“ in der Rubrik jener Abgeordneter auf, die "nicht am Votum teilnahmen“.298

So vielschichtig Reynauds Amtsführung als Ministerpräsident angelegt gewesen war, so mehrdeutig er seinen Rücktritt konzipiert hatte, so ambivalent gestaltete sich noch sein letzter politischer Akt in der Dritten Republik. Verständlich wird seine Passivität sicherlich zunächst nur vor dem Hintergrund der aufgewühlten Atmosphäre in einer von den psychischen Folgen des Desasters gezeichneten parlamentarischen Versammlung, die er in Vichy vorfand. Eine ganze Reihe von Faktoren trug dazu bei, daß sich am 10. Juli 1940 nur 80 von 649 Parlamentariern dem Appell an die „überparteiliche“ Rettergestalt Pétains entziehen mochten: die grassierende Furcht vor einem Staatsstreich Weygands und vor den näherrückenden Deutschen; die vermeintliche Plausibilität parlamentarismus-, parteien- und republikkritischer Invektiven seitens rechter Abgeordneter, die ihre Wirkung auf die Masse der Deputierten nicht verfehlten; schließlich die perfide Taktik Lavals und seiner Anhänger, die darauf abzielte, die Übertragung umfassender Vollmachten an den Marschall als akzeptable Option zu präsentieren. ${ }^{29}$ Fassungslos, stumm und wie gelähmt in dem allgemeinen Klima der Auflösung zeigten sich auch andere Politiker von zweifelsfrei demokratischer Gesinnung, so etwa Léon Blum. ${ }^{300}$ Reynauds Schweigen kontrastiert aber in so frappierender Weise mit der angespannten Aktivität und der Widerstandskraft, die er noch wenige Wochen zuvor an den Tag gelegt hatte, daß es schwerfällt, sein Verhalten nicht vor allem aus den Ereignissen der Zwischenzeit zu erklären. Die Erfahrung der endgültigen Niederlage und seines persönlichen Anteils daran; das verfehlte Kalkül auf eine irgendwie geartete Chance zur "Wiedergutmachung" in verantwortlicher Rolle; die offenkundige Desavouierung seiner Politik der britisch-französischen Zusam-

297 Zur Atmosphäre in Vichy: Shirer, Zusammenbruch Frankreichs, S. 985 ff. Zum Abstimmungsergebnis: JO, Chambre des Députés, Séance du 9 juillet 1940, S. $818 \mathrm{f}$.

298 JO, Assemblée Nationale, Séance du 10 juillet 1940, S. 8; zur Haltung Reynauds: Pierre Miquel, Les quatre-vingts. Ils ont dit NON à Pétain le 10 juillet 1940, Paris 1995, S. 193 f.; Laniel, Jours de gloire et jours cruels, S. 117.

299 Vgl. hierzu allgemein: Sagnes, Le refus républicain; Roman Schnur, Das Ende einer Republik. 10. Juli 1940 in Vichy, in: Friedrich J. Kroneck/Thomas Oppermann (Hg.), Im Dienste Deutschlands und des Rechtes. FS für Wilhelm G. Grewe zum 70. Geburtstag am 16. Oktober 1981, Baden-Baden 1981, S. 337-364; René Rémond, La fin de la IIIe République, in: Paul Isoart/Christian Bidegaray (Hg.), Des Républiques françaises, Paris 1988, S. 602-609; Berl, La fin de la IIIe République.

300 Vgl. dazu Blums eigenen Bericht in: Blum, Mémoires, S. $68 \mathrm{ff}$. 
menarbeit nach der verlustreichen Versenkung französischer Flotteneinheiten durch die Briten in Mers-el-Kébir am 3. Juli - das hätte alleine wohl schon genügt, um auch eine weniger widerstandsfähige Natur in ihrem Selbstbewußtsein zu beeinträchtigen. Dazu kamen der herbe persönliche Verlust, den er erlitten hatte, die unbegründete Anklage ${ }^{301}$, schließlich die Erfahrung erster aggressiver Unmutsbekundungen in der Abgeordnetenkammer gegen ihn als einen der „Verantwortlichen für das Desaster" 302: Diese Schläge reichten offensichtlich hin, um ihn ohne wirklichen Widerstand aufgeben zu lassen.

Sie liefern auch weitere Anhaltspunkte dafür, weshalb er Frankreich nicht verlassen hat: Das schwebende Verfahren und die Anwürfe seiner Gegner hätten eine Abreise zwangsläufig als Akt der Flucht und als indirektes politisches oder juristisches Schuldeingeständnis erscheinen lassen. Sein Legitimitätsdenken hinderte ihn daran, die Bereinigung seiner Situation außerhalb des existierenden staatlichen Rahmens zu suchen. Nicht daß Reynaud sich ohne Mitverantwortung für das Desaster gefühlt hat. In den Wochen und Monaten nach seinem Rücktritt teilte er auf ganz persönliche Weise das Gefühl der Demütigung und der Schuld, das in der öffentlichen Meinung Frankreichs im Sommer 1940 stärker noch als nach der Niederlage von 1870 vorherrschte. Er, der sein Innerstes kaum je preisgab, hat im Moment äußerster Erschütterung, wenige Minuten nach seinem Autounfall vom 28. Juni, seinen Versagensgefühlen unter Tränen Luft gemacht: „Pauvre France, j'ai fait tout mon possible pour la sauver, mais je n'ai pas réussi“'.303 Dieses Bewußtsein der Mitverantwortung hinderte ihn aber offensichtlich nicht, davon auszugehen, daß die neuen Machthaber weiterhin klar zwischen juristischer Schuld und politischem Fehlverhalten differenzieren würden. Eben dies erwies sich als eine gravierende Fehleinschätzung.

Der Schritt aus der fortexistierenden staatlichen Legitimität hinaus hätte für ihn überdies mit Sicherheit bedeutet, sich dem Vorwurf auszusetzen, ein „Deserteur“ zu sein, der das Land in größter Not im Stich lasse. Die innere Unabhängigkeit dazu hat Reynaud offensichtlich gefehlt. Das Verdikt der öffentlichen Meinung und den Bruch mit den durch sie akkreditierten Autoritäten Weygand und Pétain scheute er auch noch nach seinem Rücktritt. An eher versteckter Stelle seiner Memoiren hat Reynaud eine ungewöhnlich nachsichtige Verteidigung jener Politiker entwickelt, die Frankreich im Sommer 1940 nicht den Rücken kehren wollten; nicht zufällig liest sich die Passage wie ein Plädoyer in eigener Sache: „Prendre une décision aussi grave que celle de quitter la France pour poursuivre la guerre, non seulement sans la caution, aux yeux de l'opinion, de ces deux noms illustres: Pétain

301 Der Vorwurf der persönlichen Bereicherung gegen Reynaud wurde zwei Jahre später durch das Gutachten eines Sachverständigen widerlegt. Demnach ergab eine Überprüfung seiner Vermögensverhältnisse zwischen dem 2.11. 1938 und dem 16.6. 1940 keine Hinweise auf irgendwelche Unregelmäßigkeiten (Carlos Mulquin, Expert près la Cour d'Appel de Paris. Rapport, 27. 3. 1942; AN, 2 W 72).

302 Vgl. die Intervention des rechten Abgeordneten Tixier-Vignancour, der in Gegenwart Reynauds und unter Verweis auf ihn die „Bestrafung der Verantwortlichen“ forderte (JO, Chambre des Députés, Séance du 9 juillet 1940, S. 815).

303 Zitat: Gendarmerieprotokoll, 28.6. 1940 (AN, 74 AP 24). Allgemein zu Schuldkomplex und „Selbstgeißelung" im Gefolge der Niederlage: Berl, La fin de la III" République, S. 128 ff.; Crémieux-Brilhac, Les Français de l'an 40, Band I, S. 602-605; Robert O. Paxton, La France de Vichy 1940-1944, Paris ${ }^{2} 1997$, S. $61 \mathrm{ff}$. 
et Weygand, mais au contraire, avec leur désaveu, que, dès le lendemain, l'ennemi se serait empressé de clamer à tous les échos, ce n'était, certes, pas un facteur négligeable pour des hommes qui étaient, du fait de leur vie politique, très sensibles à l'opinion publique. D'autant plus que la situation morale de ces deux grands chefs n'était, alors, atteinte dans aucun secteur de l'opinion. Passer outre à leur opposition, briser avec eux, accepter le risque de se faire traiter par eux, avec qui se solidarisaient les chefs de l'armée, de déserteurs, ayant livré la France à l'ennemi au risque de tuer l'âme de la France, le tout, en vue de se dérober à la souffrance qui sera imposée à la patrie et à ses fils, pour parler le langage de Pétain, c'était le devoir du gouvernement, mais cela dépassa la fermeté d'âme de beaucoup.“304

Zweifellos wäre Reynaud in London mit offenen Armen aufgenommen worden, wenn er sich entschlossen hätte, dort die Führung einer Exilregierung zu übernehmen. Reynaud hat es aus einer Kombination von äußeren Zwängen, politischer Fehleinschätzung und mangelnder Entschlußkraft nicht versucht und damit wohl den gravierendsten Fehler seiner politischen Laufbahn begangen. Die Tatsache an sich und der Umstand, daß der weitere Verlauf der Geschichte de Gaulles Akt der Insubordination mit nachträglicher und umso nachhaltigerer Legitimität versehen hat, schadete Reynauds Bild in der kollektiven Wahrnehmung Frankreichs mindestens ebensosehr wie sein unglückliches Agieren als Regierungschef im Mai/Juni 1940.

Am 6. September 1940 wurde Paul Reynaud in seinem Heimatort Barcelonnette verhaftet. Fast fünf Jahre verbrachte er danach in französischem und deutschem Gewahrsam, darunter ein Jahr im Pyrenäenfort Portalet, später in den Konzentrationslagern Oranienburg, Sachsenhausen und Buchenwald, schließlich auf Schloß Itter in Tirol. Nur Schritt für Schritt hat er sich während dieser Zeit aus der Loyalitätsbindung gelöst, die er anfangs gegenüber Pétain noch empfunden hat. Es entsprach nicht nur einer bloßen Höflichkeitsformel, wenn er dem Marschall am Tag seiner Verhaftung in einem Brief versicherte: „[...] je garde pour le vainqueur de Verdun les sentiments d'admiration et de reconnaissance que lui doivent tous les Français“. Erst die immer deutlichere außenpolitische Orientierung Vichys zugunsten der Kollaboration mit Deutschland, der Mord an dem sozialistischen Politiker Marx Dormoy am 26.7. 1941 und die eigene Auslieferung an Deutschland am 20. November 1942 haben ihn endgültig umdenken lassen. ${ }^{305}$ Bis dahin hatte er sich auch eine unabhängige Bewertung des Desasters und der Situation Frankreichs zurechtgelegt: Nicht die demokratische Republik als solche trage die Schuld an der Niederlage, wie eine entfesselte Propaganda behaupte, sondern die bewiesene Unfähigkeit ihrer militärischen Führer. Der größte Fehler der gegenwärtigen Politik Pétains aber liege darin, die nötige Erneuerung Frankreichs in der Zusammenarbeit mit dem nationalsozialistischen Deutschland zu suchen. Statt im Lager der Westmächte zu bleiben, diene man sich in unehrenhafter Weise einem Besatzer an, dessen Forderungen prinzipiell unbegrenzt seien: „Quoi qu'il

${ }^{304}$ Reynaud, Au coeur de la mêlée, S. 853.

305 „Département des Basses-Alpes. Extrait du Registre des Arrêtés de la Préfecture des Basses-Alpes“, 6. 9. 1940; zwei Briefe Reynauds an Pétain, 6. 9. 1940 (Zitat) (Bibliothèque de Documentation Internationale Contemporaine (BDIC), Z 11a, „Dossier provisoire concernant P. Reynaud 1940-1941“). Reynaud an Pétain, 5. 4. 1941 und 18. 5. 1941 (Reynaud, La France II, S. 564-571). 
en soit de cette politique équivoque, de ce manque de dignité dans le malheur, cette trahison larvé ne suffit pas aux allemands qui se fâchent". In der Folge werde Frankreich unausweichlich auf den Status einer Provinz im nationalsozialistischen Europa herabsinken. Einziger Ausweg: die Rückkehr in den Kampf an der Seite der Alliierten und im Bund auch mit der Sowjetunion. 306

Die Zeit der Gefangenschaft kam für Reynaud besonders nach der Auslieferung einer Ehrenhaft gleich, die ihm trotz aller materiellen Beschränkungen und den psychischen Belastungen einer ungewissen Zukunft hinreichend Gelegenheit zur Lektüre, zur Reflexion und zum Schreiben bot. Seine Aufzeichnungen bieten deshalb das Bild eines Mannes, der nicht aufhörte, geistig zu arbeiten und politisch zu denken, und der eben daraus auch in der drohenden Depression innere Stabilität zurückgewann. Die Auseinandersetzung mit der Vergangenheit und besonders mit den Ereignissen des Juni 1940 ließ ihn die Abfassung seiner Memoiren in Angriff nehmen. Aus der Beobachtung der Kriegsereignisse über Presse und Radio, aus dem Eindruck der wachsenden materiellen Überlegenheit der Alliierten leitete er im Dezember 1942 ein Kriegsende in zwei bis drei Jahren ab - nicht ohne allerdings angesichts alliierter Rückschläge immer wieder auch in Zweifel über die Dauer seiner Haft zu verfallen. Zweifel an der Niederlage der Achsenmächte finden sich in seinen Aufzeichnungen jedoch nicht. ${ }^{307}$ Ein ganz unvermittelt im Tagebuch aufscheinender Satz läßt dagegen ahnen, daß er bereits weiterdachte: „Après la guerre, on pourra collaborer avec l'Allemagne, et ce sera dans l'honneur". 308

Vorerst allerdings war Paul Reynaud noch Opfer und Objekt einer deutschfranzösischen Kollaborationspolitik unter ganz anderen Vorzeichen. Dabei war die Initiative zur Abrechnung mit dem politischen Führungspersonal der Dritten Republik, der er seine Inhaftierung zu verdanken hatte, keineswegs von der deutschen Führung ausgegangen. Am 30. Juli 1940 bereits hatte Pétain per „acte constitutionnel no. 5" eine "Cour suprême de justice“ ins Leben gerufen, deren vage formulierte Aufgabe es sein sollte, „Verbrechen und Delikte“ von „ehemaligen Ministern und ihren unmittelbaren Untergebenen " zu verfolgen. Das Ziel Pétains und seiner Umgebung, jene zur Rechenschaft zu ziehen, die man für die Niederlage verantwortlich machte, konnte auf breite Zustimmung in der Bevölkerung rechnen. Die vergangene Republik schien die Schuldige am Debakel zu sein, und man mußte keineswegs mit der extremen Rechten sympathisieren, um vermeintliche Indizien für diese Annahme zu finden: die Schwächen des parlamentarischen Systems, die zahlreichen Skandale, die Politik der Volksfront, die „Dekadenz" der Sitten und des politischen Personals. So begann der Prozeß gegen die Dritte Republik am 8. August 1940 in Riom, ohne daß in der öffentlichen Meinung ernsthafter Widerspruch laut geworden wäre. Angeklagt wurden Léon Blum, Edouard Daladier, General Gamelin und der ehemalige Luftfahrtminister Pierre Cot wegen Versäumnissen in der Kriegsvorbereitung; gegen Paul Reynaud und Georges

306 "Je m'accuse. Mémoire pour le bâtonnier. Ecrit au Fort de Portalet“, 1. 10. 1942, S. 4-25, Zitat: S. 17 (BDIC, Q pièce 302 Res.).

307 Vgl. Reynaud, Carnets de captivité, S. 228-238 (14. 12. 1942); 216 (5. 12. 1942); 239 (18. 12. 1942); 261 (12. 3. 1943).

308 Ebenda, S. 238 (14. 12. 1942). 
Mandel waren Ermittlungsverfahren wegen „Kriegshetzerei“ bzw. „Beeinträchtigung der äußeren Sicherheit des Staates“" eröffnet worden, hatten aber nicht genügend Anhaltspunkte für eine Anklageerhebung erbracht. ${ }^{309}$

Stattdessen war es die deutsche Seite, die sich nun besonders für die beiden Politiker interessierte. Der deutsche Vertreter in Paris, Otto Abetz, sah im Frühjahr 1941 die Gelegenheit, über eine „vergangenheitspolitisch“ orientierte Kollaborationsoffensive die Zusammenarbeit mit Frankreich aus jener Krise zu bewegen, in die sie seit der Entlassung Lavals im Dezember 1940 versunken war: Schien sich doch die Chance zu bieten, in gemeinsamer Siegerjustiz die interne Abrechnung in Frankreich mit dem Nachweis der deutschen Propagandathese von der Schuld der französischen Politik am deutsch-französischen Waffengang zu verbinden. Ein zynischer Tauschhandel zum "Nutzen“ beider Seiten bildete den Auftakt. Nach Unterredungen Abetz' mit dem stellvertretenden Ministerpräsidenten Darlan erklärte sich die französische Seite bereit, Reynaud und Mandel in die Reihe der Beschuldigten von Riom aufzunehmen und zu verurteilen. Als Gegenleistung sagte Außenminister Ribbentrop die Begnadigung französischer ziviler Hilfseinheiten, sogenannter "Gardes territoriaux“, zu, die sich im Mai/Juni 1940 einiger Übergriffe gegen deutsche Flieger schuldig gemacht hatten. Zuvor hatte Abetz seinem Minister vergeblich vorgeschlagen, Reynaud und Mandel nach Deutschland bringen zu lassen, um sie dort „statt der von ihnen Verführten zu erschießen". ${ }^{310}$ In einem Akt der Willkür und in Vorwegnahme eines Urteils in Riom verurteilte Pétain die Politiker schließlich ebenso wie Edouard Daladier, Léon Blum und Georges Gamelin am 16. Oktober 1941 zu zeitlich unbegrenzter Festungshaft. Die ergebnislose Suspendierung des Prozesses, in dessen Verlauf Reynaud und Mandel nie offiziell Gelegenheit zur Verteidigung hatten, änderte nichts an dem einmal dekretierten Beschluß. Bis zum 20. November 1941 blieben Mandel und Reynaud im Pyrenäenfort Portalet inhaftiert, von wo aus sie nach der Besetzung der ehemals freien Zone auf deutschen Druck hin ausgeliefert wurden. Für Reynaud schloß sich zunächst eine knapp fünfmonatige politische Haft im Konzentrationslager Oranienburg an, bevor er am 16. April 1943 über Zwischenstationen in Sachsenhausen und Buchenwald nach Tirol verlegt wurde. Georges Mandel wurde am 4. Juli 1944 nach Frankreich zurückgebracht und dort wenig später von der französischen Miliz ermordet; Paul Reynaud erlebte am 5. Mai 1945 zusammen unter anderem mit Edouard Daladier und Maurice Gamelin seine Befreiung durch amerikanische Truppen. ${ }^{311}$

${ }^{309} \mathrm{Vgl}$. zum folgenden: Henri Michel, Le procès de Riom, Paris 1979, S. 20-63, 385-388. Zum Themenkomplex auch ausführlich: Stefan Grüner, Vom Umgang mit der demokratischen Vergangenheit. Das Deutsche Reich, Vichy und das politische Führungspersonal der Dritten Französischen Republik 1940-1945, in: Stefan Martens/Maurice Vaïsse (Hg.), Frankreich und Deutschland im Krieg (November 1942-Herbst 1944). Okkupation, Kollaboration, Résistance, Bonn 2000, S. 73-98.

310 ADAP, D, Band XII/1, Dok. 135, S. 201. Zur Wiederaufname des Vorschlags: Aufzeichnung des Botschaftsrats Hilger (z.Z. Fuschl), 15. 5. 1944 (ADAP, E, Band VIII, Dok. 28, S. 56-60. Allgemein zu den deutsch-französischen Beziehungen der Epoche: Eberhard Jäckel, Frankreich in Hitlers Europa. Die deutsche Frankreichpolitik im Zweiten Weltkrieg (Quellen und Darstellungen zur Zeitgeschichte 14), Stuttgart 1966; Duroselle, L'abîme, S. 263 ff.

311 Reynaud, La France II, S. 547-590; Reynaud, Carnets de captivité; Sherwood, Mandel, S. 287-289. 